\begin{abstract}
Title of Dissertation:

THE IMPACT OF GROUP INTERACTION ON

SHARED COGNITION: AN ANALYSIS OF SMALL GROUP COMMUNICATION

Miriam Louise Matteson, Doctor of Philosophy, 2009

Dissertation Directed By: Dr. Marilyn Domas White, Associate Professor

Emerita, College of Information Studies
\end{abstract}

Flowing from research that shows that shared mental models have a significant impact on team performance, this research investigated how small group communication influences the development of shared mental models in a committee of public librarians addressing a problem-solving task. It is a qualitative research study that examines the influence of communication theme, function, role, channel, and rule, on the group ${ }^{1} \mathrm{~s}$ development of shared mental models about their task and about their team interaction.

Over a period of a year, data were collected from the group's meetings, email messages, group documents, and interviews with each participant. The data were analyzed using several existing coding schemes and qualitative coding. The data indicate that within the group there was a strong superficial convergence around the task mental model and the team interaction mental model but a weaker convergence at a deeper level. 
Analysis of the group communication data shows that the group focused discussion on understanding the problem and identifying tasks. They enacted group communication roles and rules that facilitated sharing information, and the functions of their messages emphasized task communication. The findings suggest that communication themes most heavily influenced the development of a shared mental model about the task, while communication roles, rules, and functions were more influential in the development of a shared mental model about team interaction. The data also show the importance of the allocation of time and commitment to the task as elements impacting the development of shared mental models.

This case study of one group begins to shape an understanding of how group communication contributes to shared mental models, but additional case studies based on this same design, altering the characteristics of the group and task, are necessary to more fully explore the group communication - shared cognition relationship. Implications for practice from the study include adopting intentional tactics for surfacing mental models at various points in the group's life and anchoring the emerging model within the collective cognition of the group through devices such as narratives, objects, or documentary materials. 


\title{
THE IMPACT OF GROUP INTERACTION ON SHARED COGNITION: AN ANALYSIS OF SMALL GROUP COMMUNICATION
}

\author{
By \\ Miriam Louise Matteson \\ Dissertation submitted to the Faculty of the Graduate School of the \\ University of Maryland, College Park, in partial fulfillment \\ of the requirements for the degree of \\ Doctor of Philosophy \\ 2009
}

Advisory Committee:

Professor Marilyn Domas White, Chair

Professor Vedat Diker

Professor Ping Wang

Professor Ann Carlson Weeks

Professor Andrew Wolvin 
(C) Copyright by

Miriam Louise Matteson

2009 


\section{Dedication}

I dedicate this dissertation to my children, Samuel Philip and Cecilia Andrea. May you be lifelong learners. 


\section{Acknowledgments}

Special thanks to the members of the Accountability Group who welcomed me with great warmth and respect, and to the Library Director, for inviting me in to the organization. Thanks also to the administrators from other organizations who enthusiastically volunteered their groups to participate. Your commitment to research is much appreciated.

My grateful thanks go to my advisor, Dr. Marilyn Domas White, and to the members of my committee, Dr. Vedat Diker, Dr. Ping Wang, Dr. Ann Carlson Weeks, and Dr. Andrew Wolvin. Thank you for your encouragement, patience, and feedback.

To my colleagues at Kent State University, particularly Dr. Richard Rubin, Dr. Carolyn Brodie, Dr. Belinda Boon, Ms. Camille Smith, and Ms. Tiffany Wang-thanks for your kind words and unwavering support this year.

I wish to thank several faculty members who helped me in various ways through the program: Dr. Claude Walston, my first advisor; Dr. Delia Neuman, for introducing me to qualitative research methods; Dr. Eileen Abels, who mentored me and provided me the opportunity to work on a sponsored research project; and Dr. Douglas Oard for providing me funding and a unique opportunity to understand research from behind the scenes.

One of the most satisfying parts of my doctoral experience was the camaraderie I shared with my colleagues in the program. I extend particular thanks to Dr. Sheri Massey, Dr. Kara Reuter, and Ms. Katy Lawley for sharing their intellect, humor, warmth, and tireless support. Special thanks to Kara for sharing her technical expertise. 
Sincere thanks to the family and friends who provided care to me and my family over the years: Jonathan DeFosse and Kaori Nakamura, Brian and Sarah Deever, John Deever and Lisa Swaim, Jeff Scott, Elena Flores, Ada de Fatima Vazquez, and Josie Brown.

I am indebted to my family who provided tremendous support and made significant sacrifices so I could pursue this degree. I thank my parents Mervyn and Martha Matteson who came every time I called, and my sister, Mara Matteson, for listening and for pulling me out of a big ditch. I am also extremely grateful to my mother for showing me by example how it is possible to successfully pursue one's own academic interests as a wife and mother.

To my children, Sam and Cecilia Garcia, thank you for being constant reminders of what is really important in life.

And to my husband, Héctor García—no tengo palabras suficientes para decir cómo agradecida estoy por ti. Nunca haber pudiera terminado este programa sin tu apoyo, humor, inteligencia, ayuda, y más que todo, tu amor. Ahora comenzamos el resto de nuestra bella vida. 


\section{Table of Contents}

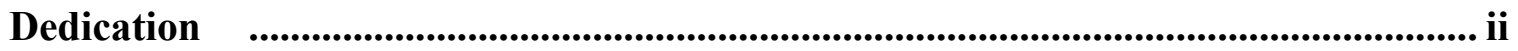

Acknowledgments ...................................................................................................................... iii

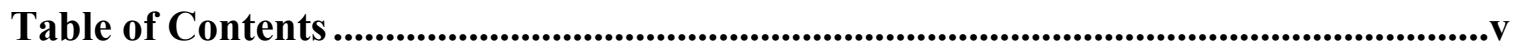

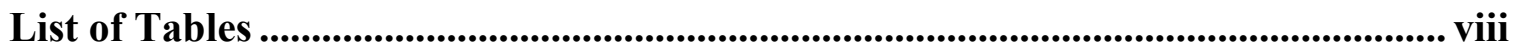

List of Figures....................................................................................................................... ix

Chapter 1: Problem Statement and Literature Review .............................................1

1.1 Problem Statement................................................................................... 1

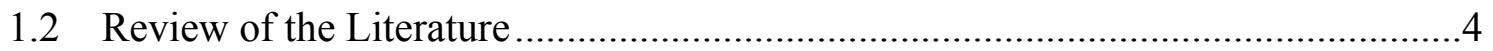

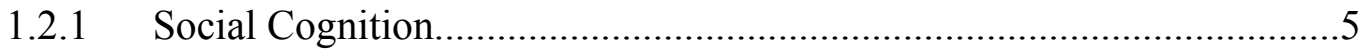

1.2.2 Small Group Communication .......................................................... 14

1.2.3 Group Communication and Shared Mental Models .............................21

1.2.4 Conceptual Framework ...............................................................24

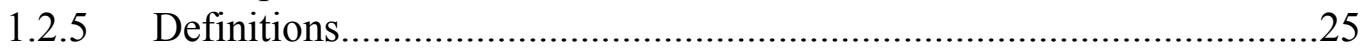

Chapter 2: $\quad$ Research Questions and Research Methodology......................................26

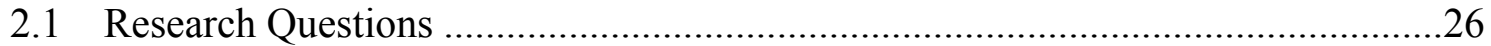

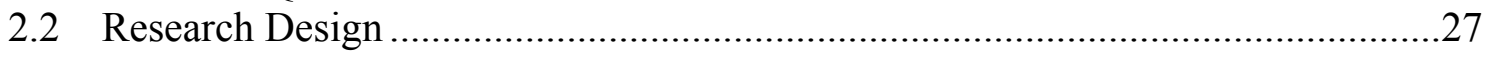



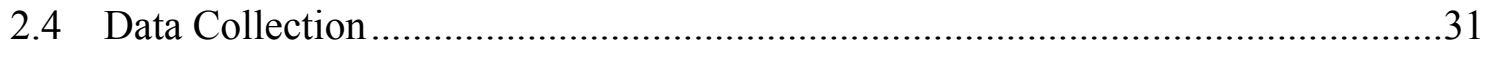

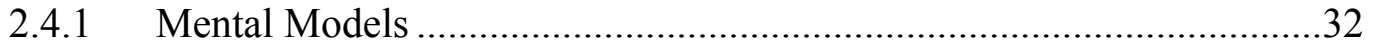

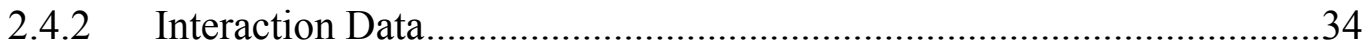



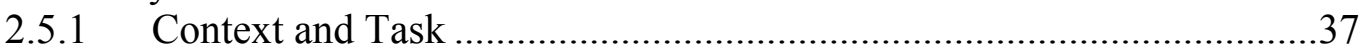

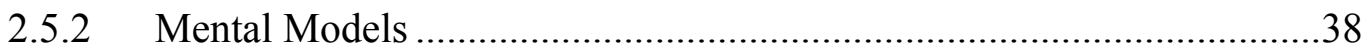

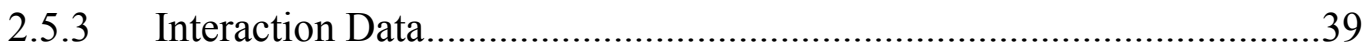

2.5.4 Integration of the Mental Model and Interaction Data .........................44

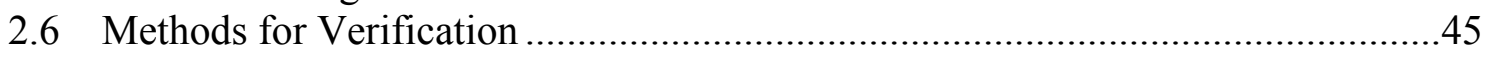

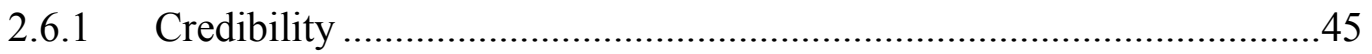

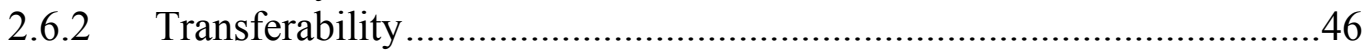

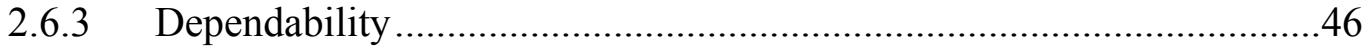

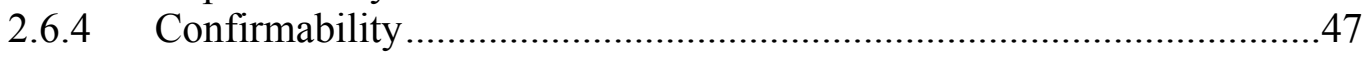

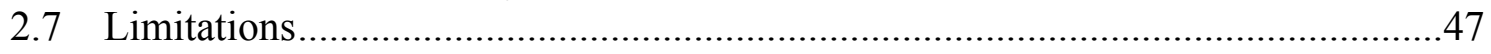

Chapter 3: Context of Study ..............................................................................................49

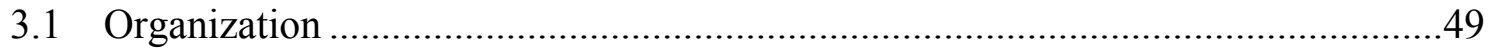

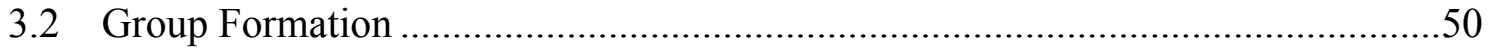

3.3 Accountability Group Members and Characteristics .......................................51

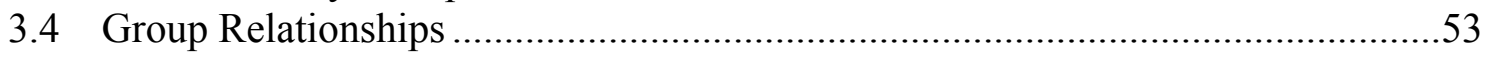




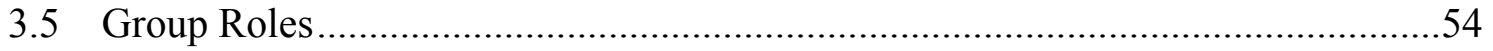

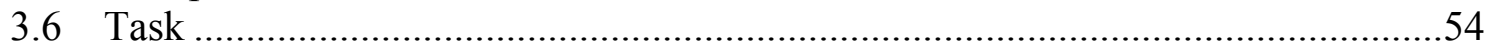

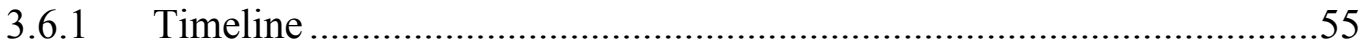

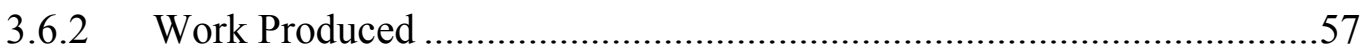

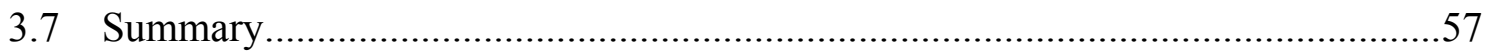

Chapter 4: Shared Mental Models ....................................................................59

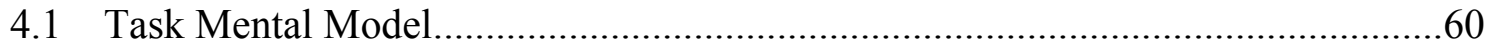

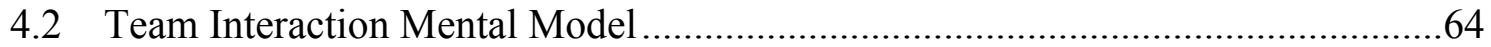

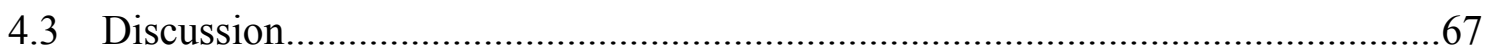

4.3.1 Comparison of the Two Models ...........................................................67

4.3.2 Task Shared Mental Model ..................................................................68

4.3.3 Team Interaction Shared Mental Model ...............................................71

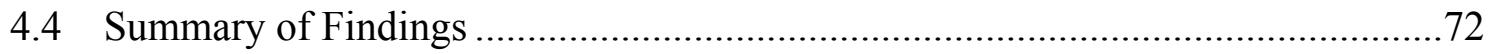

Chapter 5: Group Communication .......................................................................74

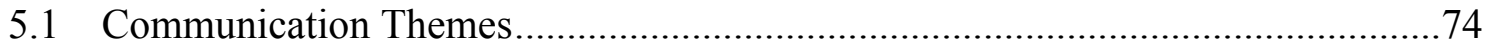

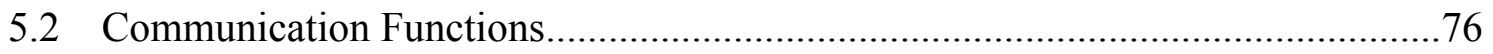

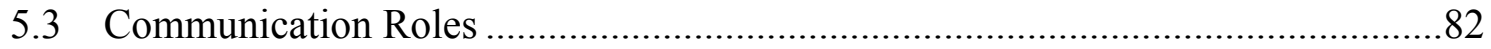

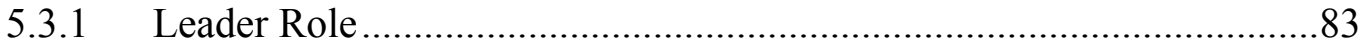

5.3.2 Functional Group Roles .......................................................................

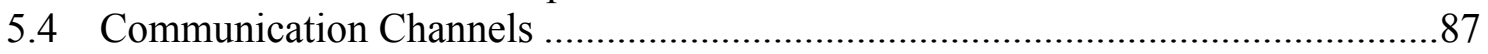



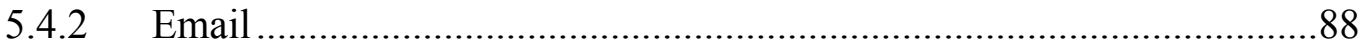

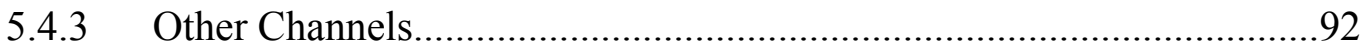

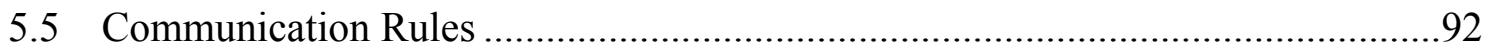

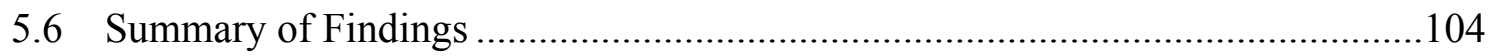

Chapter 6: Communication Influences on Shared Mental Models...........................106

6.1 Characterization of Transitions and Influence of Communication ......................107

6.2 Examples of the Influence of Communication Variables......................................109

6.2.1 Define Accountability ......................................................................110

6.2.2 P4 Performed Most of the Work ......................................................111

6.2.3 Meeting Time Exhibited Good Interaction ..........................................112

6.2.4 P4 was the Leader with High Concern for the Task .............................113

6.2.5 Differential Influence of Communication Variables ............................114

6.3 Other Influences on the Shared Mental Models ...................................................116

6.3.1 Difficulty Moving to New Libraries ......................................................116

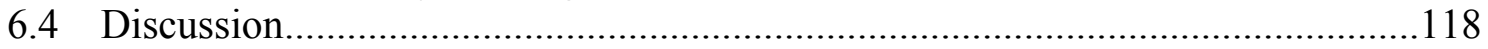

6.4.1 Communication Themes Related to the Task Shared Mental Model ..118

6.4.2 Communication Roles, Rules, and Functions Related to the Team Interaction Shared Mental Model ..........................................................120

Chapter 7: Conclusion............................................................................................................122 
7.1 The Influence of Communication on Shared Mental Models

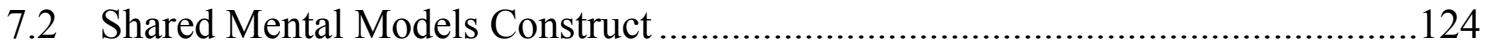

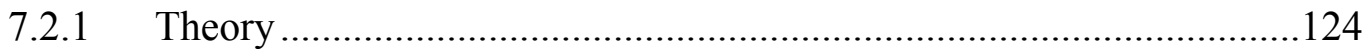

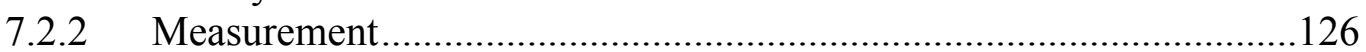



7.4 Implications for Practice.............................................................................130

7.5 Future Research ............................................................................................135

Appendix A: Solicitation Letter ..............................................................................................137

Appendix B: Institutional Review Board Approval and Extensions............................139

Appendix C: Interview Protocol for Accountability Group..............................................145

Appendix D: Data Analysis Matrix ...........................................................................................147

Appendix E: Benne \& Sheats (1948) Functional Role Definitions ................................149

Appendix F: Meeting Details .................................................................................................152

Appendix G: Analysis of Transitions and Variables Influencing Task Mental Model ........................................................................................153

Appendix H: Analysis of Transitions and Variables Influencing Team Interaction Model .................................................................................154

Appendix I: Library System Meeting Norms......................................................................155

Appendix J: Accountability Group Charge ......................................................................156

Appendix K: Accountability Cohort Report - First Draft ................................................157

Appendix L: Accountability Cohort Report - Final Draft ..............................................161

References ……...............................................................................................................164 


\section{List of Tables}

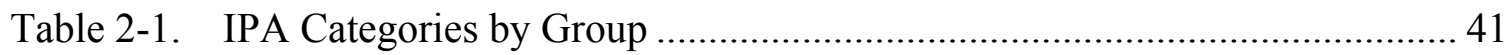

Table 3-1. Characteristics of Group Members.............................................................. 52

Table 3-2. Familiarity Ratings Among Group Members............................................... 53

Table 3-3. Documents, Date Completed, Authors and Summary of the Document Content ....................................................................................... 57

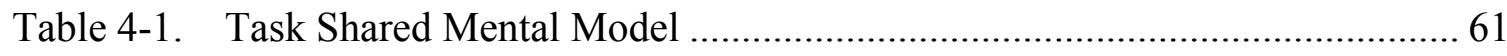

Table 4-2. Team Interaction Shared Mental Model..................................................... 65

Table 5-1. Discussion Themes by Group Event ……………………………………... 75

Table 5-2. IPA Categories by Group ……………………....................................... 77

Table 5-3. IPA Categories by Group Event ………………..................................... 78

Table 5-4. Accountability Group Percentages and Norm Ranges for IPA Categories....................................................................................... 79

Table 5-5. IPA Task and Socioemotional by Group Event …………………............... 80

Table 5-6. Benne and Sheats Group Task and Group Building Roles Distributed by Group Event...................................................................... 86

Table 5-7. Comparison of Sacks et al.'s Model of Turn Taking with the Accountability Group Turn Taking ............................................................ 98

Table 5-8. Percentage of Turns Taken by Meeting by Participant ............................. 102

Table 5-9. Distribution of Participants by Frequency of Turns Taken by Meeting...

Table 6-1. Characterization of Transitions between Component Strengths Influenced by Communication by Shared Mental Model 108

Table 6-2. Communication Variables Affecting Transitions by Shared Mental Model 


\section{List of Figures}

Figure 1-1. Model of the Conceptual Framework ………………………………...... 25

Figure 3-1. Timeline of the Meetings and Interviews and Number of

Email Messages Sent.................................................................................... 56

Figure 5-1. Comparison of the Accountability Group with Two Aggregated Groups …………………………………………………..... 81

Figure 5-2. Number of Email Messages Sent by Month with Indication of Each Meeting... 


\section{Chapter 1: Problem Statement and Literature Review}

\subsection{Problem Statement}

So much of professional and personal life is carried out in groups. In organizations, work is frequently organized around a variety of teams and small groups: project groups, cross-functional teams, task forces, standing committees, or design teams. In social life, people participate in book clubs, church groups, hobby groups, and sports teams. The prevalence of groups and teams in organizations stems from a belief that groups and teams can be effective, productive units in the organizational structure. Indeed much of the literature on groups and teams explores the processes and outcomes of group performance such as strategic planning, problem solving, decision-making, productivity outputs, or service outputs (Hackman, 1990). Related foci in the literature examine nearly all aspects of the group experience such as structure, culture, communication, shared cognition, roles, norms, cohesion, conflict, size, and composition, to understand how such aspects of group life positively affect performance outcomes. Clearly a practical reason exists for identifying factors that lead to positive group performance—organizations can take steps to establish conditions that position groups for optimal performance.

One aspect of group life thought to impact group performance is the presence of shared understandings, or shared mental models, among group members. Mohammed and Dumville (2001, p. 89) write, "The general thesis of the shared mental model literature is that team effectiveness will improve if team members have an adequate shared understanding of the task, team, equipment, and situation." Several theoretical explanations have been put forth to explain this thesis. Teams with shared mental models 
can anticipate the information needs of others due to having similar knowledge schemas (Cannon-Bowers, Salas, \& Converse, 1993; Kraiger \& Wenzel, 1997). The existence of shared mental models in a group or team can assist sense making when the team finds itself with a novel problem, or an unexpected external event. People with similar frameworks can more accurately predict what others will do and think, which speeds the process of understanding the new problem. The implication is that when team members share a similar schema of the task or team, they develop common expectations for behavior and performance. Stated differently, effective team performance "requires that team members hold common or overlapping cognitive representations of task requirements, procedures, and role responsibilities" (Cannon-Bowers, et al., 1993, pp. 221-222).

This belief has lead to a growing body of literature aimed both toward further theoretical development (content, form, and function of shared mental models) and to empirical testing of the outcomes and consequences of shared mental models. For example, findings on the outcomes of shared mental models have reported positive correlations between shared mental models and team effectiveness (Smith-Jentsch, Mathieu, \& Kraiger, 2005); and task performance (Edwards, Day, Arthur, \& Bell, 2006; Lim \& Klein, 2006; Mathieu, Goodwin, Heffner, Salas, \& Cannon-Bowers, 2000). Research exploring the antecedents to and formation of shared mental models has received less attention. Rentsch and Klimoski (2001) found some support for education similarity, position level similarity, team size, and previous experience with teams as antecedents to similar mental models (they use the term schema similarity). Most of the 
theoretical treatment on shared mental models suggests rather in passing that it is through group communication and interaction that shared mental models are developed (AllardPoesi, 1998; Higgins, 1992; Klimoski \& Mohammed, 1994; Rentsch \& Hall, 1994; Tindale \& Kameda, 2000). None, however, has explored what it is about how a group communicates that enables shared mental models to develop. This gap leads to the question that must be asked for both theoretical and practical benefits.

The theory on shared mental models while fertile in terms of defining and articulating the construct and its purpose for team performance can be made richer through additional detail on the conditions necessary for shared mental models to develop, the communication factors which best result in shared mental models, and other antecedent constructs that may impact mental model development. From a practical standpoint, groups and teams in organizations will benefit from new knowledge, empirically generated, that identifies how shared mental models are developed to achieve improved performance.

One likely reason for this gap in understanding on the formation of shared mental models is the result of disciplinary boundaries that draw clear lines between small group communication and social psychology approaches to the study of groups. The literature silos that adhere to these boundaries enable such gaps to persist. Yet, it is precisely in those gaps where contributions to knowledge building should be made.

This dissertation reports on a study that explores the shared mental models and the communication practices of a task force of public librarians, drawing from theory and research in small group communication and social cognition. The study seeks to 
understand - for this one case — how a group's communication influences its shared mental models.

\subsection{Review of the Literature}

The communication in small work groups may be directed toward many purposes such as: problem identification and solving; decision making; strategizing; taking actions; offering support; or sharing ideas. Across these, the ideas that emerge in group interactions are considered externalizations of the group's cognition (Poole, 1999). Understanding the group communication behaviors and interaction processes can lead to a deeper understanding of the group's social cognition, which, in turn, has implications for group outcomes such as effectiveness and performance quality.

Poole (1999, p. 41)writes:

Many researchers argue that phenomena analogous to individual cognitive processes, such as memory, attention, and reasoning, can be discerned in social interaction. Some researchers make the more extreme claim that some cognitive processes, such as remembering and reconstructing, are inherently socially based. The "group mind" hypothesis, which holds that social collectives think much as individuals do, has been brusquely dismissed for decades, but it is once more being entertained in more sophisticated forms (see Weick \& Roberts, 1993). Communication is part and parcel of any account of socially mediated cognition, but group communication theory and research have remained strangely silent on these issues. 
If small group communication research has not pursued the connections to social cognition, neither has social cognition research adequately explored the role of group communication in creating shared cognition. Only a few studies were identified that explore the influence of communication in shared cognition. Thus, this study adds to the small amount of research that brings together these two distinct research traditions to begin to build an understanding of how small group communication serves to develop shared cognition in groups. In this section, first research from the field of social psychology provides a theoretical background for the idea of social cognition, and introduces the construct of shared mental models. Then research from the field of communications is explored to provide insights into the interactions and processes of communication in small groups. Finally the prior research that has explored the connection between these two fields is introduced.

\subsubsection{Social Cognition}

Social cognition brings together social psychology and cognitive psychology. Social psychology is the study of how individuals' thoughts, feelings, or behaviors, are influenced by other individuals; put simply, a person's impact on someone else (Goodwin \& Fiske, 1994).

Cognitive psychology studies human beings' mental processing and covers a variety of research areas, such as memory, perception, problem solving, and knowledge representation. Within knowledge representation, cognitive psychology theory tells us that individuals have cognitive schemas or mental models of situations, events, beliefs, and experiences that enable them to understand or make sense of the world around them 
(Allard-Poesi, 1998). These schemas provide a framework through which individuals can make inferences, draw connections, position new information, or restructure existing information.

Individual cognition becomes a social phenomenon in a group setting. When a group of individuals interacts through social acts, social cognition occurs. The social experience - the sharing of individual cognitive frameworks - impacts the structure and content of the individual's cognition as well as the group's shared cognitive understandings. But shared cognition is not merely the summing of the parts, just as individual cognition is not purely intraindividual (Allard-Poesi, 1998). Every individual functions within a socially derived context that prompts to some extent how they carry out their cognitive processing. As individuals construct and reconstruct their worlds, they do so relying on the cues and messages in their environment.

The parallel point can be made for group cognition. Social cognition derives from the cues and messages in the group environment. Putting a set of individual cognitive schemas together to make group cognition is incomplete if it does not account for the social acts through which the group operates. Social cognition is more than the sum of its parts. Instead, it is enacted by members of the group. Thus, to understand group cognition, it is necessary to study the social processes of the group (Langfield-Smith, 1992). Such shared cognition emerges from the group interactions; from negotiation, argument, discussion; and interpretation carried out by group members (Walsh, 1995). Put another way, Fussell \& Kreuz (1998, p. 3) write, "Cognitive mechanisms underlying speech production and comprehension interact with social psychological factors-such as 
beliefs about interlocutors and politeness norms - and with the dynamics of the conversation itself, to produce shared meaning."

\subsubsection{Shared Mental Models}

One category of shared cognition is the notion of shared mental models. A shared mental model is a framework or schema of a particular environment or domain held by members of the same group (Klimoski \& Mohammed, 1994; Mohammed, Klimoski, \& Rentsch, 2000). Though the idea of mental models stems from cognitive psychology, the construct has been carried over into the research on groups and organizations with an increased interest in the topic developing over the last fifteen years. (See for example, the special issue of the Journal of Organizational Behavior on shared cognition, issue 22, 2001).

Numerous terms appear in the literature to describe the construct of a shared mental model. Klimoski and Mohammed (1994) use the phrase "team mental model" because the phrase shared mental model does not rule out dyadic relationships, which are fundamentally different from group sharing. Rentsch and Hall (1994) and Rentsch and Woehr (2004) use the phrase "team member schema similarity" which although clumsy, is more precise than mental model. According to Rentsch and Woehr (2004), "team member" signifies the presence of a group, but still indicates that the schema develops from individual members; "schema" clarifies what is to be shared, namely, content with a structure, "that enables individuals to understand, interpret, and give meaning to stimuli (Rentsch \& Woehr, 2004); and "similarity" to indicate how the content is "shared". 
The present research uses the phrase shared mental models to refer to the content and structure of knowledge about the task, the team, or any other domain, held in common by members of a group. The term "shared" connotes the giving and receiving, that is, the mutual interacting that facilitates development. The phrase "mental model" is used synonymously with Rentsch's schema — knowledge with some degree of structure, which enables individuals to make sense of their world.

Critics have argued, justifiably, that the construct of shared mental models has not been well defined in the literature. Klimoski and Mohammed (1994) identified multiple applications of the "team mental model" concept in the literature using a variety of terminology including group cognition, shared frames, collective mind, social cognition, and transactional memory. More recent writings, such as Canon-Bowers and Salas (2001) highlight several fundamental questions about shared cognition to be resolved. Both Klimoski and Mohammad (1994) and Canon-Bowers and Salas (2001) make the argument that for shared mental models to get better traction in the literature, researchers need to clarify how they are interpreting the construct. Canon-Bowers and Salas (2001) raise several issues, addressed in turn in the following section, and suggest researchers should be clear on these issues when researching shared mental models.

One issues addresses the nature of the content or the domain of the mental model. At an epistemological level, the literature suggests that shared mental models include both knowledge structures and belief structures (Cannon-Bowers \& Salas, 2001; Kraiger \& Wenzel, 1997). Knowledge structures include what we know, in terms of declarative (know what), procedural (know how), strategic (know why), or any other epistemic 
framework, along with how we think about a phenomenon (Banks \& Millward, 2007; Cannon-Bowers, et al., 1993; Kraiger \& Wenzel, 1997). Knowledge of these kinds may vary in degree of specificity from concrete to abstract (Kraiger \& Wenzel, 1997; Rouse \& Morris, 1986) and in degree of accuracy (Banks \& Millward, 2007; Lim \& Klein, 2006). Belief structures capture how we feel about a phenomenon, what attitudes, expectations, or positions we ascribe to a given situation or task (Cannon \& Edmondson, 2001; Carron, et al., 2003; Tyler \& Gnyawali, 2009).

The content of shared mental models also considers the different domains of mental models such as: the task; teamwork; team interaction; team members; equipment; processes; situations; relationships; goal or mission; information flow required for effective team performance; specific role responsibilities; and situation awareness (Cannon-Bowers, Tannenbaum, Salas, \& Volpe, 1995; Klimoski \& Mohammed, 1994; Langan-Fox, Code, \& Langfield-Smith, 2000). Shared mental models about the task include task related knowledge; task-related constraints; perceptions and understandings of team procedures; strategies; task contingencies; environmental conditions; and activities and action sequences (Cannon-Bowers, et al., 1993; Klimoski \& Mohammed, 1994; Lim \& Klein, 2006; Rentsch \& Woehr, 2004). Mental models about teamwork include beliefs about goal interdependence, or general personality characteristics (Rentsch \& Woehr, 2004); and interdependence, cooperation, communication, and relationships (Rentsch, Heffner, \& Duffy, 1994). Mental models about team interaction concern team members' understanding of team members' responsibilities, norms, and interaction patterns (Lim \& Klein, 2006); roles and responsibilities; information sources; 
communication channels; and role interdependencies (Cannon-Bowers, et al., 1993). Finally, mental models about the team address each member's understanding of each other's knowledge, skills, attitudes, strengths, and weaknesses (Cannon-Bowers, et al., 1993; Lim \& Klein, 2006).

These distinctions are important to demonstrate the complexity of mental models related to groups. However, a trend in the empirical literature appears to operationalize just two mental models, one for task and one for team (Mathieu, Heffner, Goodwin, Salas \& Cannon-Bowers, 2000; Rentsch \& Hall, 1994). This is supported by other team literature that speaks to two tracks of general behavior: teamwork and task work (McIntyre \& Salas, 1995).

Another issue seeks to clarify more precisely what is meant by "shared". Several possible models of "shared" exist. Similarity is often what most people mean when they write of "shared" mental models. But similarity can be further specified by degrees of similarity from identical to unique, as well as by whether it is the structure or the content that is similar (Rentsch \& Hall, 1994). Other possibilities for determining "sharedness" include holding portions of a model in common, or portions that overlap among the members of the group; models that are compatible or complementary, that is, not in conflict with each other; and lastly, models in which information is distributed among the members so each person knows his or her piece of the model, and the pieces fit together to explain a larger concept (Cannon-Bowers \& Salas, 2001; Klimoski \& Mohammed, 1994). To more fully understand any empirical findings about shared mental models, 
researchers must specify what they mean by "shared" and how their measures accurately capture the nature of that type of "sharedness".

A third issue is to clarify what outcomes are expected from shared mental models. The literature points to both positive and negative outcomes. Positive outcomes include better information processing; high levels of group cohesion; and better group performance in terms of decision quality (Cannon-Bowers \& Salas, 2001; Lim \& Klein, 2006; Mathieu, et al., 2000). But negative outcomes have also been researched including potentially negative biases such as groupthink, polarization, and group escalation of commitment (Jones \& Roelofsma, 2000).

Indeed, Janis' (1972, p. 9) notion of groupthink, “.... a mode of thinking that people engage in when they are deeply involved in a cohesive in-group, when the members' strivings for unanimity override their motivation to realistically appraise alternative courses of action" remains a popular cautionary model. As groups strive to reach shared thinking, the possibility exists that a negative effect such as groupthink may occur. Yet, the construct of shared mental models contains sufficient nuance that, developed knowledgeably in groups, should reduce the likelihood of negative outcomes such as groupthink.

A fundamental idea of shared mental models is that they are not shared at the outset of a group's experience but rather are constructed through communicative exchanges. Groups that employ well-established discussion techniques such as brainstorming, devil's advocacy, dialectical inquiry, and nominal group technique can resist the pressure to conform their thinking prematurely. Further, components of groupthink, such as 
collective rationalization, pressure to conform, self-censorship, and unanimity, which all encompass the idea of withholding communication, stand in contrast to the basic premise that shared mental models are achieved through communication (Aldag \& Fuller, 1993; Dimitroff, Schmidt, \& Bond, 2005).

Whether or not groupthink occurs seems ultimately a function of incomplete or inadequate communication practices, brought on by any number of antecedent conditions in the group structure and context. Developing shared mental models in a group ought to include communication practices and norms that protect a group from falling into a situation where negative outcomes such as a groupthink lower the group's ability to perform well.

The final issue in clarifying the shared mental model construct considers how best to measure shared mental models. The measurement of shared mental models should encompass the concepts of the model as well as the relationships that link those concepts (Mohammed, et al., 2000). Central to understanding measurement of mental models are the ideas of the elicitation of the concepts included in the model, and the representation technique used to reveal the structure of the concepts in the model for analysis. Two excellent reviews of a variety of elicitation and representation techniques have been written (see Langan-Fox, et al., 2000; Mohammed, et al., 2000). Among the techniques reviewed in those articles for elicitation are: cognitive interviewing techniques, verbal protocol analysis; content analysis, observation of the task; card sorts; repertory grid technique; pair wise ratings, and causal maps. Techniques identified to represent the models are multidimensional scaling, pathfinder, and cognitive mapping. 
In addition to describing four techniques for measuring mental models, Mohammed, Klimoski, and Rentsch (2000) provide a critique of those methods according to how well they treat the content and structure of the models; whether there is a standard procedure for implementing the technique; what reliability evidence exists in support of the technique, and noteworthy strengths and weaknesses. They ultimately conclude that no one method performed better than another. They suggest when choosing methods, researchers must carefully consider what phenomenon they wish to measure; whether content or structure or both are important; and what purpose will the method be used for (diagnosis, prediction, etc.) They also suggest that multiple methods are necessary given the complex nature of shared mental models.

Kraiger and Wenzel (1997) make the case that because shared mental models may contain knowledge, behavior, or attitudes as separate components, no single measure can adequately capture the complexity of the shared mental models. They suggest four separate measures to better understand the contents of shared mental models. An information processing measure assesses how the group members react to new information. An information organization measure assesses the similarity of the structure of the group members' mental models in terms of the relationships identified among the elements in the model. They also suggest measuring the degree to which attitudes important to the task or the team are shared within the group, along with measures to capture the degree to which group members share similar expectations of behaviors, roles, responsibilities, or decision-making. 
This research operationalizes shared mental models as the structure and content that individuals use to organize information about a given domain. The study examines mental models of both the task the group is performing and mental models of team interaction. "Sharedness" is understood as the degree of similarity in "presence and strength" (Langan-Fox, et al., 2000) of the content and structure of the models. The underlying assumption about outcomes is that that groups with higher levels of shared mental models of the task and of team interaction will exhibit high levels of performance of the task. Finally, in contrast to most of the empirical work on mental models, this research employs qualitative methods to elicit and represent the mental models of the participants.

\subsubsection{Small Group Communication}

A small group is typically characterized as a group of people between three and fifteen in number; organized around a shared purpose; where group members' interaction is interdependent with one other; operating within a perceived boundary, where individuals can be identified as "inside" or "outside" the group; with regular communication among the group members (Hirokawa, Cathcart, Samovar, \& Henman, 2003).

The small group communication literature is broad. Categories of research include the nature and structure of groups, including issues such as diversity, conflict management, social dynamics, and individual/group tensions. This literature also is concerned with how groups organize, group development, group leadership, and social influence. Group 
processes are also studied, such as group decision-making, problem solving, and delivering feedback in groups.

\subsubsection{Functional Theory}

A number of general theories exist in the small group communication literature that can be used to explain specific group communication phenomena. This research follows a functional theory perspective. Poole (1999, p. 42) writes "Theories concerned with group functions assume that the important effects are those that enable a group to address a particular problem to achieve its goals... communicative behaviors are analyzed to determine which functions they serve" in terms of the "needs, goals, or problems the group must satisfy to maintain their well-being”. Hirokawa writes:

Functional approaches to the study of group interaction have consistently appeared in the literature for almost half a century. The popularity of these approaches is largely due to their intuitive appeal. Simply put, it makes good sense to believe that group interaction is consequential — that it is capable of producing various consequences or outcomes (both good and bad) for the group and its members. When group members communicate with each other, their utterances do more than just provide information. Additionally, they can advance or discredit ideas, build or break down interpersonal relationships, and facilitate or hinder the formation of shared attitudes, values, and beliefs among group members. (1994, p. 542)

In this research, the communication behaviors of the group were analyzed to see how they served the function of contributing to the development of shared mental models. 
Specifically, five dimensions of communication were selected to explore how they impact shared cognition in groups. They are: the topical themes of the communication; the function of the communication message; the roles the actors adopt in communicating; the channels used to communication; and the rules followed in the interaction.

Communication themes: Communication themes reflect the content of group communication - the topical ideas and interpretations of those ideas the group develops over time. To understand how communication impacts shared cognition, a first step must capture and code the content of the knowledge, ideas, beliefs, or assumptions that are expressed by group members in a social context. Once identified, this content can be traced over time as it is constructed and transformed through group communication and interaction. Content analysis is a commonly used analysis technique to understand topical themes employed in a range of applications including presidential speeches, company reports, theoretical articles, as well as group communication. In a laboratory setting, Kim (2003) used content analysis of group discussion to uncover the frequency that certain types of content was discussed and its subsequent effect on the group's degree of information sharing and performance on a decision task. Benbunan-Fich, Hiltz, \& Turoff (2003) examined group discussion using content analysis to compare the process and content of communication in face-to-face groups vs. asynchronous groups in a decisionmaking task. Wallace (1987) examined the group discussions of building design teams using content analysis to explore conflict over different approaches to cost factors in the design process. Wheelan and Krasick (1993) explored how content themes emerge, are transmitted, and are accepted within groups in a social system. Using content analysis 
they traced the presence of key themes across meetings of a professional four-day conference.

Communication functions: Communication functions describe the purpose, rather than the content of communicated messages. Bales' (1953) Equilibrium Theory states that for a group to function effectively, it must balance task needs with socioemotional needs. To achieve this balance, the function of communication in the group shifts between focus on the task and focus on socioemotional interaction to maintain group functioning (Poole, 1999). Of interest to this study is how communication functions contribute to shared cognition in groups, and in particular, whether task functions and socioemotional functions differentially impact shared mental model development.

Communication functions are analyzed through the study of group interactions. A number of approaches exist to examine group interaction (see Kelly, 2000 for a review of different models for analyzing group interaction). Interaction Process Analysis (IPA) (Bales, 1951) is the best-known schema for analyzing group messages by the function or purpose of the message. IPA has received extensive use in the literature for more than fifty years. Bales and his followers carried out many tests of the schema with groups of varying sizes and purposes to study interaction patterns and role patterns (Bales, 1958; Bales \& Hare, 1965). IPA has also been applied to the study of gender differences in communication (Eskilson \& Wiley, 1976; Mabry, 1985; Piliavin \& Martin, 1978). Other applications of IPA have studied the interaction patterns of groups engaged in creative problem solving (Tindall, Houtz, Hausler, \& Heimowitz, 1982); comparing communication patterns in face-to-face and online groups (Hiltz, Johnson, \& Turoff, 
1986); and the nature of relational messages in a breast cancer support group (Keyton \& Beck, 2009).

Communication roles: Group communication roles are the functions or responsibilities that guide behaviors in small group interaction (Strijbos, Martens, Jochems, \& Broers, 2004). Much literature exists characterizing the nature of the role of leader of the group (for recent examples see Eby, Cader, \& Noble, 2003; Hogg, et al., 2006; Hogg, Hains, \& Mason, 1998; Nye, 2002; Rozell \& Gundersen, 2003; Sparrowe, Soetjipto, \& Kraimer, 2006). Beyond the role of leader, group roles are also studied in terms of the functions they perform. Two categories of group roles have been found to exist in small groups: task roles which are related to accomplishing the group's task, and group building and maintenance roles which serve to maintain positive interpersonal relations in the group (Benne \& Sheats, 1948; Dipboye, Smith, \& Howell, 1994). Benne and Sheats were among the first researchers to devise a typology of functional roles beyond that of the leader of the group. They believed there were many other roles neglected by the predominance of research on leader roles. In emphasizing the importance of group member roles, they wrote, (1948, p. 42) "The functions to be performed both in building and maintaining group-centered activity and in effective production by the group are primarily member roles.” Their classification includes 27 roles arranged into three categories: task roles, group building and maintenance roles, and individual roles. The group task roles are those roles that focus on carrying out the task. The group building and maintenance roles are those behaviors which emphasize "building group-centered attitudes or orientation" (Benne \& Sheats, 1948, p. 44). 
Individual roles were viewed as roles unrelated to the group's tasks and roles that are neutral to or have a negative effect on group building.

The Benne and Sheats typology has been used in the small group literature as a basis for developing other role typologies (Mumford, Van Iddekinge, Morgeson, \& Campion, 2008); as the basis for coding schemas on group interaction (Hirokawa, 1980; Pavitt, Whitchurch, McClurg, \& Petersen, 1995; Zigurs \& Kozar, 1994); in analyses of group interaction in face to face and online classroom settings (Goodman, et al., 2005; Mudrack \& Farrell, 1995); as well as in practical strategies teaching students how to work effectively in teams (Butler, 1995).

Communication channels: The recent research literature is filled with studies analyzing group communication in a computer-mediated environment. Current themes include decision-making effectiveness with group support systems (Shirani, 2006); impact of communication medium or channel on group processes (Andres, 2006); and communications issues in virtual teams (Schwartzman, 2006; Timmerman \& Scott, 2006). The new research questions that have come to light as a result of the impact of information and communication technologies (ICTs) on groups are substantive enough to be their own topics of dissertations, and thus this research does not focus on the role of ICTs on group communication and shared mental model development. However, the ubiquity of electronic communications channels in work teams is such that the potential effects of communication channels are inextricably linked to group communication. Thus, the final communication variable explored in this research is the types of 
communication channels used by the group and their potential effect on the development of shared mental models.

Communication rules: Groups develop normative practices around a variety of behaviors such as how time is kept (lateness, keeping to a schedule); appropriate dress (Dipboye, et al., 1994); or where people sit in the meeting space (Burgoon, 2003). Communicative norms exist that are both explicit, such as following Robert's Rules of Order for proper procedure, and implicit, such as whether or how humor or informal "small talk" is used in group discussion. Communication norms have been called communication rules in the literature (Jabs, 2005; Schall, 1983; Shimanoff, 1980). Schall (1983, p. 560) defined communication rules as, “...tacit understandings (generally unwritten and unspoken) about appropriate ways to interact (communicate) with others in given roles and situations; they are choices, not laws (though they constrain choice through normative, practical or logical force), and they allow interactors to interpret behavior in similar ways (to share meanings)." By this definition, the communication rules held by a group may be used by groups to reach shared meanings.

Communication rules comes from rules theory that when applied to groups says that for groups to communicate, members must hold shared beliefs about how the group should interact (Shimanoff, 1980). According to rules theory, rules are followable, prescriptive, contextual, and domain specific (Shimanoff, 1980). That is, communication rules are choices available to people that prescribe what behavior is expected in a given context by a particular individual (Jabs, 2005). When there is deviation from the expected behavior, sanctions may be imposed by members of the group. Sanctions may take the 
form of ignoring the deviator, nonverbal gestures, verbal reprimands, a less favorable impression of the deviator, or some level of ostracism (Shimanoff, 1988). One method to classify communication rules is according to: 1) who says, 2) what, 3) to whom, 4) when, 5) with what duration and frequency, 6) through what medium, 7) by what decisionprocedure (Scheerhorn \& Geist, 1997; Shimanoff, 1988). Classifying communication patterns in this way reveals the rules that are established in a group, enabling connections to be made between communication rules and shared mental model development.

Research on communication rules has looked at the effectiveness of communication rules in developing descriptions of organizational culture (Schall, 1983); a shared understanding of communication rules as an antecedent of group process satisfaction and task performance (Park, 2008); what communication rules govern the display of emotions in organizations (Kramer \& Hess, 2002), and how employees learn the communication rules that exist in organizations (Gilsdorf, 1998).

\subsubsection{Group Communication and Shared Mental Models}

There is strong theoretical agreement that shared meanings in groups come from group communication and interaction (Allard-Poesi, 1998; Goodwin \& Fiske, 1994; Higgins, 1992; Krauss \& Fussell, 1991; Tindale \& Kameda, 2000). However, little empirical work has been done to identify more precisely what aspects of the interaction prove to be influential in the development of shared cognition.

To cite some examples, a study by Brauner (as cited in Tindale \& Kameda, 2000), found that two groups with dissimilar mental models about their experimental task at the beginning of the project came to reach a large degree of convergence in their thinking 
about the task after two group discussion sessions. Hastie and Pennington (1991) examined jurors' deliberation patterns and found that in evidence driven deliberation, jurors use group discussion to reveal differences in conclusions reached about the case and to "attempt to influence one another to reach consensus on a single group story of what happened" (p. 315).

Other research has found that group interaction mediated the relationship between role differentiation (the different roles necessary to perform the task) and shared mental models, albeit in the opposite direction than anticipated (Levesque, Wilson, \& Wholey, 2001). Using a longitudinal study design, they found that due to the high level of role differentiation at time one of their study, less frequent interaction occurred at time two, resulting in less similar mental models at time three.

Mathieu, Heffner, Goodwin, Salas, and Cannon-Bowers (2000) examined communication as an outcome (rather than an antecedent as in this study) of shared mental models which subsequently affects performance. They hypothesized that team processes, including communication, would mediate the relationship between team and task mental model convergence and team performance and found substantial support for their hypothesized model. Though their findings lend support to a directional model opposite to the research reported here, Mathieu's et al., findings are not necessarily contrary. The distinction to be made is that communication in this study is only examined as an antecedent to shared mental models, but does not preclude any relationships between shared mental models and subsequent group communication. Given that social cognition is constructed over time through multiple interactions, it is entirely reasonable 
to view group communication as an outcome of shared mental models, relating to group performance, as modeled by Mathieu, et al. This dissertation is intentionally limited to an examination of communication events leading to the formation of shared mental models.

More recent research has explored semi-automatic methods for assessing team communication data as a way to access team mental models. Cooke, Salas, Kiekel, and Bell (2004) have developed automated procedures for analyzing group communication in terms of the frequency of speech for each team member, as well as for communication flow patterns. To analyze content data, they use latent semantic analysis, using a language corpus such as an encyclopedia as a source from which meanings of words are extracted based on word co-occurrence. A vector for each word is created based on its dimensions of co-occurrence which can then be compared with study data to examine patterns of similarity from one speech act to the next, across teams, and within teams. Similarity assessments, based on the vectors, are then used to infer team cognition.

Finally, He, Butler and Kim (2007) found good support for their hypothesized model that team interaction, framed as communication frequency, would be positively correlated with measures of team cognition including an awareness of expertise in the group and a shared understanding of the task, and further that awareness of expertise location and shared task understanding would have positive significant effects on team performance. They tested their model with self-report surveys from fifty-one teams performing a synthetic task (derived from a real-world problem) in software design over a five-week period. Their findings showed that meetings and phone call frequency were positively 
associated with both aspects of team cognition, and that team cognition was positively correlated with team performance.

\subsubsection{Conceptual Framework}

Because this study is exploratory following the practices of naturalistic inquiry, a priori hypotheses have not been constructed. Instead, a conceptual framework derived from the two literatures reviewed underpins the study. The underlying conceptual framework of this study is summarized in these statements of understanding:

- Individuals hold mental models of knowledge, beliefs, ideas, assumptions, or understandings.

- Individuals' mental models are made known to the group through communication and interaction.

- Group communication is a key mechanism through which social cognition occurs.

- Shared mental models are an instantiation of social cognition.

- Groups with similar mental models perform at a higher level than groups without shared mental models 
A model of the constructs and relationships underpinning this research is shown in

Figure 1-1.

Individuals' with
cognitive schemas $\rightarrow \quad \begin{aligned} & \text { Interact through group } \\ & \text { communication (themes, } \\ & \text { roles, rules, functions, } \\ & \text { channels) }\end{aligned} \quad \rightarrow \quad \begin{aligned} & \text { Develop shared } \\ & \text { mental models }\end{aligned}$

Figure 1-1. Model of the Conceptual Framework

\subsubsection{Definitions}

Constructs of interest to this study are defined as follows:

Communication channel The means through which communication occurs in the small group. Expected channels include: meetings, informal conversations, electronic communication paths (i.e., e-mail, threaded discussion).

Communication function The function of a communication message in small group interaction as either related to task communication or in support of socioemotional communication.

Communication role The functional responsibilities guiding individual communication behavior in small group interaction.

Communication rule Communication norms; understandings about acceptable or appropriate communication behaviors in a small group.

Communication theme A topic or idea that is talked about by two or more team members for a sustained period of time.

Shared mental models The framework or schema used to organize information about a given domain, held in common among members of a small group. 


\section{Chapter 2: $\quad$ Research Questions and Research Methodology}

This chapter describes the research design for the study. It first presents the main research question and foreshadowing questions and then describes the data collection and analysis procedures. The chapter closes with a discussion of the steps taken to ensure the credibility, dependability, confirmability, and transferability of the study and the study's possible limitations.

\subsection{Research Questions}

The main research question guiding this investigation is: How does group communication contribute to the development of shared mental model(s)?

The research question is separated into the following foreshadowing questions:

1. How do communication themes impact the development of shared mental models?

a. What themes emerge from the group interaction?

2. How does the function of communication messages impact the development of shared mental models?

a. Are some types of communication messages more influential than others in developing shared mental models?

b. Do the different types of communication messages serve different purposes in developing the shared models?

3. How do communication roles impact the development of shared mental models? 
a. Are some group communication roles more influential in developing shared mental models?

b. Do the different roles serve different purposes in developing the shared models?

4. How do different communication channels affect the development of shared mental models?

a. What channels of communication are used?

b. For what purposes?

5. How do communication rules impact the development of shared mental models?

a. What group communication rules emerge?

b. What sanctions are employed if rules are violated?

6. What mental models does the group develop?

a. For a particular mental model domain, what components of the model does the group identify at different stages of task performance?

b. How is the content and structure "shared"?

\subsection{Research Design}

This research design is based on qualitative methodology. Because the research questions seek to explore the meaning, processes, and context of a phenomenon through the voice of the participants, the qualitative paradigm is appropriate (Maxwell, 1996). A particular strength of qualitative methods is the depth and complexity of the data used for analysis. Kreps and Herndon (2001, pp. 3-4) write, "Nondirective ethnographic forms of 
data communication behaviors, examining texts and artifacts, and encouraging full accounts of members' perspectives on organizational performance (rather than constraining subjects' responses to limited-response, close-ended measurement scales) can provide very relevant and revealing data." This study adheres to that idea by collecting data from observation, interview, and textual artifacts. Data collected through these qualitative methods emphasize the participant's voice over the researcher's, reflecting the world as constructed by the participant (Frey, 1994). In this study in particular, which seeks to capture the mental models of the participants, it is important to employ research methods that privilege the voice of the participants.

This research study follows a case study approach. Creswell, (2003, p. 15) defines case studies as studies, "in which the researcher explores in depth a program, an event, an activity, a process, or one or more individuals. The case(s) are bounded by time and activity, and the researchers collect detailed information using a variety of data collection procedures over a sustained period of time." Case study is a useful approach when research questions explore complex phenomena involving multiple, unknown variables. This approach is also appropriate when the phenomena studied are new or emerging, and the research findings may be used to build theory and generate hypotheses. Finally, the case study is a good strategy to use for examining everyday behavior that may not be revealed to its richest extent in one session or observation (Hartley, 2004). This project studies complex phenomena through the lens of everyday behavior. It is likely to generate emerging findings, bounded by a particular activity, over an extended period of time. 
The case study approach requires comprehensively describing and explaining, "the variety of components in a given social situation using multiple sources of evidence" (Arneson \& Query, 2001, p. 154). However, a case study is not without particular focus. Stake (1994) describes the process of building the focus of a case study in the following manner. First the researcher identifies the topical area of concern. Within that topic, the researcher poses foreshadowed problem(s) related to the case. The researcher then concentrates on issue-related observations that relate to the topical concern and the foreshadowed problem(s). The data collected from the issue-related observations are interpreted for patterns that become assertions or comments about the case (Stake, 1994, p. 239).

The topical area of concern in this study is the development of shared mental models. The foreshadowed problem is the small group communication processes that influence mental model development. The issue-related observations for this study come from the events of the case group over the life of the project, including observations of meetings, interviews with participants, and meeting and email transcripts. The comments made about the case come from analyses and interpretations about the data collected from these events.

\subsection{Case Selection}

The following section describes the steps taken by the researcher to locate and select a group to be participants in the study. 
At the time the study was proposed, no group had been chosen to participate. Rather, the following list of characteristics had been identified that would guide selecting an appropriate group:

- The group should be a work group.

- It should be a small group, with 3 to 10 members.

- The group should be beginning a task.

- The task should be non-routine and relatively complex.

- Accomplishing the task should be likely to take several group meetings and interim communications.

- The task should have an end-state, with perhaps a deliverable, e.g., a report or service.

- The group should work within a library or archive.

- The library or archive should be located in the Washington, D.C./Baltimore metropolitan area.

- The group should be starting on the task from August 1, 2006 through early fall and preferably completing it by December 30, 2006.

To find a group matching these characteristics, the researcher's advisor sent a letter to approximately forty library directors in the greater Baltimore/Washington, D.C. area (see Appendix A: Solicitation Letter). The organization population included academic libraries, public libraries, and special libraries. The letter described the study and asked each director to identify possible groups within his organization and to indicate his organization's willingness to participate in the study. Letters were sent in July 2006. In 
addition to the letter, the researcher sent an email message to the College's electronic listserv reaching primarily information professionals in the metropolitan area, soliciting groups for the study.

Eight organizations responded favorably, resulting in seven potential projects. After considering the details of the seven possible groups, the list was reduced to three that best fit the stated criteria. The researcher conducted a meeting by telephone with administrators at each of the three organizations to learn more about each project. On considering match to the criteria and willingness to participate, the researcher selected the Accountability Group from a suburban public library system. Chapter three includes a complete description of the group, setting, and task.

In parallel with the efforts taken to locate a group, the researcher also secured permission to undertake the proposed research in compliance with the University of Maryland's Institutional Review Board (IRB). Official approval to undertake the research was initially received September 1, 2006. The application was renewed in July 2007 and July 2008 (see Appendix B: Institutional Review Board Approval and Extensions.) Participants gave their informed consent for participation in the study at the beginning of the initial interview before research commenced.

\subsection{Data Collection}

The design of this study dictates that two broadly defined types of data be collected: data reflecting the group's shared mental models and data reflecting small group communication, referred to in this chapter as interaction data. 


\subsubsection{Mental Models}

Data were collected that reflected individual group members' mental models of the task and of the team interaction at three different points during the study, roughly corresponding to the beginning, middle, and end of the project. These data were collected through interviews with each group member.

The measurement techniques for capturing shared cognition should be linked to the definition of shared cognition used in the study (Cannon-Bowers \& Salas, 2001). As previously defined, shared mental models are the structure and content that individuals use to organize information about the task the group is performing and about the team's models of interacting. "Sharedness" is defined as the degree of similarity in "presence and strength" (Langan-Fox, et al., 2000) of the content and structure of the models.

For the interviews, the researcher developed an interview protocol to elicit the participants' understandings about the task(s) they were working on and the nature of the team's interaction. Interview questions were drafted and tested with a pilot group prior to selecting the group for this study. The pilot test of the interview questions resulted in reducing the number of questions asked.

Each participant was interviewed at three points in time. The first interview occurred prior to the group's first meeting; the second interview occurred between meetings two and three; and the final interview occurred after the group met for the last time. The same interview protocol was used at each interview, with allowances for temporal changes, such as "what tasks will be you working on? " at interview 1, and "what tasks did you work on?" at the third interview. The interview questions focused on the two mental 
model domains of interest in this study, task and team interaction. Within those parameters, the questions were open-ended and when necessary, follow-up questions and probes were used to redirect the participant (see Appendix C: Interview Protocol for Accountability Group.)

Although several techniques exist to capture and measure mental models, including pathfinder nets, repertory grid, concept and cognitive maps, and card sorts (Langan-Fox, et al., 2000), for the purpose of this study, open-ended interviewing was chosen as the best approach to elicit the content and structure of the individuals' mental models. In this approach, participants use their own words and expressions to identify and relate their internal schemas. Also, for participants, it is a cognitively simpler task to answer questions than to create graphic representations of their thinking or to make similarity judgments on a large set of concepts. The interview questions were purposefully intended to be broad to allow the participants to respond as naturally as possible and avoid influencing the direction or content of the responses. An inherent challenge in measuring mental models in this manner is the inability of the researcher to access the mind of the participants to capture their thinking on a topic that they did not voice. Due to that limitation, only ideas that were verbally expressed by the participants can be analyzed. The absence of a comment about an idea from a participant cannot be interpreted to mean disagreement with that idea. But neither would it be accurate to assume that the absence of a comment on an idea equals agreement, so this study is limited to analyzing the ideas verbalized by the participants, recognizing that those verbalizations will not always be a comprehensive or fully accurate expression of their thinking. Further, the task and team 
interaction models that emerged from the interviews are in fact representations of the researcher's model of the participants' model and may be influenced by the researcher's background and experiences. Thus the representations of the group's mental models are an approximation of their thinking, viewed through the researcher (Rouse \& Morris, 1986).

\subsubsection{Interaction Data}

The interaction data include data from the communication events and interactions that occurred among the group members throughout the duration of the study. In following a social cognition approach in this research, the important phenomena to observe are the interactions within the group - the construction of the social experience as it plays out in the work being performed. Allard-Poesi (1998, p. 410) writes:

Interactions, and communication in particular, activate cognitive and social dynamics which allow organizational members to develop realities and representations of these realities. Small groups ... which permit an indepth analysis of these dynamics, can be regarded as a relevant level of analysis for the study of collective representations in organizations.

These interaction data, although collected from each individual in the group, represents a group level rather than individual level unit of analysis. Group communication is the collection of exchanges of the members in the group: the message exchanges and the assignment of meaning to those messages. It should be noted here that that interaction data that were collected were limited to communication that could be 
recorded and transcribed, that is, verbal interaction. Non-verbal communication falls outside the scope of this study.

The interaction data included:

- audio transcripts of group meetings;

- written e-mail messages within the group;

- researcher field notes from observing the group interaction;

- diary entries from group members recording communication events that occurred outside the time the researcher was present to capture them.

\subsubsection{Transcripts}

The interactions of the group during meetings were audio taped and transcribed for analysis.

\subsubsection{E-mail messages}

The e-mail messages sent by the group were also captured. The messages were redacted to hide identifying information of the participants and reformatted to remove unnecessary text supplied by the email system.

\subsubsection{Field Notes}

The researcher attended each group meeting and recorded her observations of the group interaction. These data captured both descriptive information and reflective notes (Creswell, 1998). The descriptive data include information such as start and stop times, names of participants, a summary of the order of events, and details on the seating arrangements and room set-up. The reflective notes record the questions, perceptions, and 
other personal ideas that arose during the observation period. The field notes supplement the meeting transcripts.

\subsubsection{Diary Entries}

In keeping with a naturalistic tradition, every effort was made to capture the communication event data as events naturally occurred among members of the group. A communication event such as a scheduled meeting was relatively easy to record, but other communication, such as informal, spontaneous communication among members, out of the presence of the researcher, posed logistical problems. To capture the informal exchanges, the researcher created a diary form to record informal communication events, such as an impromptu conversation in the hall. However, once the data collection period started, it became apparent that the group had little opportunity to have informal, spontaneous exchanges since group members did not work in the same facilities. To be sure, the researcher periodically e-mailed the participants to inquire if they had had any exchanges with other group members about their work outside the scope of the group's meetings. In every case the response was no and so the diary forms, although available, were not used.

\subsection{Data Analysis}

Creswell (1998) describes data analysis in qualitative research as a spiral in which the researcher examines the data through a number of steps to arrive at an interpretation of the phenomenon. The analysis begins with organizing the data into the appropriate format and units. Interviews and interactions are transcribed and captured in electronic format. The researcher reads through the entire transcript, making notes, and writing questions 
that arise. Then he or she codes the text, compares the coded material, and classifies it according to larger themes. From the coded data, he or she drafts descriptions and identifies contextual elements. Finally the researcher represents the categories through visual elements, such as models or tables, and through a narrative account of the phenomenon, often illustrating findings with excerpts from the data. The following section describes how this analysis process was employed within this research.

The major objective of the data analysis was to relate the development of shared mental models with the communication that occurred and that required three distinct phases of analysis: a) characterizing the mental models that developed; b) characterizing the five different communication variables within the group; and c) relating the two by examining the communications findings and analyzing their possible influence on components of the mental models. It is important to note that the analysis described here was a) ongoing throughout the project, and b) iterative, moving forward and backward through the procedures, guided by the direction of the analysis and interpretation. (See Appendix D: Data Analysis Matrix for a summary table that maps the foreshadowing questions to the data collection and analysis.)

\subsubsection{Context and Task}

The context in which the small group operates is important in understanding the group. Many contextual variables may be at play within a particular group setting: allocation of resources; support for the group's task; organizational climate and culture; industry or market forces; management involvement in the group; deadline pressures, to name only a few. Contextual elements are perceived by members of the group, although 
not always the same elements, nor in the same way, and are reflected in the communication messages delivered by group members. The interplay of contextual perceptions and the social interaction of the group creates the environment. Barge and Keyton (1994) call this an enactment view of context. Understanding the salient contextual influences operating within the group and how they are reflected through group interaction contributes to an understanding of how groups develop shared cognition.

In keeping with the case study approach, the data collected throughout study were used to create a thick, rich description of the context in which the group operated such as the background of the group, a description of the organizational setting, and institutional groups and procedures that impacted the group. The task that the group is performing is also an important parameter to consider in the analysis of the data. The nature of the task, for example, if it is exploratory or requires specific action, will likely impact the kind of mental models the group develops (Mohammed, et al., 2000) as well as their communication patterns. Along with a description of the context in which the group operated, details and characteristics of the task are described in detail in chapter three, to set the stage in which the findings are situated.

\subsubsection{Mental Models}

As described in the data collection section, the interview protocol was designed to elicit the participants' mental models about the task and the team interaction. The interview questions reflect broad areas, referred to as elements, of each of the two mental models. The participants' responses were coded for element and then for components or 
sub-facets of the elements. The elements were derived from previous literature and functioned as existing codes, while the components were inferred from the data provided by the participants. Comparisons were made across the components to assess the degree of similarity in the participants' responses (Strauss \& Corbin, 1998).

The degree of similarity among responses was established whereby a particular idea or concept was considered to be shared if the words the participants used to describe it were highly similar in meaning. Components of the mental models were considered strongly shared when six or seven group members expressed the same or highly similar meaning; four or five similar responses were considered moderately strongly shared; two or three similar responses were labeled weakly shared and single responses were considered not shared. Matrices were built for each of the two mental models (task and team interaction) to display the elements of the model, the components of each element, and the degree of sharedness of each component among group members.

\subsubsection{Interaction Data}

The interaction data were analyzed to characterize different aspects of communication within the group.

\subsubsection{Themes}

The interaction data were coded for content themes, operationalized as a topic or idea discussed by two or more team members for a sustained period of time. First the interaction data were grouped by event, with each of the four meetings as a separate data set, and the collection of all e-mail messages exchanged formed the fifth set. Then the email messages were grouped by theme which was made up of the initial message sent on 
a particular topic, and all messages responding to that same topic, usually indicated through the use of the "reply all" feature and easily identified by the subject line. Starting with the first meeting, the researcher read the transcript and identified the topics of conversation. Statements about the same topic were coded together revealing mid-level classifications of themes and then were abstracted to higher-level general categories. This process was followed for the five sets of data.

\subsubsection{Functions}

The data were analyzed to explore the function of the group's messages using Bales' Interaction Process Analysis (IPA). IPA examines the purpose a communicated message serves, as opposed to the topical meaning it carries. IPA examines group communication at the level of the utterance and assigns one of 12 functional categories to each utterance. The 12 categories collapse into two groups: six functions relate to task communication and six functions relate to socioemotional communication. The six categories within the socioemotional group can be further divided into three positive and three negative functions. The six task categories divide into task-questions and task-answers. Table 2-1 shows the 12 IPA categories, grouped by task and socioemotional area. 
Table 2-1. IPA Categories by Group

\begin{tabular}{|c|c|}
\hline IPA groups & IPA categories \\
\hline Socioemotional-positive & $\begin{array}{ll}\text { 1. } & \text { Shows solidarity } \\
\text { 2. } & \text { Shows tension release } \\
\text { 3. } & \text { Agrees }\end{array}$ \\
\hline Task-answers & $\begin{array}{ll}\text { 4. } & \text { Gives suggestion } \\
\text { 5. } & \text { Gives opinions } \\
\text { 6. } & \text { Gives information }\end{array}$ \\
\hline Task-questions & $\begin{array}{ll}\text { 7. } & \text { Asks for information } \\
\text { 8. } & \text { Asks for opinion } \\
\text { 9. } & \text { Asks for suggestion } \\
\end{array}$ \\
\hline $\begin{array}{l}\text { Socioemotional- } \\
\text { negative }\end{array}$ & $\begin{array}{l}\text { 10. Disagrees } \\
\text { 11. Shows tension } \\
\text { 12. Shows antagonism }\end{array}$ \\
\hline
\end{tabular}

The data were segmented into utterances, considered as smallest segment of text that expresses a complete thought. The units ranged from a single word, i.e., "What?" to a single, simple sentence. Each segment was assigned one of the 12 categories. Bales' (1951) own definitions of the categories were rigorously observed, and the researcher also kept a memo to record her coding procedures and her interpretations and applications of the codes. A procedure to test internal consistency was performed by isolating and reviewing all the utterances coded at each category. As a result of that review, a small number of utterances were re-coded and noted in the coding memo.

Because IPA codes the data at the level of the utterance, it is possible to analyze the data at the level of each group member's communication messages and develop profiles for each participant. However, in this study, the unit of analysis of interest regarding communication is the group level interaction, not individual communication, and thus the analysis and interpretation of the data coded using IPA focused on group level 
characterizations of communication function, rather than characterizing patterns of individual group members.

\subsubsection{Roles}

The communication roles that participants played were derived from the meeting and email data. First, the researcher read the transcripts of each meeting and prepared a posthoc agenda for that meeting based on the interactions that occurred. (The group did not create their own agendas.) The researcher also drafted meeting notes that summarized each of the agenda items. Then the full transcript was divided into segments, each representing an agenda item. This process did not always result in a linear division; at times a conversation about an agenda item would emerge at different points throughout the meeting. The intent of this unitizing was to bring together all the communication related to each item on the agenda. Each agenda-based segment was then analyzed for dominant occurrences of any of the twenty-seven roles identified by Benne and Sheats (1948) typology of functional group roles. The segments were treated as discrete communication events and the functional roles that were most dominant and influential in guiding the event were the roles that were coded. The emphasis was on detecting the range of roles that were influential to a specific segment. (See Appendix E: Benne \& Sheats (1948) Functional Role Definitions for the roles and their definitions.) The segments were also analyzed for instances of leadership behaviors, which are not included in the Benne and Sheats typology.

Other units of analysis were considered in examining the roles participants played, including the utterance, the conversational turn, and conversational themes. These were 
ultimately discarded as being unnecessarily granular for the data. Grouping the data into longer segments based on a meeting agenda structure still permits the breadth of roles to emerge in a given segment but avoids the problem of forcing a role code on a portion of text too small or vague to be certain of the accuracy of the assigned code.

\subsubsection{Channels}

The interaction data were separated by channel and analyzed to examine the group's use of different communication channels. As described in the research design section, the study was prepared to capture group communication over multiple communication channels, but the only two channels in use were face-to-face meetings and email messages. The interaction data, divided by channel, were compared to observe similarities and differences in the content and purpose of the group's communication across channels.

\subsubsection{Rules}

The interaction data were also examined to identify the communication rules that developed within the group. Communication rules were operationalized as understandings about acceptable or appropriate communication behaviors in a small group. The transcripts were read multiple times to identify patterns in the group's interaction that depicted a rule. To identify these patterns, the researcher applied the schema: 1) who says, 2) what, 3) to whom, 4) when, 5) with what duration and frequency, 6) through what medium, 7) by what decision-procedure (Scheerhorn \& Geist, 1997; Shimanoff, 1988) to the entire data set. The rules that emerged from this schema were found to be consistent across the group's lifetime. 


\subsubsection{Integration of the Mental Model and Interaction Data}

The final phase of the data analysis looked for evidence of the influence of five communication variables on the two shared mental models. This analysis occurred in three stages.

In the first stage, each component of the two shared mental models (task and team interaction) was examined to identify when it first emerged (interview 1,2, or 3 ) and how it transitioned over time. Transition refers to any change to a component between one interview and the next in terms of the shared mental model. Components that emerged at the first interview were not included in the analysis on how the communication variables may have impacted them because the first interview occurred prior to the group starting their work, and thus no group communication could have been expected to have been influential.

Next, each transition was coded based on the direction of the change. A transition was coded as strengthened when a component of the model emerged, or increased in the degree of sharedness from the previous time. A transition was coded as neutral if it maintained the same degree of sharedness as the previous time. Weakening occurred when a component of the model decreased in degree of sharedness from the previous time.

Finally, for each of the components of the two mental models, the findings of the five communication variables (theme, function, roles, channels, rules) that occurred in the time period prior to that component were systematically examined to identify which, if any, of the communication variables were influential in the development of that 
component of the mental model. If none of the five communication variables seemed to be influential other source(s) were considered which might have influenced its formation.

These analyses were arranged in matrices for each of the mental models and examined for overall trends to answer the main research question.

\subsection{Methods for Verification}

All research must demonstrate standards of rigor and trustworthiness. Guba (1981) defines four aspects of trustworthiness: truth value, applicability, consistency, and neutrality. In naturalistic inquiry, these four elements are thought of as credibility, transferability, dependability and confirmability. These characteristics are goals a qualitative researcher strives for; they are not evaluated by tests for which there are predetermined levels of acceptability. Various practices exist that when followed, lend support to the overall trustworthiness of the research through these four elements. The next section discusses the practices the researcher observed regarding credibility, transferability, dependability, and confirmability.

\subsubsection{Credibility}

Credibility that the results of the study are indeed plausible was addressed through extended time observing the group and persistent observation of the communication events. The researcher attended every meeting the group held and recorded her perceptions of the communication events as they were happening. The researcher also was in regular contact with group members via e-mail to ask about any informal, unrecorded communication with other group members. 
Data were triangulated by comparing field notes, transcripts from the meetings, and interview responses. The researcher wrote memos to herself during the coding process to describe and record the development of the coding structure to ensure consistency. Finally, the coding and analysis made by the researcher were shared with the dissertation advisor and several colleagues as a form of peer debriefing to check for unstated assumptions (Creswell, 1998).

\subsubsection{Transferability}

Transferability of the research speaks to the ability to generalize the findings to other situations. Given that one of the primary tenets of qualitative research is that social action is situated in a unique context, it would not be expected that the same findings could be made observing a different group in another setting. However, the characteristics of the group in this study, which were derived from theory on shared mental models and small group communication, provide a basic context for the group and could serve as a rough comparison point for other studies. Additionally, the extensive description of the setting and the task provided in chapter three provides the context to demonstrate how the findings are relevant given that context and enables other readers to judge for themselves the applicability of the findings to other settings (Guba, 1981).

\subsubsection{Dependability}

Dependability is the extent to which the findings of a study reflect an accurate understanding of the environment where the study took place (Guba, 1981). To support to the dependability of the findings, an audit trail consisting of all non-confidential data such as redacted transcripts to maintain confidentiality, coding schemas, memos, notes, 
and graphical analytical tools have been saved and could be made available for review of the research process.

\subsubsection{Confirmability}

The confirmability of the study - the degree to which the findings are consistent with the data as confirmed by someone else - was addressed through the practice of reflexivity (Guba, 1981). This is a technique in which the researcher notes the assumptions and introspections that occur during the course of the study. These thoughts were collected on paper as they occurred and provided guided reflection for the researcher to clarify distinctions between her personal ideas or assumptions and the interpretations grounded in the data. The researcher also did debriefing with her advisor and student peers through the coding and analysis process to check assumptions and interpretations of the data.

\subsection{Limitations}

Although every effort was made to ensure the validity of the findings reported here, the study has several limitations regarding the transferability and dependability of the study:

- The study is a single case, and thus the findings for this group may not extend to groups with different characteristics. The full description of the group in context in chapter three provides rich detail the reader may use to consider the transferability of the findings to another group.

- The study uses interviews to elicit the participants' mental models, limiting the model to what they could verbalize. This verbalization may not fully or accurately represent the content of the individual's cognitive structure. Any 
self-reporting measure is subject to potential distortions due to bias, forgetfulness, and perceptions of social desirability. Further, the mental models are representations of the researcher's understanding of the verbalizations of the participants and may be influenced by her background and experiences.

- Subconscious biases held by the researcher may color the interpretations of the data. Steps taken to minimize this effect include discussing the analysis and findings with the researcher's advisor and with student peers, along with intentionally testing alternative explanations of the data.

- The presence of the researcher and the use of the recording equipment may have affected the group's behavior.

- The study focuses on five variables of group communication as influences of shared mental models, although the researcher readily acknowledges these are not a complete set of possible influences.

- The group's work pace resulted in several periods of inactivity, which may have affected the clarity and the richness of the mental models. 


\section{Chapter 3: $\quad$ Context of Study}

This chapter describes the context of this study. It provides relevant information about the organization, its geographic setting, the task itself, and the group, including the nature of its formation and characteristics of its membership. It also provides a timeline of the group's activities and a brief description of their interim and final work products.

\subsection{Organization}

The setting for this study is a large, suburban county public library system in the midAtlantic region, serving an affluent, highly educated, and ethnically diverse population of 932,000 (http://quickfacts.census.gov). The median household income for the county in 2007 was $\$ 91,440$, above the 2007 national median of $\$ 50,233$ (US Census Bureau, 2008). In 2006, 56.8\% of adults 25 and older attained a bachelor's degree or higher, also above the national rate of $24.4 \%$. The county is home to a diverse population: white, 67.5\%; black, 16.8\%; Hispanic, 13.8\%; and Asian, 13.4\%. In 2000, 26.7\% of the population was foreign born, and $31.6 \%$ reported speaking a language other than English at home (http://quickfacts.census.gov).

In 2006, the library system served 525,000 registered cardholders in the county, close to $60 \%$ of the population. In addition, the library system attracts users from nearby communities through reciprocal borrowing arrangements. The library system has 20 branches, serves a correctional institution, and operates a bookmobile. The collection includes 2.9 million books, compact discs, digital videodiscs, downloadable and audio books, and other materials. In 2006, the library system circulated 11.4 million items and recorded more than 1.2 million visits to the website. The library system hosts 262 Internet 
workstations that were used 770,000 times in 2006, averaging 14 people every library service hour.

The system has approximately 700 staff members. The Executive Committee is the highest governing body within the library system. It consists of seven members: the Library Director and senior management from public services, technical services, and business and administration. The group meets bi-monthly to direct the operations of the library system as a whole. The current library director has been in place since August 2005. The library system uses a formal performance evaluation process for all employees, referred to as the Performance Development Plan (PDP), to establish work expectations and evaluate employee performance. The PDP system includes a work plan for each employee that lists specific work that person will perform in a given cycle (usually a year). At the end of the cycle, the supervisor rates each employee's performance on the items in his PDP with ratings such as "exceeds standard", "meets standard". Each unit in the library system also has a PDP outlining the responsibilities of that unit. The library system has also developed a Standards of Service document that outlines the expected quality of service of each employee. These documents were frequently referenced in the group discussions.

\subsection{Group Formation}

In June 2006, the library system held a day-long planning retreat for all public services managers across the entire system. During the retreat the participants discussed areas in which the library system should either maintain a current level of service or work to improve service. The participants identified seven areas that fit those criteria: statistics 
and benchmarking; innovation and risk taking; new models of service; customer services; human resources; accountability; and connecting communities.

For subsequent action that would take place away from the planning retreat, task forces were formed for each issue. The task forces were instructed to generate ideas or solutions for sustaining and/or improving service in their respective areas.

Shortly after the retreat was held, the researcher contacted the library director in search of a group to study for this research. The library director offered the researcher access to any of the task forces that had recently formed. After considering the characteristics of the different task forces in relation to the required criteria for the study, the researcher selected the Accountability Group for the research project.

\subsection{Accountability Group Members and Characteristics}

The Accountability Group had seven members. To maintain anonymity each is referred to only by number, preceded by Participant or P throughout. All members of the Accountability Group held positions classified as managers and were present for the daylong retreat where the various task forces were launched. For the most part, the members worked at different library branches across the system; two were at the same branch but in different units. Table 3-1 describes selected characteristics of each group member. 
Table 3-1. Characteristics of Group Members

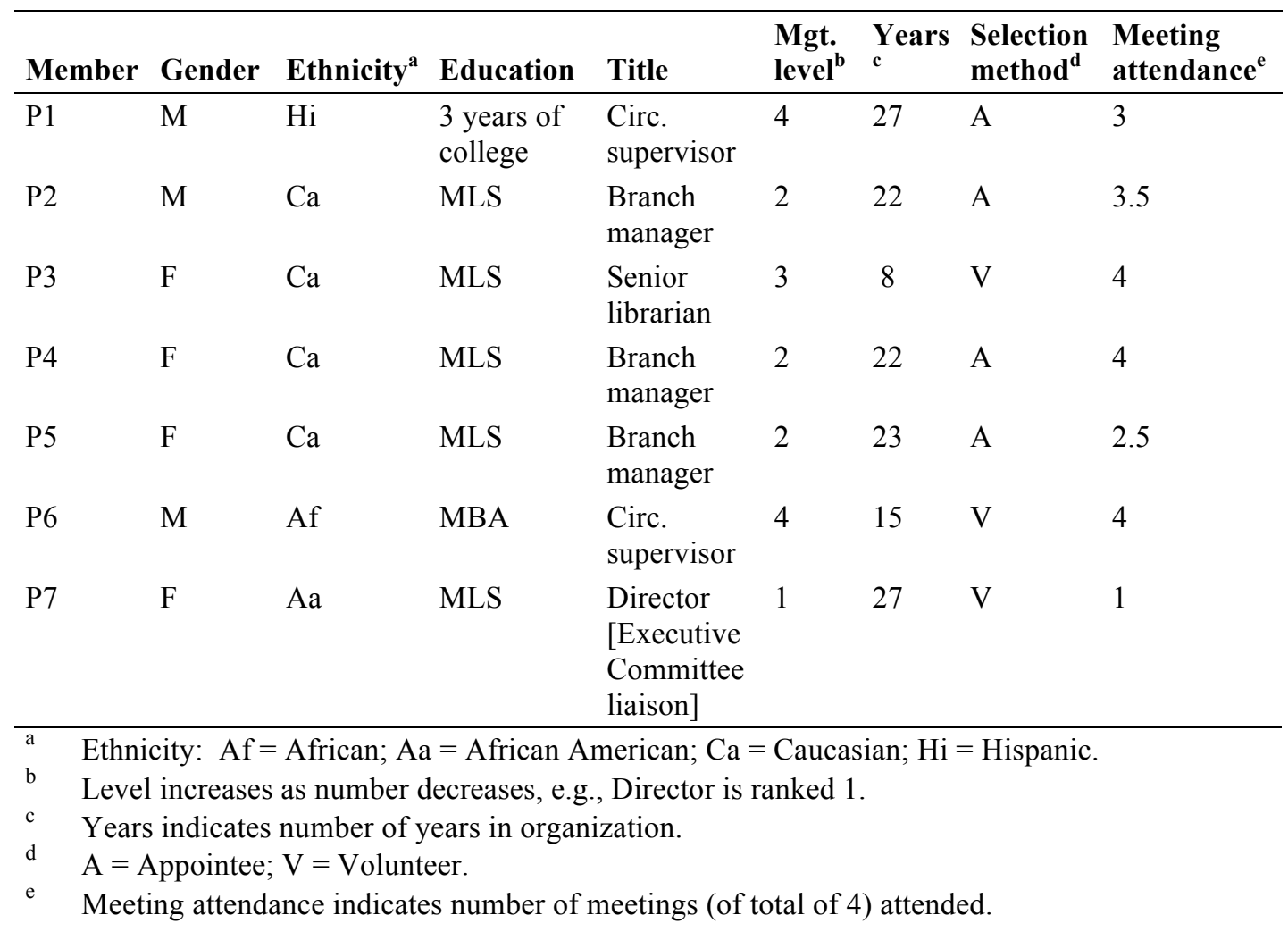

Summarizing briefly from Table 3-1, the group:

- Is approximately evenly divided in gender;

- Is diverse in terms of ethnicity;

- Consists predominantly of professional librarians with an MLS degree;

- Represents all management levels (Note: at the outset of the study, the researcher had some concern about the possible influence the library director might have on the committee and their communication. As the table shows, however, her participation was minimal and ultimately her position did not emerge as a significant factor.); 
- Has a mean longevity in the organization of 20 years and at least half the group had worked in the library system for 22 years;

- Is approximately evenly divided between volunteers and appointed members.

\subsection{Group Relationships}

In the first interview the group members were asked to rank their familiarity with others in the group on a scale of 1 to 3 (not familiar to very familiar). Their responses are noted in the matrix in Table 3-2. The participant named in the left column, labeled raters, refers to the individual who made the familiarity assessment. Reading across a row, the number indicates the rater's familiarity with the participant named in each of the subsequent column headings (i.e., P1 was very familiar with P2, somewhat familiar with P3, somewhat familiar with $\mathrm{P} 4$, etc.)

Table 3-2. Familiarity Ratings Among Group Members

\begin{tabular}{lccccccc}
\hline Raters & P1 & P2 & P3 & $\begin{array}{c}\text { Rated } \\
\text { P4 }\end{array}$ & P5 & P6 & P7 \\
\hline P1 & 3 & 3 & 2 & 2 & 1 & 3 & 3 \\
P2 & 2 & 3 & 2 & 2 & 2 & 1 & 2 \\
P3 & 2 & 2 & 2 & 2 & 2 & 2 & 2 \\
P4 & 2 & 3 & 2 & 3 & 2 & 1 & 3 \\
P5 & 3 & 2 & 3 & 2 & 3 & 3 & 3 \\
P6 & 3 & 2 & 2 & 3 & 2 & 2 & 3 \\
P7 & 15 & 15 & 13 & 14 & 12 & 12 & 16 \\
\hline Total Rating & Note. Ratings: 3 = very familiar; 2 somewhat familiar; 1 = not familiar.
\end{tabular}

The group members all had at least a passing acquaintance with each other, and several of the members were quite familiar with others from having worked at the same branch in the past or from serving on other committees together. Summarizing from the table:

- Overall members are mostly familiar with each other. 
- P7 ranks highest in familiarity among the other members.

- P5 and P6 are least familiar to the rest of the group.

- Not all pair-wise ratings of familiarity are mutual; P5 and P6 both have four unequal ratings, and each participant has at least one occurrence of an unequal assessment of familiarity with someone else in the group.

\subsection{Group Roles}

When the task forces were formed, the Library Director assigned three people within each group to be leaders. After the group members had begun to work together, they could keep the assigned leaders or re-organize. The three people chosen to lead the Accountability Group were P1, P3, and P4. The Library Director chose those three employees because they came from three different levels of the management hierarchy. The Director's intent was to create a situation in which junior managers would have an opportunity to develop their leadership skills with mentorship from the more senior members in their group.

\subsection{Task}

As described earlier, accountability was named as an area that needed to be improved across the library system. The Accountability Group was thus tasked to address this problem, but the group was never given any specific information about the perceived accountability problem, nor did the group receive any formal instruction on how to address the problem. The group was free to explore the problem as they saw fit. The members were expected to establish a formal charge and scope of work, and they were given complete latitude for the tasks they would perform and the work they would 
produce. The Library Director expected that the group would complete its work within the fiscal year, which ended in June 2007, but the group was free to establish work timelines within that expectation. The group was expected to report to the Executive Committee of the library system.

The Accountability Group's task is best described as a problem-solving task. Jonassen (2000) identified two attributes required in problem solving: 1) a mental representation (mental model) of the situation or problem space; and 2) active manipulation of the problem space in some way. He further identified a typology of 11 types of problems, ranging from well structured to ill structured. The task facing the Accountability Group can be classified as a diagnosis-solution problem type according to this typology. A diagnosis-solution problem exists in a real world context and is situated within the problem, in which there are faults to a system with a range of possible solutions. The problem solving group's task is to identify the system faults and then identify and evaluate the treatment options.

\subsubsection{Timeline}

The group worked over a period of ten months from October 2006 to July 2007. In that time period they had four meetings and reported twice to the Executive Committee. They also exchanged 119 email messages over the course of the project. The timeline in Figure 3-1 displays key events in the project, including the group's meetings, interviews with the researcher, and the number of email messages sent per month. As the timeline shows, the group met irregularly with long gaps between meetings and email communication. 

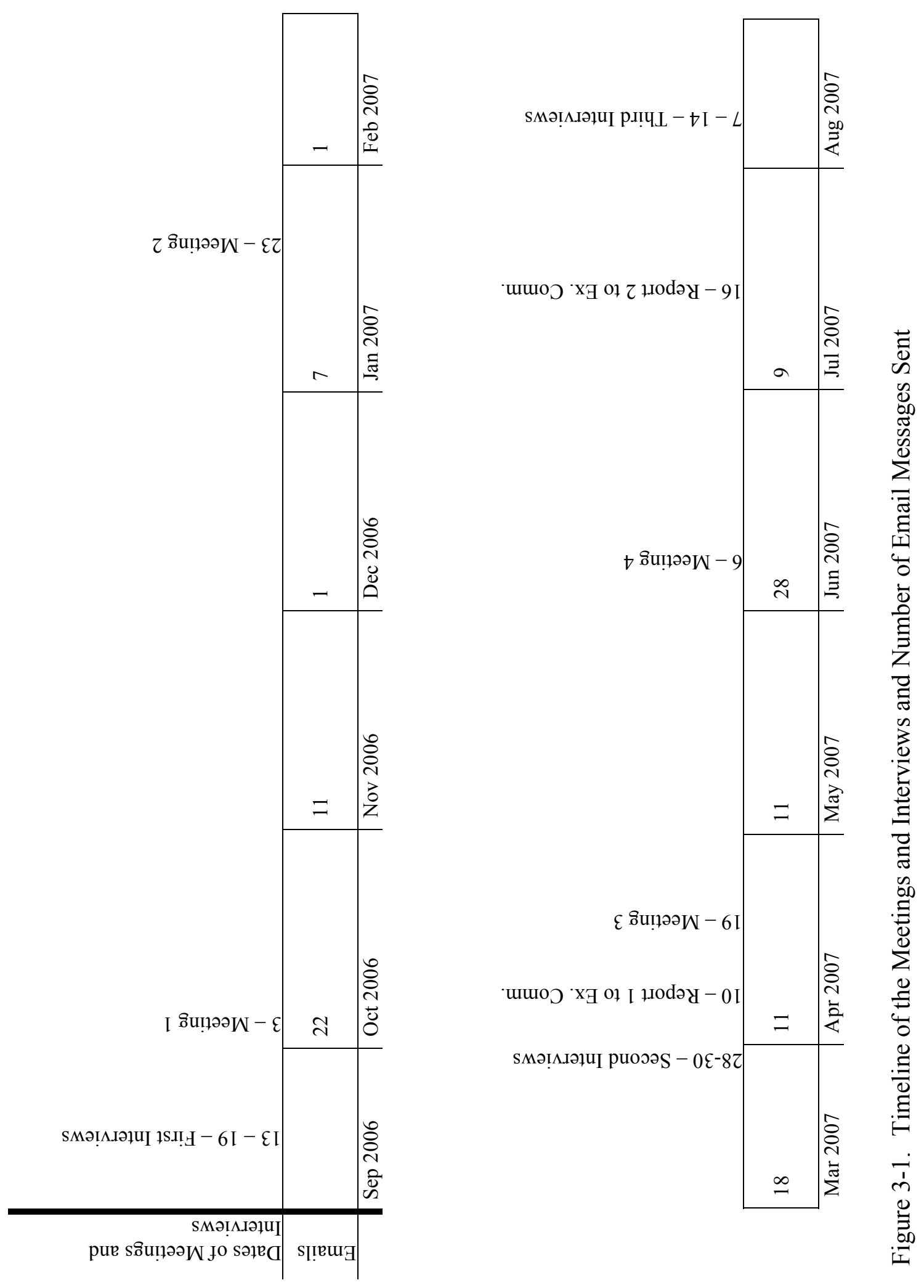


\subsubsection{Work Produced}

Table 3-3 provides background on the work products that the group produced during the project. See appendices J, K, and L for the Charge, First Report, and Final Report.

Table 3-3. Documents, Date Completed, Authors and Summary of the Document Content

\begin{tabular}{|c|c|c|c|}
\hline Document & Date & Author(s) & Summary of content \\
\hline Charge & $\begin{array}{l}\text { Accepted } \\
11 / 09 / 06\end{array}$ & $\begin{array}{l}\text { Primary }=\mathrm{P} 4 \\
\text { Secondary }=\mathrm{P} 6\end{array}$ & $\begin{array}{l}\text { Charge was to define accountability, } \\
\text { to determine if it should be } \\
\text { incorporated as a core value in } \\
\text { systems mission statement, and to } \\
\text { look at ways to communicate } \\
\text { importance of accountability to staff. }\end{array}$ \\
\hline $\begin{array}{l}\text { Definition of } \\
\text { Accountability }\end{array}$ & $\begin{array}{l}\text { Agreed to in } \\
\text { April, } 2007\end{array}$ & $\begin{array}{l}\text { Borrowed from } \\
\text { U.S. Air Force, } \\
\text { found on the } \\
\text { Internet }\end{array}$ & $\begin{array}{l}\text { Accountability was defined as 1) } \\
\text { setting appropriate and reachable } \\
\text { organizational goals; 2) } \\
\text { communicating the goals and tasks to } \\
\text { others; 3) clarifying expectations and } \\
\text { defining roles and responsibilities; 4) } \\
\text { establishing meaningful } \\
\text { measurements of success; and 5) } \\
\text { fostering effective feedback loops. }\end{array}$ \\
\hline $\begin{array}{l}\text { First Report to } \\
\text { Executive } \\
\text { Committee }\end{array}$ & $04 / 10 / 2007$ & Primary $=\mathrm{P} 4$ & $\begin{array}{l}\text { Report updated Executive Committee } \\
\text { on discussions thus far. }\end{array}$ \\
\hline $\begin{array}{l}\text { Final Report to } \\
\text { Executive } \\
\text { Committee }\end{array}$ & $07 / 16 / 2007$ & $\begin{array}{l}\text { Primary }=\mathrm{P} 4 \text { and } \\
\mathrm{P} 1\end{array}$ & $\begin{array}{l}\text { Report made seven recommendations } \\
\text { for system to implement to improve } \\
\text { accountability and established five } \\
\text { outcomes to measure accountability. }\end{array}$ \\
\hline
\end{tabular}

\subsection{Summary}

The case study occurred within a suburban public library system serving an affluent, highly educated, and diverse community. In summer 2006, acting with input from public services managers, the library director formed a task force to address a perceived problem 
of accountability across the library system. Seven people were members of the committee - three volunteers and four recruits. The group members came from different branch locations in the library system, and the six primary members worked in public services. The members spanned four layers of management, and all were at least minimally familiar with each other. The group was tasked with a problem solving activity, requiring them to diagnose the problem space and identify possible solutions. The group project lasted ten months during which time the group held four meetings, exchanged 119 email messages, and reported to the library system's senior management group twice. The group's final work product consisted of a set of recommendations and a list of measurable outcomes for the library system to consider adopting to improve accountability. 


\section{Chapter 4: $\quad$ Shared Mental Models}

The chapter describes the group's shared mental models. Although groups may develop shared mental models in any number of domains, this research focuses exclusively on task and team interaction. Mental models were elicited through semistructured interviews with individual group members at three points. It may be useful to reiterate some time-related events to put the interviews in perspective (see the timeline in Figure 3-1). Interview 1 occurred prior to the onset of the project. The group had been formed and its membership, appointed leaders, and assignment were known, but the group had not yet met. Interview 2 occurred after the first two meetings before any reports had been developed. Interview 3 took place at the end of the project after the progress report to the Executive Committee, the third and fourth meetings, and the final report to the Executive Committee.

The following terms were selected to describe the shared mental models. The shared mental model is the highest unit, and this study examines two: the shared mental model of the task and the shared mental model of the team interaction. Each shared mental model contains elements, that is, aspects or sub-domains of the shared mental model. Each element of the shared mental models has multiple components. The components are the actual shared content of the shared mental models - the ideas provided by the group members and analyzed for similarity.

The form of representation used for both shared mental models in this study is a table showing: the model components, categorized by the model elements; an indication when the content developed (by interview); and the strength of sharedness among the 
participants at each interval. The scale for strength of degree of sharedness of the group about a particular characteristic consists of: strong, 6 to 7 participants agreed; moderate, 4 to 5 participants; weak, 2 to 3 participants. No characteristic appears in the table if only one group member mentioned it. A pertinent and important caveat about both models is that they are based only on verbalized expressions. It is entirely possible that the perceptions developed initially were still held but not expressed verbally again after the group had passed to another stage of resolution of the problem.

In the following analyses, the two shared mental models are presented sequentially via their tables with some textual explanation of the significant findings. The final discussion section first points out some parallels between the two models, then addresses each in turn.

\subsection{Task Mental Model}

Previous research has shown that the components of a group's mental model about the task may include understanding of the nature of the problem; the task(s) and subtasks; task-related constraints; strategies, procedures, or contingencies; and measures of success of failure (Cannon-Bowers, et al., 1993; Klimoski \& Mohammed, 1994; Lim \& Klein, 2006; Rentsch \& Woehr, 2004). The interview protocol elicited information about these elements, and they were used as the basis for content analysis of responses. 
Table 4-1. Task Shared Mental Model

\begin{tabular}{|c|c|c|c|c|}
\hline \multirow[b]{3}{*}{ Element } & \multirow[b]{3}{*}{ Component } & \multirow{2}{*}{\multicolumn{3}{|c|}{$\begin{array}{c}\text { Strength of component } \\
\text { Interviews }\end{array}$}} \\
\hline & & & & \\
\hline & & 1 & 2 & 3 \\
\hline \multirow[t]{6}{*}{ 1. Problem } & 1.1 We are uncertain about the problem. & $\mathrm{S}$ & & \\
\hline & $\begin{array}{l}1.2 \text { We think not everyone in the organization is being held } \\
\text { accountable. }\end{array}$ & M & & \\
\hline & $\begin{array}{l}\text { 1.3 Accountability means professional responsibility (T-1 } \\
\text { only). }\end{array}$ & $\mathrm{S}$ & & \\
\hline & 1.4 Our objective is to address accountability. & & $\mathrm{S}$ & \\
\hline & 1.5 The nature of accountability is that it is on-going. & & & $\mathrm{M}$ \\
\hline & 1.6 Accountability is a complex issue. & & $\mathrm{S}$ & $\mathrm{S}$ \\
\hline \multirow[t]{5}{*}{ 2. Tasks } & 2.1 We are uncertain about the tasks. & $\mathrm{S}$ & & \\
\hline & 2.2 We should/are/did define accountability. & & M & $\mathrm{S}$ \\
\hline & $\begin{array}{l}2.3 \text { We need to consider how to incorporate accountability } \\
\text { into existing organizational structures, such as the PDP or our } \\
\text { core values. }\end{array}$ & & M & \\
\hline & 2.4 We need to introduce the issue to the whole organization. & & M & \\
\hline & $\begin{array}{l}2.5 \text { We need to determine "what will this look like at in the } \\
\text { library system?". }\end{array}$ & & & $\mathrm{S}$ \\
\hline \multirow[t]{3}{*}{$\begin{array}{l}\text { 3. Work } \\
\text { strategies }\end{array}$} & $\begin{array}{l}3.1 \text { Our work should be divided in a systematic way such as } \\
\text { by equal assignment, by availability, or by skill set. }\end{array}$ & M & & \\
\hline & $\begin{array}{l}3.2 \text { Our work is carried out through group interaction tactics } \\
\text { such as brainstorming, discussing, or emailing. }\end{array}$ & & M & \\
\hline & $3.3 \mathrm{P} 4$ did most of the work. & & & $\mathrm{S}$ \\
\hline \multirow{3}{*}{$\begin{array}{l}\text { 4. Task } \\
\text { progress }\end{array}$} & 4.1 We think there is more work to do. & & $\mathrm{M}$ & $\mathrm{M}$ \\
\hline & 4.2 We are waiting for Executive Committee feedback. & & M & \\
\hline & 4.3 [The nature of accountability is that it is on-going.] & & & $\mathrm{M}$ \\
\hline \multirow[t]{3}{*}{ 5. Difficulties } & 5.1 One difficulty was a lack of time; we were busy. & & $\mathrm{S}$ & $\mathrm{M}$ \\
\hline & 5.2 [Accountability is a complex issue.] & & $\mathrm{S}$ & $\mathrm{S}$ \\
\hline & $\begin{array}{l}5.3 \text { One difficulty was the fact that several of us were moving } \\
\text { to and opening new library facilities. }\end{array}$ & & $\mathrm{S}$ & $\mathrm{M}$ \\
\hline \multirow[t]{2}{*}{ 6. Success } & $\begin{array}{l}\text { 6.1 Success is measured by organizational outcomes, such as } \\
\text { seeing employees be more accountable, establishing a } \\
\text { common understanding of accountability in the organization. }\end{array}$ & M & $\mathrm{S}$ & $\mathrm{M}$ \\
\hline & $\begin{array}{l}\text { 6.2 Success is measured by group performance and group } \\
\text { output, such as time put toward the project, quality of the } \\
\text { discussion, quality of the work product. }\end{array}$ & & M & $\mathrm{S}$ \\
\hline
\end{tabular}


Table 4-1 characterizes the group's shared mental model about the task. Several significant findings emerge from this table. Each is preceded by a brief phrase indicating its focus. The first three findings speak to the model as a whole.

Acceptance of structure: The group expressed no concerns that the elements of mental models about tasks identified through other research and used in this project to elicit their mental model were deficient as a framework.

Complexity of model: In terms of complexity, measured by number of components, the group's initial shared mental model, based on the interview preceding their first meeting, was relatively simple; it was most complex midway through the project although relatively few perceptions from the onset of the project carried over. It had become slightly less complex by the end of the project.

Dispersion of content across model: Points made in the initial interview did not continue across the other interviews. Only half of the perceptions expressed midway carried over to the last interview as well; no consistent patterns emerged in how they were transformed from one interview to the next.

The remaining six findings refer to specific aspects of the model.

Problem: Perceptions about the problem occurred primarily at the onset of the project and were usually strongly held: initial uncertainty about the problem and that accountability meant professional responsibility. The group agreed only moderately that accountability was not ubiquitous within the organization. Midway through the project (Interview 2) the group strongly concurred that their objective was to address 
accountability. By the end of the project the group moderately agreed that accountability is on-going.

Tasks: Uncertainty about tasks appeared strongly initially (Interview 1) in conjunction with uncertainty about the problem but, by midway through the project, the group moderately agreed that the group must define accountability, consider how to incorporate it into existing structures, including Performance Development Plans (PDP), and introduce it to the entire organization. By the end of the project, group members agreed strongly that they had defined accountability and determined what accountability meant within the library system.

Strategies: The group agreed moderately initially on systematic division of work but, by the end of the project (Interview 3), they recognized strongly that P4 had done most of the work. Midway they moderately agreed that the work would be carried out through group interaction techniques, such as brainstorming and discussion, and that email interactions would occur along with the meetings.

Task progress: Perceptions about task progress not surprisingly occurred only in Interviews 2 and 3 and were moderately held: that more work remained; midway (Interview 2) that the group needed feedback from the Executive Committee.

Difficulties: The group strongly felt difficulties, including the initial uncertainties about the problem and task: lack of time, the complexity of the issue; and conflicts arising from library moves (which involved five of the group members). Two of these had moderated by the end of the project but the group still agreed strongly on the complexity of accountability. 
Success: The group agreed moderately on organizational outcomes initially and at the end, but strongly midway through the project. They moderately expressed how to measure success of their own group midway through, but by the end they strongly agreed that success of their own group should be measured through group performance measures and the quality of the work product.

\subsection{Team Interaction Mental Model}

The research on components of a group's shared mental model about team interaction indicates that the model may include understanding of member responsibilities, norms, and interaction patterns (Lim \& Klein, 2006); roles and responsibilities, information sources, communication channels, and role interdependencies (Cannon-Bowers, et al., 1993). The interview protocol elicited information about some of these elements, and they were used as the basis for content analysis of responses.

Table 4-2 is similar to Table 4-1. It characterizes the group's shared mental model about the team interaction. Following the same approach used previously, the significant findings presented below are preceded by a brief explanatory phrase to indicate focus. The first three parallel those mentioned for the task mental model, referring to the model as a whole. 
Table 4-2. Team Interaction Shared Mental Model

\begin{tabular}{|c|c|c|c|c|}
\hline \multirow[b]{3}{*}{ Element } & \multirow[b]{3}{*}{ Component } & \multirow{2}{*}{\multicolumn{3}{|c|}{$\frac{\text { Strength of component }}{\text { Interviews }}$}} \\
\hline & & & & \\
\hline & & 1 & 2 & 3 \\
\hline \multirow[t]{5}{*}{$\begin{array}{l}\text { 1. Group } \\
\text { participation }\end{array}$} & $\begin{array}{l}\text { 1.1 There should be equitable participation among } \\
\text { members in some way. }\end{array}$ & M & & \\
\hline & $1.2 \mathrm{P} 4 \mathrm{did}$ most of the work. & & M & $\mathrm{M}$ \\
\hline & 1.3 The work was not divided equally. & & $\mathrm{M}$ & M \\
\hline & 1.4 Members contributed as they were able. & & $\mathrm{W}$ & M \\
\hline & $1.5 \mathrm{P} 4, \mathrm{P} 3, \mathrm{P} 1 \mathrm{did}$ most of the work. & & & $\mathrm{M}$ \\
\hline \multirow[t]{3}{*}{ 2. Meetings } & $\begin{array}{l}\text { 2.1 Meetings should be used for activities requiring } \\
\text { group interaction, such as brainstorming, decision- } \\
\text { making, or reporting back to group on individual effort. }\end{array}$ & $\mathrm{M}$ & & \\
\hline & $\begin{array}{l}2.2 \text { Meetings have included good interactions, in terms } \\
\text { of sharing ideas, listening to each other, respecting } \\
\text { differences of opinion. }\end{array}$ & & $\mathrm{M}$ & M \\
\hline & 2.3 We needed more meetings. & & & M \\
\hline \multirow{3}{*}{$\begin{array}{l}\text { 3. Decision- } \\
\text { making }\end{array}$} & 3.1 Decisions should be made by reaching consensus. & $\mathrm{M}$ & & \\
\hline & 3.2 Decisions were made by default. & & $\mathrm{M}$ & \\
\hline & 3.3 Decisions were made collectively. & & $\mathrm{M}$ & \\
\hline \multirow[t]{2}{*}{$\begin{array}{l}\text { 4. Managing } \\
\text { disagreement }\end{array}$} & $\begin{array}{l}\text { 4.1 We should employ strategies for managing } \\
\text { disagreement such as acknowledge dissent, confront the } \\
\text { problem, show respect, agree to disagree, listen. }\end{array}$ & $\mathrm{M}$ & & \\
\hline & 4.2 The group did not experience disagreement. & & $\mathrm{M}$ & M \\
\hline \multirow[t]{4}{*}{ 5. Group roles } & 5.1 There should be a leader or leaders. & M & & \\
\hline & $\begin{array}{l}5.2 \mathrm{P} 4 \text { was the leader, and was positively perceived in } \\
\text { that role. }\end{array}$ & & $\mathrm{M}$ & $\mathrm{M}$ \\
\hline & $\begin{array}{l}5.3 \text { P4's leadership focused on a high concern for the } \\
\text { task. }\end{array}$ & & $\mathrm{M}$ & $\mathrm{M}$ \\
\hline & 5.4 P1, P3, and P4 shared leadership. & & & M \\
\hline \multirow[t]{4}{*}{ 6. Group norms } & $\begin{array}{l}6.1 \text { There are codified group meeting norms within the } \\
\text { organization. }\end{array}$ & M & & \\
\hline & 6.2 We may need to be reminded of them. & M & & \\
\hline & $\begin{array}{l}6.3 \text { We should follow group norms such as everyone } \\
\text { should share their ideas, all ideas should be respected, } \\
\text { and the group should adhere to meeting times. }\end{array}$ & M & & \\
\hline & $\begin{array}{l}\text { 6.4 This experience was similar to other groups with } \\
\text { which we have been involved. }\end{array}$ & & & $\mathrm{M}$ \\
\hline
\end{tabular}


Acceptance of structure: The group accepted the structure already provided in research connected to team interaction (elements), and members were able to express more specific instantiations, i.e., components for their group.

Complexity of model: In terms of complexity, the model was relatively complex through all interviews although slightly more complex at the end.

Dispersion of content across model: Points made in the initial interview did not continue across the other interviews. Most of the perceptions expressed midway carried over to the last interview as well but did not grow in strength.

The following six findings describe particular aspects of the team interaction mental model.

Group participation: The group initially agreed moderately that participation should be equitable but later concurred that the work was not divided equally, thinking that either P4 did most of the work or that she shared workload with P3 and P1.

Meetings: Their moderate perception of an approach within meetings actually continued across all meetings, initially in anticipation, and in the last two interviews, based on actuality. At the end the group moderately held that they should have had more meetings.

Decision-making: Initially the group agreed moderately on reaching decisions by consensus. Midway through they moderately perceived that decisions were made by default and/or collectively. 
Managing disagreement: The group agreed moderately on strategies for managing disagreement at the onset but perceived moderately later at Interviews 2 and 3 that the group experienced no disagreements.

Group roles: Perceptions about the leader occurred in all interviews. Initially they agreed moderately that the group should have a leader or leaders. They later converged moderately on P4 as a positive leader with a high concern for the task, although the group also moderately perceived at the end that P4 had shared leadership with P1 and P3.

Group norms: Initially the group concurred moderately that they should follow group norms and could articulate some; that codified norms existed within the organization; but that they may need to be reminded of those norms. By the end of the project, the group saw similarities in their experience with this group and with other groups in their background.

\subsection{Discussion}

\subsubsection{Comparison of the Two Models}

The actual contents of the two models are dissimilar and cannot be compared. They are addressed separately below. But some structural comparisons can be made, and it is useful to note these since, in time, they can be used as a basis for comparison with the experiences of other groups. First, the group accepted the structure of the models, as reflected in the elements used in the semi-structured interview protocol for eliciting input about both of their mental models, indicating the transferability of structures identified in other research to other settings. Second, of the two mental models articulated by the group, the task shared mental model had a higher degree of sharedness. The group 
expressed either strong or moderate agreement with all of the noted elements and components. In the team interaction shared mental model, the groups expressed moderate agreement generally, never strong. Third, the models were common in complexity, as measured by total number of components, with 20 and 21 noted for the task mental model and the team interaction model respectively. This comparison is made with some concern since it is based on content. Nevertheless the similarity in number across models of different domains, despite the slight variation in the number of elements for each, may be predictive of implicit limitations in shared mental models, either in eliciting them, coding them, or in the actual number of components likely to be articulated by a group. Finally, in both models, shared perceptions identified in the initial interview before actual activities as a group were not carried over. Greater overlap occurred in both models in the number of components expressed midway and in the final interview. In the task mental model no patterns emerged in the growth in sharedness; in the team interaction model, characteristics generally stayed at the same level of sharedness.

\subsubsection{Task Shared Mental Model}

In this case study, the group never developed a detailed articulation of the problem. Although the group easily agreed that they were addressing accountability, primarily because that figured into the group's formation, they did not understand the problem as it existed within their organization. Apparently, the fact that all had attended the original day-long retreat in which the issue first surfaced did not help their understanding. In addition, they diverged on ideas of how the perception of accountability had changed 
between the second and third interviews. Tremendous uncertainty about the problem existed at the beginning of the project and that uncertainty was never clarified.

The group reached a shared understanding at a broad level of tasks to be performed but, as with the problem, did not develop a shared detailed understanding of specific aspects of the tasks nor of how those tasks were performed.

What is most striking about their shared mental model of work strategies is the shift from how the tasks were carried out (Interview 2) to who carried out the tasks, not what they were. This shift in focus confirms that few group members were involved in the tasks (acknowledged by the group as a whole) and thus knowledgeable about them.

Also interesting are the shared perceptions of the group's progress with the task, especially the group's moderate agreement on the need for feedback from the Executive Committee. As noted previously in chapter three, a diagnosis-solution problem such as the one faced by the group requires collecting inputs to understand the "illness" or the system fault (Jonassen, 2000). The group was unable or unwilling to provide these inputs, as evidenced by their uncertainty about the problem and possible solutions, so the group turned to the Executive Committee to provide them. By the end of the project they had developed a strong sense that they had not yet completed their task, perhaps because they were gradually developing a shared appreciation for, if not understanding of, the complexity of the problem.

The group was strongly aware of both external and internal pressures. Even the internal pressure was seen in comparison with an external fact. The group saw accountability as a more complex, fuzzy, and abstract problem than those faced by other 
groups formed at the same time. In addition, especially midway through the project members expressed strong concerns about conflicting demands on their time because outside demands were pressing and important and could not be relegated easily to other staff members. Membership in the group and its presumed responsibilities were in addition to normal work activities; the group received no reduction in workload for participation. Five of the seven participants moved location about midway through the project, and two group members actually were responsible for the move of a library, a complex, risky, and relatively unique task with immediately observable outcomes. These factors naturally increased anxiety for members involved and, not surprisingly, were likely to impact on the Accountability Group with its more open-ended schedule and perhaps less visible, more open-ended outcome. Toward the latter part of the project, the moves had been completed and concerns about external difficulties were alleviated somewhat. It is interesting that, faced with future demands on time, the group did not opt to compress activities into a shorter time frame so that the group could dissolve earlier.

The group eventually understood success at two levels: success for the organization, seeing evidence of the group's work in action; and success for the group itself in terms of how well the group carried out its assignment. Across time the group maintained fairly similar thinking on success at the organizational level, but perceptions of group performance were more strongly shared over the life of the project. By the end of their project the group believed strongly that they had been successful as a group. They moderately agreed that the group's recommendations were good but that success can only be determined by the effects of the recommendations in action. 


\subsubsection{Team Interaction Shared Mental Model}

Perhaps the most significant finding related to the team interaction model is the disjunction that appeared for some components between the Team Interaction model as specified in the first interview and in later interviews. In the first interview, which occurred prior to the first meeting, the group talked more abstractly about what they anticipated would happen or what should happen. Especially in connection with participation, decision-making, and norms, the group initially presented a mental model that represented an ideal or preferred set of behaviors. As subsequent chapters on communication show, actual behavior varied. The group generally acknowledged the variations in subsequent interviews. For example, although they moderately agreed on consensus decision making, they split during the project with some agreeing decisions were made by default and others perceiving negotiation and weighing options to reach consensus.

All group members had been in the organization for many years (see Table 3-1) and had participated in other groups. They had no reason to believe that the Accountability Group would behave differently and, indeed, in the final interview, agreed that their experiences in this group were similar to their experiences in other groups. In addition, norms for behavior in group settings had been developed within the library system (see Appendix I: Library System Meeting Norms). The group had acknowledged to some extent the influence of the norms by moderately agreeing that they might need to be reminded of them during the project. Nevertheless they moderately converged on positive norms, such as mutual respect, anticipation of participation by all in discussions, and 
adherence to meeting times, and acknowledged later negative norms that had developed within the group, such as working inconsistently, not having agendas, and not responding promptly to emails.

The strength of the sharedness about meetings and managing disagreement were consistent over time and matched to a large extent the anticipated behavior expressed in the first interview. Meetings were a vehicle for group interaction, such as brainstorming and discussion. Although they moderately agreed in the first interview about meeting norms, such as having an agenda, adhering to a time limit, they rarely mentioned these later, focusing more broadly on perceptions of the nature and quality of meetings.

The group did not differentiate roles within their shared mental model other than that of leader. To the extent that they focused on roles, they agreed on the need for a leader, the person who emerged as that leader, and the nature of her leadership. P7's initial effort to involve three levels of management in group leadership may have had a negative effect on the efficiency of the group, although the group agreed moderately at the end of the project that, although $\mathrm{P} 4$ was the definite leader, $\mathrm{P} 3$ and $\mathrm{P} 1$ had also assumed more work than the others. Designating three leaders from six participants may have inhibited involvement from the other three.

\subsection{Summary of Findings}

This chapter developed and analyzed the two shared mental models formed by the Accountability Group for the task and for team interaction. These models are based on interview data, not comments or behaviors in the meetings and emails. The analysis 
shows not only the content, both specifically and broadly, but also the extent of sharedness and the development of the models over the course of the project. 


\section{Chapter 5: Group Communication}

The next two chapters address the communication within the group. Chapter five broadly characterizes the group's communication practices, focusing on several aspects of communication: themes that emerged in their interaction; the function of the messages they communicated; the communication roles within the group; the channels of communication the group used; and the group's communication rules. Because so many variables are covered, some in considerable detail, discussion is integrated with findings for each variable. Chapter six revisits these elements and explores them as influences on the group's shared mental models. In this chapter, the analyses are based on content analysis of transcripts of the four meetings and all email messages. Where pertinent coding schemes already exist in the research literature, as for communication roles and functions, they are applied. For other variables a more qualitative approach, using constant comparison, was applied to identify relevant aspects of the variable.

\subsection{Communication Themes}

Communication theme is defined as a topic or idea that is talked about by two or more team members for a sustained period of time. The data were grouped by communication event (meetings and email) and coded thematically.

In Table 5-1 the themes are arranged in phase order with occurrence indicated across the meetings and email. The early themes appear at the top of the columns, the later themes farther down, and in a left to right order, following the order of the meetings. As noted in the definition of a theme, any occurrence indicates participation by more than one group member over a sustained period of time. An X in the table indicates only that 
the theme appeared sometime during the meeting. The final column provides some indication of the extent to which that discussion occurred repeatedly, i.e., in more than one event.

Table 5-1. Discussion Themes by Group Event

\begin{tabular}{|c|c|c|c|c|c|c|c|}
\hline \multirow[b]{2}{*}{ No. } & \multirow[b]{2}{*}{ Themes } & \multicolumn{4}{|c|}{ Meetings } & \multirow[b]{2}{*}{ Email } & \multirow[b]{2}{*}{ Total } \\
\hline & & 1 & 2 & 3 & 4 & & \\
\hline 1. & $\begin{array}{l}\text { We need to get more information on the } \\
\text { problem. }\end{array}$ & $\mathrm{X}$ & & & & & 1 \\
\hline 2. & We need to define accountability. & $\mathrm{X}$ & $\mathrm{X}$ & & & $\mathrm{X}$ & 3 \\
\hline 3. & We need to produce something. & $\mathrm{X}$ & & & & & 1 \\
\hline 4. & We need to get feedback. & $\mathrm{X}$ & $\mathrm{X}$ & & & & 2 \\
\hline 5. & We need to determine the group's charge. & $\mathrm{X}$ & & & & $\mathrm{X}$ & 2 \\
\hline 6. & $\begin{array}{l}\text { How severe is accountability a problem in the } \\
\text { library? }\end{array}$ & $\mathrm{X}$ & $\mathrm{X}$ & & & & 2 \\
\hline 7. & Where is the problem? & $\mathrm{X}$ & $\mathrm{X}$ & & & $\mathrm{X}$ & 3 \\
\hline 8. & $\begin{array}{l}\text { Does accountability fit into existing } \\
\text { organizational procedures and documents? }\end{array}$ & $\mathrm{X}$ & $\mathrm{X}$ & & & $\mathrm{X}$ & 3 \\
\hline 9. & How should we implement a solution? & $\mathrm{X}$ & & & & & 1 \\
\hline 10. & $\begin{array}{l}\text { We could create examples of being } \\
\text { accountable. }\end{array}$ & & $\mathrm{X}$ & & & & 1 \\
\hline 11. & We need to establish credibility with staff. & & $\mathrm{X}$ & & & & 1 \\
\hline 12. & Solution A is to focus on a task. & & & $\mathrm{X}$ & & & 1 \\
\hline 13. & $\begin{array}{l}\text { Solution B is creating accountability for each } \\
\text { unit. }\end{array}$ & & & $\mathrm{X}$ & & & 1 \\
\hline 14. & Solution $\mathrm{C}$ is to post all staff PDPs on intranet & & & $\mathrm{X}$ & & & 1 \\
\hline 15. & $\begin{array}{l}\text { We need to consider the Executive Committee } \\
\text { mandate "What does it look like?" }\end{array}$ & & & $\mathrm{X}$ & & & 1 \\
\hline 16. & Share criticism of draft recommendations. & & & & $\mathrm{X}$ & & 1 \\
\hline 17. & Integrate Solution A and Solution B. & & & & $\mathrm{X}$ & & 1 \\
\hline 18. & Collaborate on edits to the recommendations & & & & $\mathrm{X}$ & & 1 \\
\hline 19. & Is there a need for training? & & & & & $\mathrm{X}$ & 1 \\
\hline
\end{tabular}

Note. Under Meetings and Email, an X indicates that the theme was discussed.

The themes correspond generally to phases in resolution of a problem that occur, for the most part, chronologically in this case study, although the discussion at each meeting was circular and nonlinear. Group members introduced ideas that were discussed for a 
time and then were set aside, only to resurface later in the meeting, or, alternatively, were dropped altogether.

Only six themes were discussed in more than one meeting (Nos. 2, 4-8), and the overlap occurred between the first and second meeting. These themes marked early stages in problem definition and resolution, and the repetition of discussion across meetings reflects some indecision and uncertainty on the part of the members during the first two meetings. The uncertainties were evidently resolved by the end of the second meeting.

Generally the discussion in the first two meetings was more wide-ranging, addressing ten and eight themes respectively, whereas the last two meetings focused on fewer topics but devoted more time to those topics. At this stage the group was evaluating two possible solutions and then fine-tuning the final solution.

Email communications related to themes discussed in one or more meetings with one exception. Need for training (19) was discussed only in email. If reoccurrence in individual meetings and email reflects task complexity, then the themes that reflected complex tasks requiring the most discussion were those themes that described the group's efforts at clarifying the nature of the problem (6-8) and determining what the group should do about the problem $(2,4-5)$.

\subsection{Communication Functions}

To understand the functions of the messages exchanged in the meetings and email, the researcher used Bales' (1951) Interaction Process Analysis (IPA) for analyzing data from both the meetings and email. IPA consists of 12 mutually exclusive categories that 
can be grouped to explore different aspects of the communication (see Table 5-2). Bales groups six categories $(1-3,10-12)$ into socioemotional functions, with 1-3 as positive functions and 10-12 as negative. The remaining six categories are task-focused with 4-6 addressing answers, and 7-9, questions. In the analysis in this study, each event's data were unitized to the utterance, defined as the smallest segment of text that expresses a complete thought, and then assigned to a category.

Table 5-2. IPA Categories by Group

\begin{tabular}{lll}
\hline IPA groups & \multicolumn{2}{l}{ IPA categories } \\
\hline Socioemotional-positive & 1. & Shows solidarity \\
& 2. & Shows tension release \\
& 3. & Agrees \\
\hline Task-answers & 4. & Gives suggestion \\
& 5. & Gives opinions \\
& 6. & Gives information \\
\hline Task-questions & 7. & Asks for information \\
& 8. Asks for opinion \\
& 9. & Asks for suggestion \\
\hline Socioemotional- & 10. Disagrees \\
negative & 11. Shows tension \\
& 12. Shows antagonism \\
\hline
\end{tabular}

Table 5-3 shows the distribution of messages by function, across the four group meetings and email. 
Table 5-3. IPA Categories by Group Event

\begin{tabular}{|c|c|c|c|c|c|c|c|c|c|c|c|c|}
\hline \multirow[b]{2}{*}{ IPA category } & \multicolumn{2}{|c|}{ Meeting 1} & \multicolumn{2}{|c|}{ Meeting 2} & \multicolumn{2}{|c|}{ Meeting 3} & \multicolumn{2}{|c|}{ Meeting 4} & \multicolumn{2}{|c|}{ Email } & \multicolumn{2}{|c|}{ Total } \\
\hline & $\mathbf{N}$ & $\%$ & $\mathbf{N}$ & $\%$ & $\mathbf{N}$ & $\%$ & $\mathbf{N}$ & $\%$ & $\mathbf{N}$ & $\%$ & $\mathbf{N}$ & $\%$ \\
\hline $\begin{array}{l}\text { 1. Shows } \\
\text { solidarity }\end{array}$ & 25 & 3.0 & 14 & 1.2 & 34 & 4.4 & 35 & 2.4 & 114 & 18.6 & 222 & 4.6 \\
\hline $\begin{array}{l}\text { 2. Shows } \\
\text { tension } \\
\text { release }\end{array}$ & 20 & 2.4 & 17 & 1.5 & 26 & 3.4 & 35 & 2.4 & 11 & 1.8 & 109 & 2.4 \\
\hline 3. Agrees & 94 & 11.1 & 300 & 26 & 151 & 19.7 & 291 & 19.6 & 16 & 2.6 & 852 & 17.5 \\
\hline $\begin{array}{l}\text { 4. Gives } \\
\text { suggestion }\end{array}$ & 115 & 13.6 & 87 & 7.5 & 59 & 7.7 & 69 & 4.7 & 71 & 11.6 & 401 & 8.2 \\
\hline $\begin{array}{l}\text { 5. Gives } \\
\text { opinion }\end{array}$ & 272 & 32.2 & 393 & 34.1 & 170 & 22.2 & 290 & 19.6 & 130 & 21.2 & 1255 & 25.8 \\
\hline $\begin{array}{l}\text { 6. Gives } \\
\text { information }\end{array}$ & 162 & 19.1 & 227 & 19.7 & 225 & 29.4 & 539 & 36.3 & 208 & 33.9 & 1361 & 28 \\
\hline $\begin{array}{l}\text { 7. Asks for } \\
\text { information }\end{array}$ & 69 & 8.2 & 67 & 5.8 & 65 & 8.5 & 168 & 11.3 & 29 & 4.7 & 398 & 8.2 \\
\hline $\begin{array}{l}\text { 8. Asks for } \\
\text { opinion }\end{array}$ & 43 & 5.1 & 22 & 1.9 & 20 & 2.6 & 36 & 2.4 & 25 & 4.1 & 146 & 3 \\
\hline $\begin{array}{l}\text { 9. Asks for } \\
\text { suggestion }\end{array}$ & 16 & 1.9 & 3 & 0.3 & 5 & 0.7 & 4 & 0.3 & 0 & 0 & 28 & 0.6 \\
\hline 10. Disagrees & 25 & 3.0 & 19 & 1.6 & 11 & 1.4 & 16 & 1.1 & 0 & 0 & 71 & 1.5 \\
\hline $\begin{array}{l}\text { 11. Shows } \\
\text { tension }\end{array}$ & 5 & 0.6 & 3 & 0.3 & 0 & 0.4 & 0 & 0 & 7 & 1.1 & 15 & 0.3 \\
\hline $\begin{array}{l}\text { 12. Shows } \\
\text { antagonism }\end{array}$ & 0 & 0.0 & 2 & 0.2 & 0 & 0.0 & 0 & 0 & 2 & 0.3 & 4 & 0.1 \\
\hline Total & 846 & 17 & 1154 & 24 & 766 & 16 & 1483 & 31 & 613 & 13 & 4862 & 100 \\
\hline
\end{tabular}

At the most specific level, the group members were, in order, giving information (6), giving opinions (5), and agreeing (3). The three negative socioemotional categories (1012) were extremely low overall. This combination of functions reflects the nature of the discussion at the meetings: a high degree of discussion and sharing of ideas, in a positive, supportive environment.

From Bales' studies of the communication in various different groups, he identified a range of scores for each category that he considered appropriate for the group to achieve equilibrium among the task/socioemotional tensions, expressed as a percentage of the 
total number of communication utterances (Keyton, 1997). Table 5-4 shows the Accountability Group percentages and the norm ranges.

Table 5-4. Accountability Group Percentages and Norm Ranges for IPA Categories

\begin{tabular}{lllll}
\hline IPA category & $\begin{array}{l}\text { Accountability } \\
\text { group }\end{array}$ & $\begin{array}{l}\text { By } \\
\text { quadrant }\end{array}$ & $\begin{array}{l}\text { Norm } \\
\text { ranges }\end{array}$ & $\begin{array}{l}\text { By } \\
\text { quadrant }\end{array}$ \\
\hline 1. Shows solidarity & 4.6 & 24.5 & $2.6-4.8$ & $16.3-25.8$ \\
2. Shows tension release & $2.4^{*}$ & & $5.7-7.4$ & \\
3. Agrees & $17.5^{*}$ & & $8.0-13.6$ & \\
\hline 4. Gives suggestion & $8.2^{*}$ & $62^{*}$ & $3.0-7.0$ & $38.7-60.9$ \\
5. Gives opinion & $25.8^{*}$ & & $15.0-22.7$ & \\
6. Gives information & 28 & & $20.7-31.2$ & \\
\hline 7. Asks for information & $8.2^{*}$ & 9.1 & $4.0-7.2$ & $6.6-12.5$ \\
8. Asks for opinion & 3 & & $2.0-3.9$ & \\
9. Asks for suggestion & 0.6 & & $.6-1.4$ & \\
\hline 10. Disagrees & $1.5^{*}$ & $1.9^{*}$ & $3.1-5.3$ & $8.9-15.7$ \\
11. Shows tension & $0.3^{*}$ & & $3.4-6.0$ & \\
12. Shows antagonism & $0.1^{*}$ & & $2.4-4.4$ & \\
\hline
\end{tabular}

Note. Values marked with as * indicate those outside the norm ranges.

As the table shows, the Accountability Group percentages fall outside the norm ranges in more than half the categories, which, according to Bales' theory, may indicate an imbalance between task and socioemotional acts in the group. But further examination suggests the differences are less severe when compared by quadrants, rather than across categories. When grouped by quadrants, the Accountability Group percentages fall within the norm ranges for socioemotional-positive and task-questions and are just slightly over the norm range for task-answers. The one area in which the Accountability Group differs most from the suggested norms is socioemotional-negative (10-12) in which both across individual categories and grouped as a unit the Accountability Group made fewer negative socioemotional comments than the normal range would suggest. 
Table 5-5. IPA Task and Socioemotional by Group Event

\begin{tabular}{lccccccccccccc}
\hline & \multicolumn{1}{c}{ Meeting 1 } & \multicolumn{1}{c}{ Meeting 2 } & \multicolumn{2}{c}{ Meeting 3 } & \multicolumn{1}{c}{ Meeting 4 } & \multicolumn{2}{c}{ Email } & & \\
\cline { 2 - 9 } IPA group & $\mathbf{N}$ & $\mathbf{\%}$ & $\mathbf{N}$ & $\mathbf{\%}$ & $\mathbf{N}$ & $\mathbf{\%}$ & $\mathbf{N}$ & $\mathbf{\%}$ & $\mathbf{N}$ & $\mathbf{\%}$ & Total & \% \\
\hline $\begin{array}{l}\text { Task } \\
\begin{array}{l}\text { Positive } \\
\text { socioemotional }\end{array}\end{array}$ & 677 & 80.0 & 544 & 69.2 & 544 & 71 & 1106 & 74.6 & 463 & 75.5 & 3589 & 74 \\
$\begin{array}{l}\text { Negative } \\
\text { socioemotional }\end{array}$ & 139 & 16.4 & 211 & 28.7 & 211 & 27.5 & 361 & 24.3 & 141 & 23 & 1183 & 24 \\
\hline
\end{tabular}

Note. For IPA Group, task includes IPA categories 4-9; Positive socioemotional includes categories 1-3; and Negative socioemotional includes categories 10-12.

A closer examination of the distribution of categories by task vs. socioemotional functional communication (Table 5-5) shows that the Accountability Group was highly task oriented, infrequently issuing socioemotional messages, the majority of which were positive in nature.

Using IPA categories it is possible to compare the Accountability Group to other groups in the research literature. Bales conducted numerous studies using the IPA method on groups of different sizes, completing different tasks. Bales (1958) reported the distribution of IPA functions of an aggregation of 24 groups of different sizes performing a task in an experimental setting. In addition, Bales and Hare (1965) reported the average distribution of the functions for 21 different groups, including, for example, work groups, therapy groups, married couples, and children's groups. Figure 5-1 charts the distribution of the communication functions for the Accountability and the two other sets of groups. 


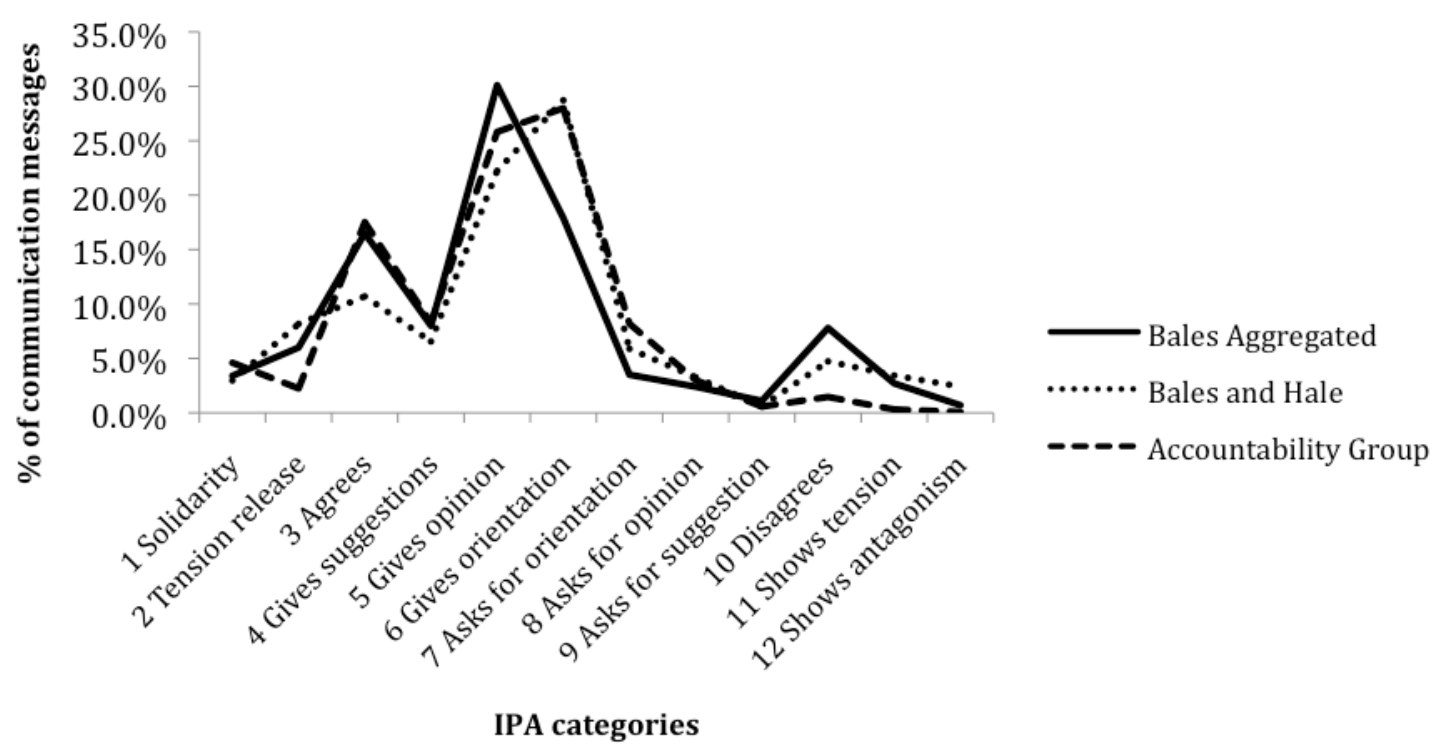

Figure 5-1. Comparison of the Accountability Group with Two Aggregated Groups

The overall shape of the chart is similar among the groups: Gives information scores highest on the task functions and Agrees scores highest on the socioemotional functions. This similarity suggests that, even when related variables such as group size, task, and composition vary, a common functional profile exists for small groups, and that the Accountability Group matches that general profile.

The IPA profile that emerges from the Accountability Group suggests an underlying consistency both within the group across time and compared to other groups. The percentages of each IPA category are quite similar across each data point, emphasizing a strong focus on the task and only nominal attention paid to building the group through socioemotional communicative acts. This split demonstrates that the group focused mainly on their task, but that the focus may have occurred at the expense of groupbuilding. Equilibrium theory, on which Bales based his method, suggests that a group's 
task environment can be difficult and, in maneuvering through it, the group may

encounter conflict about the task. Task conflict should be balanced through

socioemotional acts to advance group development and group cohesion. Yet, as the group

focuses on building its socioemotional ties, task communication suffers. The low degree

of socioemotional communication generally, and negative socioemotional

communication in particular, implies the group may not have achieved a high positive

social structure or group cohesion. It may also have been that the group tried to avoid unnecessary or unproductive task conflict, which would have resulted in the need of socioemotional repairing and rebuilding, in lieu of getting the task completed. The low level of negative socioemotional messages, suggesting a low degree of task conflict, may have impacted the group's overall performance. Although this research did not examine the quality of the group's work, literature on organizational conflict suggests that groups can improve performance through effective management of task conflict (Rahim, 2002). At a minimum, the percentages of the positive and negative socioemotional communication functions reflect the high degree of politeness and civility in the group's interactions. Perhaps not having to attend to any degree of hostility or conflict also enabled the group to focus primarily on their task.

\subsection{Communication Roles}

Communication roles are the functional responsibilities guiding individual communication behavior in small group interaction. To do the content analysis, the researcher first prepared a post-hoc agenda for each meeting based on the themes discussed. Then she coded and segmented the transcripts by agenda topic. The unit of 
analysis is a segment of group conversation, grouped by subject theme. After grouping the data in this manner she carefully read each segment to identify functional roles the group members played in the meetings. Analysis allowed for identifying a leader and showing the nature of leadership in the group. Except in discussion of leadership, which clearly identifies a group leader, the analysis focuses on the presence of particular roles within the group during discussions, not on associating roles with individual members.

\subsubsection{Leader Role}

In the group the hierarchical structure based on job position places P7 as the senior member of the group and a likely leader. Prior to the group's first meeting, however, P7 assigned three other group members to be co-leaders (P1, P3, and P4), and removed herself from a position of leadership. She attended only the first meeting. Of the three assigned co-leaders, group members unanimously reported in individual interviews that P4 emerged as the leader of the group. The researcher's observations corroborated this perception. $\mathrm{P} 4$ was one of three group members in the next highest hierarchical rank; all three had comparable years of service.

A common definition of leadership is the ability to influence the behavior and attitudes of others to achieve a common goal (Dipboye, et al., 1994). Leaders may draw on sources of influences such as position power and/or personal power sources. Position power draws from formal powers that exist inherent in a position, such as direct supervisory authority, power to reward or punish, or power derived from limited access to valuable information. Personal power sources are the characteristics or traits an individual possesses that others recognize as powerful, such as expert power, charisma, 
rational persuasion, or likeability (Greenberg, 2002). In the case of the Accountability Group, although P4 was viewed as the undisputed leader, she had limited access to these traditional sources of power. Her only positional power was the legitimate power that came through P7's designating her as one of the leaders at the start of the project. Beyond that, she had no supervisory, reward, or punishment power over anyone in the group, nor was she privy to exclusive information. Neither could she draw on any personal power sources: she was not seen as an expert on the topic; she did not provide logical arguments to influence the group; and, although the group liked her, she did not demonstrate any authority based on likeability.

Instead, her power to influence the Accountability Group came from behaviors best characterized as facilitation behaviors. These facilitation behaviors are noted below:

Recording ideas: No one routinely took the minutes at meetings, but $\mathrm{P} 4$ served as scribe at selected times in the four meetings. She recorded the ideas she wanted recorded and omitted ideas she did not wish to record. Being the scribe also allowed her to edit and interpret the ideas and words of the other group members in the act of recording them.

Directing and redirecting conversation: $\mathrm{P} 4$ steered the conversation in a different direction when she felt it had drifted from the intended topic. An extended look at this behavior is included in the section on communication rules (section 5.5).

Choosing to meet: Except for the first meeting, which P7 called, P4 arranged all subsequent meetings. She decided when it was necessary to meet and proposed meeting dates and times. 
Initiating meetings: P4 facilitated the meetings by initiating the conversation, unilaterally in Meeting 2 and 4, and collaboratively at meeting 3 .

Drafting work products: Of the two group work products, P4 was the sole author of the first and a co-author (with P1) of the final report. The first was a status report presented to the Executive Committee the first time the Accountability Group met with them. She wrote the draft independently and circulated it to the rest of the group for opinions. In writing the draft of the final report, P4 invited P1 to collaborate in preparing the document that was subsequently circulated to the rest of the group.

Influencing opinions: Throughout the interaction in the group, P4's opinions carried more weight than other members. When another member would make a suggestion that P4 did not agree with, her critique usually swayed the group away from the idea.

\subsubsection{Functional Group Roles}

In addition to identifying the leader role in the group and indicating how leadership was exerted, additional analysis focuses on identifying roles occurring within the group but not in attributing these roles to specific individuals. Benne and Sheats' (1948) classification of group roles was used as the basis for content analysis to identify other group roles. The classification includes 27 roles distinctively named and arranged into three categories: task roles, group building and maintenance roles, and individual roles. Appendix E: Benne \& Sheats (1948) Functional Role Definitions defines each role and indicates its category.

Table 5-6 identifies the roles that at least one group member played at some time

during the group's meetings and in email. Since none of the individual roles in Benne and 
Sheats' classification scheme appeared in the Accountability Group data, only Task and Group Building roles are noted in the table.

Table 5-6. Benne and Sheats Group Task and Group Building Roles Distributed by Group Event

\begin{tabular}{llllllc}
\hline & & \multicolumn{4}{c}{ Meetings } & \\
\cline { 2 - 5 } Role type & Role & $\mathbf{1}$ & $\mathbf{2}$ & $\mathbf{3}$ & $\mathbf{4}$ & Email \\
\hline Task & Initiator-contributor & $\mathrm{X}$ & $\mathrm{X}$ & $\mathrm{X}$ & & $\mathrm{X}$ \\
& Information seeker & $\mathrm{X}$ & $\mathrm{X}$ & $\mathrm{X}$ & $\mathrm{X}$ & \\
& Opinion seeker & $\mathrm{X}$ & & $\mathrm{X}$ & $\mathrm{X}$ & $\mathrm{X}$ \\
& Information giver & $\mathrm{X}$ & $\mathrm{X}$ & $\mathrm{X}$ & $\mathrm{X}$ & $\mathrm{X}$ \\
& Opinion giver & $\mathrm{X}$ & $\mathrm{X}$ & $\mathrm{X}$ & $\mathrm{X}$ & $\mathrm{X}$ \\
& Elaborator & $\mathrm{X}$ & $\mathrm{X}$ & $\mathrm{X}$ & & $\mathrm{X}$ \\
& Coordinator & & $\mathrm{X}$ & & $\mathrm{X}$ & $\mathrm{X}$ \\
& Orienter & $\mathrm{X}$ & $\mathrm{X}$ & $\mathrm{X}$ & $\mathrm{X}$ & $\mathrm{X}$ \\
& Evaluator-critic & $\mathrm{X}$ & $\mathrm{X}$ & & $\mathrm{X}$ & $\mathrm{X}$ \\
& Energizer & & & & & \\
& Procedural technician & $\mathrm{X}$ & & & & $\mathrm{X}$ \\
& Recorder & & $\mathrm{X}$ & & $\mathrm{X}$ & $\mathrm{X}$ \\
\hline Group \\
building & Encourager & $\mathrm{X}$ & & & & \\
& Harmonizer & $\mathrm{X}$ & & & & \\
& Compromiser & $\mathrm{X}$ & & & & \\
& Gate-keeper and expediter & $\mathrm{X}$ & & & & \\
& Standard setter or Ego ideal & & & & & \\
Group-observer and & & & & \\
commentator & & & & \\
& Follower & & & & \\
\hline
\end{tabular}

Note. $\mathrm{X}=$ indicates the presence of the role in the meeting or email.

Based on Table 5-6, the predominant finding is that this group focused on task, both in every meeting and in emails. With rare exceptions all task-related roles appeared in at least two to four events (including both meetings and email). Conspicuously absent are group building roles that appeared only in the first meeting when the group was just forming. The similarity of task-related roles in evidence at each meeting suggests the group developed or perhaps even possessed in advance of this group's formation a 
preferred meeting interaction style. Only the Energizer role was totally absent. In interviews, group members revealed a general lack of enthusiasm for this particular project. Because no member was personally very highly motivated to put effort toward the problem, it follows that no one took on the role of prodding or stimulating the group to more activity.

The absence of other task roles in specific meetings can be attributed to the activities of the group at that point. For example, the absence of the Coordinator role in the first and third meetings is consistent with the inconclusiveness of the discussion in these two meetings. Many ideas were put forth at the first meeting and many concerns were raised at the third meeting, but at no point did anyone try to tie things together, clarify the relationships among the ideas on the table, or coordinate group efforts.

\subsection{Communication Channels}

The Accountability Group used two channels of communication during their project, face-to-face meetings and email messages. Over the course of the project the group held four meetings and exchanged 119 email messages. The data were first separated by channel (face-to-face and email) and then content analysis was conducted on the data in each channel. Comparisons on the differential use of each of the channels are discussed below.

\subsubsection{Meetings}

The group used face-to-face interaction through group meetings as their primary channel of communication. Meetings were scheduled for one or two hour time blocks and meeting room space was reserved for the group's use (see Appendix F: Meeting Details). 
In the meetings the group communicated information about all aspects of the work: raising and discussing ideas, strategizing and evaluating, brainstorming, drafting and editing work products, assigning responsibilities, and resolving logistical details. The group also exchanged interpersonal conversation and small talk before and after meetings.

\subsubsection{Email}

The group exchanged emails as a secondary means of communicating. All group members were familiar with and proficient at using email and used it regularly as a part of their jobs. They knew how to send messages to multiple recipients and tended to use the feature "reply all" to ensure each group member received each email (including the researcher). The email messages tended to be short in length and largely focused on the task. The group sent a total of 119 messages over the 10 months the group was active.

Three peaks in email communication occurred in October just after the group assembled; in late March, prior to the first time they reported to the Executive Committee; and in June, prior to presenting their work to the Executive Committee for the second time. A dip in email communication occurred from the end of November to March. During that period, the group met one time, and the messages in January were almost entirely related to scheduling that meeting.

Figure 5-2 displays the number of messages by month, with markers indicating when each meeting was held. 


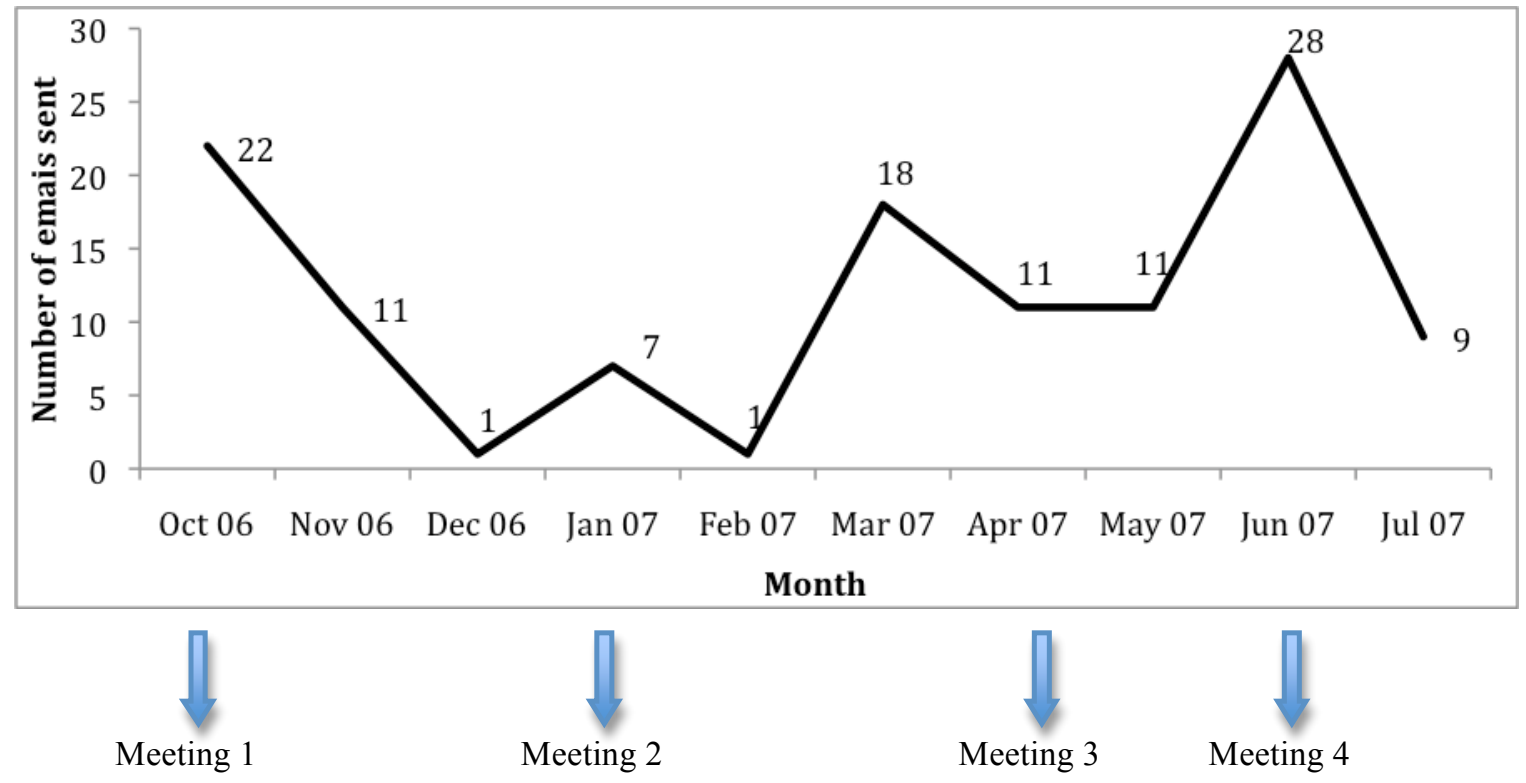

Figure 5-2. Number of Email Messages Sent by Month with Indication of Each Meeting

In general, the group viewed email communication as an extension of the group's face-to-face communication. Their plan was to use email to continue discussing ideas that emerged in meetings; to give themselves time to reflect, and then respond with thoughts, comments, or new ideas over email; and to carry out work that was started in a meeting. As a result, many of the topics of conversation that emerged in the meetings also existed in the email messages, as discussed in the findings on communication theme above.

The group used email for several specific tasks during their project: 1) to draft their charge; 2) to request feedback on drafts of work products 3) to schedule meetings; 4) to circulate minutes; and 5) to apologize for and explain gaps in responses.

Drafting their charge: Most of the primary issues relating to the group's task were introduced and heavily discussed in face-to-face communications and only in a few instances carried over into email discussion and, even then, discussed only superficially 
over email. An exception to this practice was how the group drafted their charge. At the first meeting, the director reminded the group at several points that they needed to develop a charge. By the end of the meeting, they still had not done so. The director then suggested a charge and there appeared to be agreement around it. However, two weeks later, over email, the director asked the group for their charge, never mentioning the charge she suggested at that first meeting. Several group members emailed suggested charges, also never mentioning the charge put forth at the first meeting. The director rejected those suggestions because they did not match the form she was expecting. The director then emailed examples of the charges of two other task forces. Two group members then emailed new versions of a charge to the group, and one of those versions was edited slightly by another member and accepted by the director.

Requesting feedback: After each of the four meetings, the group decided to circulate via email the document or notes that captured the work they had completed at that meeting and then solicit feedback from group members with the intent to continue on with the work. In actuality, they did not always stick to that plan. In two of the four times they continued working on the document over email, and with the other two times the work was dropped with only a few or no comments.

Scheduling meetings: Email was the preferred channel by which to handle scheduling. All four group meetings and both presentations to the Executive Committee were arranged via email.

Circulating minutes: No formal minutes were ever recorded from the meetings, however, on two occasions informal notes were typed and circulated to the group via 
email: notes from the first presentation to the Executive Committee, and notes from the third group meeting.

Apologies: Related to their use of email to request feedback, the group also used email to apologize for not responding or not responding more promptly to requests for feedback. Group members sent email messages apologizing for not replying and offered explanations why they had not yet replied or why they would not be able to reply until some time in the future, due to heavy workloads.

While the group intended to use email as an extension of their face-to-face communication, the email messages lacked the robustness the face-to-face communication allowed. As described above, not all of the primary or secondary issues related to their task came up via email. Those issues that were raised via email were discussed largely in a pragmatic manner in the form of brief messages that shared an opinion about something already mentioned, rather than introducing anything new to the discussion. Many of the comments were statements of agreement with what the original poster sent. There was very little discussion or debate over email. And so while the group throughout the project expressed the desire to use email to continue their face-to-face interaction, in reality, the email communication was sparse and only supplementary, rather than equal to the robust interaction that occurred in their face-to-face communication.

Although it was not a stated purpose for using email, the group regained momentum after periods of inactivity by starting up an email thread. Since the group did not have regularly scheduled meetings or a timetable for work production, the group was able to 
let down and effectively stop working for periods of time. P4 used email after those lulls to bring the group back to life and push on for the next activity or task.

\subsubsection{Other Channels}

The group never discussed using any other technology or channels of communication such as telephone or videoconferences, wikis, or blogs. Nor was there much opportunity for informal, face-to-face communication among members outside the structure of the scheduled meeting, largely because the seven members of the group worked in different locations within the library system and rarely had face-to-face contact except for scheduled meetings for this group.

During the ten months the group was active, two group members moved from separate facilities into the same building and one became the new supervisor of the other. A diary tool had been created at the beginning of the project to capture any face-to-face communication that might occur informally between individuals in the group about their group work. However, these two individuals consistently reported that they had no informal discussion about the group work outside the meetings so the diaries were not necessary.

\subsection{Communication Rules}

Communication rules are the group's understandings about acceptable or appropriate communication behaviors within the group. Content analysis of the transcriptions of each meeting and the set of all email messages focused on some of the facets of Shimanoff's (1988) schema. Shimanoff's entire schema looks at: 1) who says, 2) what, 3) to whom, 4) when, 5) with what duration and frequency, 6) through what medium; and 7) with what 
decision process. This section discusses Categories 1-5; Category 6, medium, is covered in Section 5.4 on communication channels. Category 7, decision process, was not included in the analysis of communication rules but rather was examined as an element of the group's shared mental model of their team interaction. Additionally, because the group was involved in a problem-solving task, decision-making was not a primary aspect of their communication.

Although these facets seem obvious, it may be useful to explain each briefly as applied in this study. "Who" relates to the person communicating and expectations about whether certain people should communicate certain messages. "What" looks at the appropriateness of content communicated; it identifies rules the group develops about what can be said and may be time-specific. "To whom" addresses the intended recipient of the communication exchanged, indicating, for example, if comments are addressed to a particular person, subgroup, or the group as a whole. "When" is obviously time-related. The first aspect addresses who speaks when, framed in terms of turn-taking rules. The second aspect of when looks at the appropriateness of what is said at a given point in the interaction. Typically group rules regarding this aspect of time relate to use of an ordering device, such as an implicit or explicit agenda. "Duration" refers to rules governing the length of an individual's comment, expressed perhaps in time or in number of turns. With "frequency" Shimanoff is referring to the number of times a person may speak, although occurrence may be a better descriptor.

An important general finding about the communication rules in the Accountability Group is the nearly complete lack of any explicit negotiation or discussion about the 
rules. The group never used a prepared agenda; the members rarely discussed process issues about when or how their discussions would take place. Yet they were quite consistent with their rules, even from the first meeting, and experienced very little violation of the norms or incidents of sanctioning.

The Accountability Group implicitly adopted ten communication rules. In this section, the text, arranged by rule, explains the rule as necessary, shows how it emerged, and provides brief example(s) of the rule's application if possible. In the numbers assigned to the rule, the first number refers to the schema facet; the second indicates order within that facet. Rule 2.1, for example, refers to the first rule related to the second facet, what.

Rule 1.1 Who: Leader starts the meeting: For the first meeting, the leader was P7, the library director, since the group was just forming and no internal leader had been established yet. P4, who emerged soon as the group's primary leader, started the remaining meetings informally. As the group members assembled in the meeting room, they engaged in small talk. Generally the leader (P7 or P4) focused everyone's attention by making a work-related statement to begin the meeting. For example,

Okay, so P7 did accept our charge so now the group has to decide how we want to roll it out and what pieces we have to put in place in order to make accountability a part of our core values. (P4, Meeting 2)

Rule 1.2 Who: Everyone was encouraged to speak and spoke in the meetings: Everyone in the group was encouraged to participate in the discussion both actively and by responses to his or her comments. Each group member voiced his or her ideas 
throughout the meeting. Although the frequency counts (discussed later) show disparity among members in terms of actual conversational turns taken, everyone in the group contributed substantive ideas to the discussion.

The rule emerged from two patterns set at the first meeting. First, at the beginning of the first meeting, the group elected to go around the table so that each could offer his or her thoughts on accountability. That strategy gave everyone an explicit chance to speak, without having to be asked or invited, and established a norm that it was permissible, even expected, for each person to contribute his or her ideas. Also, the group's response to each person's contribution was neutral or positive; no one issued any negative feedback to anyone's contribution. This type of response set a pattern of civility and openness. The second aspect that contributed to the rule for everyone to be free to speak was pattern that P4 established. She made a point on several occasions to specifically invite certain people to speak. For example,

What do you think, P1? (P4, Meeting 1)

P5, what were you going to say? (P4, Meeting 1)

P7, we haven't heard from you and I would like to hear your definition. (P4, Meeting 1)

This explicit invitation from the person who had emerged as the leader, also helped establish the practice that all voices were encouraged to contribute.

Rule 1.3 Who: Leader was permitted to re-focus the conversation: The group also adopted a norm in which the leader could decide when to refocus the group by changing the topic or by returning to a previous topic. In essence, she functioned as the 
conversational traffic light, deciding when to change topics, and determining when the conversation had reached an impasse. She became the arbiter of time allotted on a particular topic. Although the subject of the conversation naturally changed over the course of the meeting, the leader was allowed to explicitly redirect or refocus the discussion.

Okay, we've been here an hour, so we still need to work on reframing the definition. (P4, Meeting 2)

Rule 2.1 What: Members were expected to communicate respectfully: Although never made explicit, the group clearly adhered to a "rule of niceness", that is, a rule of civility and nicety in the way they spoke to each other. There were no personal attacks, no heated exchanges, and no evidence of negative communication. The group was able to disagree and debate the issues while refraining from rude or impolite communication. For example, at one point in the fourth meeting several group members were saying, "I think we should do it this way", and another group member (P6) responded saying, "I think we should do it that way." They debated back and forth for a few turns, at which point, P2 said:

Yeah, that's two different ways of looking at this issues and I think today we're looking at it a little bit differently. (P2, Meeting 4)

That degree of civility was prevalent in all the discussions and never violated.

Rule 2.2 What: A member was free to speak his mind: The group followed a rule allowing everyone free speech. Each member was free to say what he or she wanted to, and to move the conversation in different directions. The conversation reflected a clear 
sense of openness and freedom of conversation, evidenced by many instances of group members making suggestions, countering with alternative suggestions, or leading the conversation down different paths. In addition, the absence of any type of sanction in response to a particular topic of conversation also points to a rule of free speech.

Rule 3. To Whom: Members speak to other members: Unlike other groups, where each comment might be directed to the leader, or groups where friends talk only to their friends but not to people they do not know, the Accountability Group directed their comments to everyone in the room. Certainly in the normal course of conversation, a group member answered a question asked by someone else in the group, in which case the answer was primarily intended for one recipient. But that pattern does not suggest any specific rules about who might speak to whom, only that the group adhered to standard conversational turn-taking practices (Sacks, Schegloff, \& Jefferson, 1974). Only on rare occasions did conversation occur between only a sub-section of the group. Despite clear differences in the frequency with which the members spoke, on no occasions did the conversation involve just two or a few group members to the exclusion of the others.

Rule 4.1 When: Members follow common turn-taking practices: The first part of when in communication rules refers to who speaks when, framed in terms of turn-taking rules. For this particular aspect of Shimanoff's framework, Sacks, Schegloff, and Jefferson's (1974) model of turn-taking in conversation was used as a tool for comparison, to determine to what extent the Accountability Group's turn-taking practices fit within or vary from that well-established framework (Table 5-7). 
Table 5-7. Comparison of Sacks et al.'s Model of Turn Taking with the Accountability Group Turn Taking

Sacks et al. model
$\begin{aligned} & \text { 1. Speaker-change recurs, or at } \\ & \text { least occurs }\end{aligned}$
$\begin{aligned} & \text { 2. One party talks at a time } \\ & \text { (mostly) }\end{aligned}$
3. Occurrences of more than one
speaker at a time are common,
but brief
but brief

4. Transitions between turns with no gap and no overlap are common.

5. Turn order is not fixed, but varies.

6. Turn size is not fixed, but varies.

7. Length of conversation is not specified in advance.

8. What parties say is not specified in advance.

9. Relative distribution of turns is not specified in advance.

\section{Accountability Group}

Observed. At each event, all participants had multiple turns as the speaker.

Observed.

Observed. It was common that as the current speaker was finishing his or her turn, the next speaker (self-selected) would begin speaking, overlapping with the outgoing speaker, but not enough to cover or talk over the current speaker. Sacks, et al. describe this phenomenon as the "projectability of possible completion". The next speaker could sense when the current speaking was winding up his turn and overlapped just slightly.

Observed. Both a slight overlap as well as no overlap was the most common transitions with the Accountability Group. Less common were gaps between turns. Except for portions of meeting 2, the group was heavily engaged in their discussion and few if any gaps or pauses in the conversation were noted.

Observed. The group developed no rules about the order in which members were allowed to speak. Although, as Sacks et al. point out, while turn order varies, it is not entirely random. As an example of the rubric they named "current speaker selects next speaker", there were times during the discussion when a comment or question was obviously directed to a particular group member, in which case, that person was chosen as next speaker.

Observed.

Limited by meeting length. Here Sacks et al. refer to the length of the conversation, not the specific turn. Within the Accountability Group, no specified length to any particular topic of conversation was established, such as could have been the case if they had used an agenda with timed limits to particular portions of the agenda. Instead, the length of the conversation was bounded by the duration of the meeting time, either 1 or 2 hours.

Observed. There was no advanced determination of what group members would say, in contrast to, for example, turn-taking in an interview setting or turn-taking in a more formal, ceremonial setting.

Observed. Even though the distribution of turns was unequal, the pattern of distribution was not pre-determined and was not fixed. 


\begin{tabular}{|c|c|}
\hline Sacks et al. model & Accountability Group \\
\hline 10. Number of parties can vary. & $\begin{array}{l}\text { Observed. The turn-taking rules did not change when the number of } \\
\text { participants at each meeting varied. }\end{array}$ \\
\hline $\begin{array}{l}\text { 11. Talk can be continuous or } \\
\text { discontinuous. }\end{array}$ & $\begin{array}{l}\text { Observed. The majority of the conversation in the Accountability was } \\
\text { continuous, that is, using Sacks et al. terms, the maximum period of } \\
\text { non-talk only reached the level of gap, and not lapse. }\end{array}$ \\
\hline $\begin{array}{l}\text { 12. Turn allocation techniques are } \\
\text { obviously used (current } \\
\text { speaker selects the next } \\
\text { speaker, self-select). }\end{array}$ & $\begin{array}{l}\text { Observed. The group moved seamlessly between these two turn } \\
\text { allocation techniques. The technique "current speaker selects next } \\
\text { speaker" was invoked when a question or comment was directed to a } \\
\text { particular group member. In all other cases, the group adhered to the } \\
\text { technique of self-selecting the next speaker, whereby the next speaker } \\
\text { was the person who started speaking first at the next conversational } \\
\text { turn. }\end{array}$ \\
\hline $\begin{array}{l}\text { 13. Various turn constructional } \\
\text { units are employed (sentential, } \\
\text { clausal, phrasal, and lexical). }\end{array}$ & Observed. \\
\hline $\begin{array}{l}\text { 14. Repair mechanisms exist for } \\
\text { dealing with turn-taking errors } \\
\text { and violations. }\end{array}$ & $\begin{array}{l}\text { Observed. The examples Sacks et al. provide were observed in the } \\
\text { Accountability Group: } \\
\text { a. Premature stopping when two speakers began speaking at the } \\
\text { same time } \\
\text { b. Inviting a speaker to finish their turn if it was interrupted in any } \\
\text { way } \\
\text { c. Acknowledging an interruption with "excuse me", or another } \\
\text { such marker }\end{array}$ \\
\hline
\end{tabular}

Rule 4.2 When: Members follow implicit agendas in the form of loosely agreed upon goal(s) for each meeting: The second aspect of time and timing in communication rules examines the appropriateness of what is said at a given point in time in the interaction. Typically rules regarding this aspect of time and timing relate to the use of an agenda. An agenda identifies the topics for discussion, the order for discussing them, and perhaps even the time to be spent on each topic. In situations with agendas, rules can be inferred from that agenda about the appropriateness of a topic at a given time. The accountability group did not use explicit agendas prepared in advance of the meetings. They did adhere to implicit agendas, in the form of loosely agreed upon goal(s) for the meetings, which 
helped determine what was considered appropriate conversation. When violations of those tacit agendas occurred, mild sanctions were enacted in the form of redirecting the conversation back to the approved topics. For example, in connection with the goal/agenda item, determine the group's charge,

So my job is to convene the meeting, the group, and P4 and P3 and P1 were identified as leaders. So one of the first tasks that we have to do, and then I am turning it over to the leaders, is to determine our charge, our scope of work, more or less, and then our timetable. And so I've done my job by bringing us together, by scheduling the first meeting, so I now turn it over to P3 and P1 and P4, who will lead us and figure out how we're going to get our work done. (P7, Meeting 1)

As the group strayed from this goal, the director referred to the charge throughout the meeting to refocus the group. For example, I'm just kind of thinking, so what's our charge? Do we do this? Or do we do our charge, or can we do a charge without doing this? (P7, Meeting 1)

Of all meetings, the first meeting had the least formed implicit agenda. P7 stated the goal — that the group needed to develop its charge—in her opening statement. No formal time was dedicated to drafting the charge. Instead, the conversation moved freely from topic to topic, and only periodically would someone mention the charge, or remind the group members they needed to develop a charge. In this case, the group agreed upon the appropriateness of a topic (the charge), although they did not force themselves to systematically discuss it. Rather, the topic of the charge was used to re-focus the group 
and bring them back to the immediate task at hand. The act of mentioning the charge functioned as a benign sanction indicating the group had moved away from the agreed upon goal.

5.1 Duration: Members' turn length varied but adhered to an outer bound: This facet of Shimanoff's schema pairs with the Sacks (et al.)'s finding that turn size varies conversation. That variability was true with the Accountability Group in general, although an outer bound for turn size was detected.

Even though there was no explicit negotiation about turn length, the group generally adhered to speaking briefly instead of expounding at length. Turns ranged from a single word or few words, to short sentences, to longer comments. Although actual word counts for each turn were not done as part of the analysis, a cursory examination of the meeting transcripts shows that with great regularity, no speaker's turn lasted more than seven or eight lines of text, roughly three to five sentences. This length of turn was consistent across all meetings. It suggests that group members developed an internal sense of how long they should hold the floor and were consistent in not violating that perceived length. No examples occurred of a speaker's being sanctioned externally in any way for a long turn size.

\subsection{Frequency: Each member spoke at whatever frequency he preferred: Table 5-8} shows the percentage of turns taken by meeting by each member. In the absence of any imposed frequency structure, individual turn-taking frequencies reveal some consistent patterns, which are summarized in Table 5-9. 
Table 5-8. Percentage of Turns Taken by Meeting by Participant

\begin{tabular}{lrrrr}
\hline Person & Meeting 1 & Meeting 2 & Meeting 3 & Meeting 4 \\
\hline P1 & $9 \%$ & n.a. & 18 & 9 \\
P2 & 13 & 26 & 20 & 8 \\
P3 & 11 & 25 & 13 & 21 \\
P4 & 34 & 32 & 33 & 32 \\
P5 & 15 & n.a. & 8 & 19 \\
P6 & 5 & 17 & 7 & 11 \\
P7 & 13 & n.a. & n.a. & n.a. \\
\hline Note
\end{tabular}

Note. n.a. indicates the person did not attend the meeting.

Table 5-9 categorizes the percentages of turns taken across all members over time into high, medium, and low categories and shows a high degree of consistency among the group members.

Table 5-9. Distribution of Participants by Frequency of Turns Taken by Meeting

\begin{tabular}{llll}
\hline & \multicolumn{3}{c}{ Frequency of turns } \\
\cline { 2 - 4 } Meeting & High & Medium & Low \\
\hline 1 & P4 (34\%) & P5 (15\%) & P1 (9\%) \\
& & P2 (13\%) & P6 (5\%) \\
& & P7 (13\%) & \\
& & P3 (11\%) & \\
2 & P4 (32\%) & P2 (26\%) & P6 (17\%) \\
& & P3 (25\%) & \\
3 & P4 (33\%) & P2 (20\%) & P3 (8\%) \\
& & P1 (18\%) & P6 (7\%) \\
4 & & P5 (13\%) & \\
& & P3 (21\%) & P2 (11\%) \\
& & P5 (19\%) & P1 (9\%) \\
\end{tabular}

P4 led the group with number of turns taken, averaging about $32 \%$ of all turns at each meeting. P6 consistently took the fewest number of turns at each meeting, at less than $10 \%$ for all but the second meeting, in which the fewer attendees caused his turn percentage to climb above the $10 \%$ mark. P1 was also mostly in the low group with the 
exception of the third meeting. The middle group was occupied for the most part by P5, $\mathrm{P} 2$, and $\mathrm{P} 3$. Because $\mathrm{P} 7$ only attended the first meeting, analysis of her turn frequency is not possible. The exceptions to these patterns can be explained by several factors. Attendance altered the frequency patterns on several occasions. As previously stated, because only four people attended meeting 2, the numbers for P6 are higher than the other meetings, although proportionally his turn taking was consistent. Attendance at the third meeting was erratic. P6 and P3 came late to the meeting, which contributed to their lower percentages. P4, P2 and P1 were the only members at the meeting for the first 20 minutes or so, which explains P1's higher than typical percentage. P2's percentage at the fourth meeting is explained by the fact that he shut down to some extent after battling for his idea early in the meeting. He became quiet for some time after not gaining any support for his idea and only re-engaged in the discussion late into the meeting.

This distribution of turn frequency suggests that individual group members possessed an internally developed sense of turn-taking appropriateness and each consistently adhered to his own preferred turn frequency. That each member's turn frequency was consistent from the first meeting (when accounting for the differences explained by attendance) indicates that preferences were established prior to membership in the Accountability Group and represent individual differences among members.

The most likely reason for the internalized rules that did not have to be discussed formally is the group's position within the larger organization of the library system. Although the seven group members had no history together as a group, they had all worked in the system for years and had participated on other committees and groups 
before this experience. They had developed a familiarity and comfort with rules and norms of group interaction in the system setting and brought that past experience to their time together in this configuration. This finding is consistent with Feldman's (1984) argument that past experiences contribute to the development of group norms.

In general, the group developed very few rules to govern communication within the group. The rules observed were permissive, open, and focused on positive communication. Most rules were the same for all members, with the exception of two specific powers granted to the leader. Because the rules were not restrictive, the group had little difficulty in complying, and thus the group had very few instances of rules violations or sanctions.

\subsection{Summary of Findings}

When examined through the lenses of these five communication variables, a general profile emerges to characterize the communication patterns in the Accountability Group.

The group focused their communication primarily about the task they were assigned. They spent a significant amount of time clarifying the nature of the problem and exploring possible solutions. In doing so, the functional aspect of their communication was also predominantly task-focused. One participant, P4, emerged as the clear leader, demonstrating leadership through facilitation behaviors. Group roles other than that of the leader consistently emphasized task roles over group building roles.

Face-to-face communication at scheduled meetings was the preferred communication channel for the group. Email was used to supplement discussions that were initiated at meetings and for handling logistical details such as circulating documents and scheduling 
meetings. The communication rules observed by the group were largely implicit, although consistently followed. Rules encouraged open participation and mutual respect, and the group adhered to common turn-taking practices.

In the next chapter, the findings from these communication variables are considered against the mental models reported in chapter four. An audit of the communications patterns assesses how they may have influenced the development of the group's shared mental models. 


\section{Chapter 6: Communication Influences on Shared Mental Models}

This chapter answers the main research question by linking the communication variables discussed in chapter five to the group's shared mental models described in chapter four. It follows the methodology described in detail in section 2.5.4. Briefly this methodology involves selecting each of the components of the two mental models, identifying the transitions, classifying them by the direction of change, and then carefully analyzing the communication surrounding the transitions to determine the relative influence of the five communication variables and other factors on the transitions.

Transition refers to what happened to a component between one interview and the next in terms of the shared mental model. Theoretically a component could strengthen during that time, could remain the same, i.e., in effect, have a neutral change, or could weaken. A transition was considered strengthened if it emerged in the second or third interview (presumably based on communication among the group) or the degree of sharedness changed positively from the previous interview, e.g., if it moved from moderate to strong. A transition was neutral if no change occurred in the degree of sharedness, e.g., if it was moderate at both interviews 2 and 3. A transition was weakened if the extent of sharedness about the component decreased between interviews, e.g., if it moved from strong to weak.

Interpreted conservatively, as in this study, if a component were mentioned in one interview but not mentioned at a subsequent interview, it cannot be characterized. It would be wrong to assume that absence is equal to weakening or that the component is no 
longer a part of the model. Interpreting absence is a limitation in any research method that elicits concepts in an individual's thinking without priming or biasing the individual by asking about specific concepts. It is impossible to know if omission reflects simply a problem in recall or elimination of the concept from the individual's model. Thus the components of the task and team interaction models that fall into this condition (mentioned at one time and not mentioned subsequently) are not included in the analysis.

The first section presents the general findings on the identification of transitions, assessment of their direction, and influence of communication on the development of the shared mental models. The second section describes specific examples from the data to illustrate the general findings. The third section presents one example of a transition affected by a non-communications variable. The final section discusses the findings about the important influences on the development of both shared mental models.

\subsection{Characterization of Transitions and Influence of Communication}

In the analysis, a total of 41 transitions were identified for both models: 22 for the task shared mental model; 19 for the team interaction shared mental model. Of these only 11 were influenced by communication variables for the task model, 14 for the team interaction model. All others were influenced by external variables that could be identified or by unknown factors. Table 6-1 characterizes only the 25 transitions influenced by communication variables since the relationship between communication and shared mental models is the main focus of this research. 
Table 6-1. Characterization of Transitions between Component Strengths Influenced by Communication by Shared Mental Model

\begin{tabular}{lcc}
\hline Direction of transition & Task & Team interaction \\
\hline Strengthen & 10 & 9 \\
Neutral & 1 & 5 \\
Weaken & 0 & 0 \\
\hline Total & 11 & 14 \\
\hline Note. $\mathrm{N}=25$ transitions. Strengthen = emerged or increased in degree of sharedness; \\
Neutral = no change in the degree of sharedness; Weaken = decrease in the degree of sharedness.
\end{tabular}

A transition can be affected by more than one communication variable. Table 6-2 shows the communication variables influencing the transitions by shared mental model.

Table 6-2. Communication Variables Affecting Transitions by Shared Mental Model

\begin{tabular}{lcccccc}
\hline & Theme & Function & Role & Rule & Channel & Other \\
\hline Task & 9 & 0 & 3 & 1 & 0 & 3 \\
Team interaction & 2 & 6 & 9 & 9 & 0 & 0 \\
\hline
\end{tabular}

Note. $\mathrm{N}=25$ transitions; 11 for Task; 14 for Team Interaction. A total of 42 instances of the variables were influential across the transitions.

This table shows:

- Neither shared mental model was influenced by channel.

- The task mental model was influenced by three variables, excluding function, plus external variables; the team interaction model by four of the communication variables studied.

- Theme played a major role in the task shared mental model but was relatively insignificant in forming the team interaction model. In the team interaction model, role, rule, and, to a slightly lesser extent, function influenced its development. 
Not obvious in this table but shown in the extended analysis in Appendix G: Analysis of Transitions and Variables Influencing Task Mental Model and in Appendix H: Analysis of Transitions and Variables Influencing Team Interaction Model is the conjunction of the variables. In a number of cases communication theme was the only communication variable of those studied that could be linked to mental model development. In some cases, communication role was the only communication variable affecting a particular model. Communication rules were never the only influential variable. As noted above, communication function appeared only in the team interaction model and always co-occurred with communication rules, suggesting a link between the two variables.

\subsection{Examples of the Influence of Communication Variables}

Following are several representative samples of transitions to illustrate the influence of the communication variables on changes in the status of the model's components. The examples show how communication variables both strengthened a component of the shared mental model and maintained (kept neutral) a component of the shared mental model. No transitions showed a weakening due, in part, to the conservative interpretation of components not voiced for the mental models. As noted earlier in chapters two and four, the degree of strength of similarity or sharedness in the mental models is determined by the number of respondents who expressed the same or similar meaning. Strong refers to six or seven group members expressing the concept; moderate refers to four or five members; and weak refers to two or three members. In the examples, explicit references are made to the appropriate tables showing the mental models in Chapter 4 (Table 4-1 for 
task and 4-2 for team interaction), and to the individual component whose transition(s) were analyzed.

\subsubsection{Define Accountability}

The group agreed that one of their tasks was to define accountability (Table 4-1, Component 2.2). This component emerged at the second interview as moderately shared and became strongly shared at the third interview. This example illustrates the strengthening of the task shared mental model.

The development of this component of the group's task mental model can be traced to communication themes the group discussed and to communication roles members of the group enacted. At the first two meetings, the group discussed the themes of "Define accountability", which focused on the need to define accountability and what the definition should contain. They also discussed the theme "What is accountability"; each member offered his own ideas about what accountability means and provided examples of good and bad accountability. The group's conversations about the need to produce a definition, and their discussion of the meaning of accountability contributed to a shared sense that defining accountability formed part of the group's tasks.

Members assumed communication roles that also contributed to developing this shared sense of task. In interaction at the first two meetings, each member played the role of Opinion Giver and Information Giver when he or she shared his or her ideas about the meaning of accountability. Additionally, P4 acted as a facilitator at both meetings, including directing a brainstorming session on what accountability means at Meeting 1, directing and redirecting the conversation to stay on the subject of defining accountability 
at Meeting 2, and recording the ideas contributed for a definition of accountability at the second meeting. Group members' collective performance of these opinion and information giving roles and the facilitation behaviors of $\mathrm{P} 4$ contributed to their developing a shared mental model that part of their task was to define accountability.

The group agreed on the definition of accountability just after the second interview, so the meetings and email between the second and third interviews no longer included discussion about the definition, except to acknowledge that the members had a definition for accountability. Although defining accountability was no longer a task the group was actively performing, the group's shared mental model about the task grew from moderately shared at the second interview to strongly shared at the third interview, reflecting a shared sense of certainty about accomplishing that specific task.

\subsubsection{P4 Performed Most of the Work}

The group developed a strongly shared mental model that P4 performed most of the work in the group (Table 4-1, Component 3.3). This component of the task model appeared at the third interview only. This example, too, illustrates the strengthening of the task shared mental model.

Group members were asked about work strategies they employed over the project"how did you get the work done?" Surprisingly, at the third interview, the group's strongly shared response to that question was not a characterization of how their work was performed, but, rather, who performed it. They implied nothing negative in this shared perception, considering it simply a statement of fact. They were unable to say how the work was performed, because in this shared view, primarily only one person 
performed it. The source for this shared perception rests clearly with group roles they enacted. As characterized in chapter six, $\mathrm{P} 4$ emerged as the group's leader/facilitator. As P7 (Interview 3) noted, "P4 did most of the work." In addition to performing the tasks associated with meeting facilitation, she also worked independently, and, toward the end of the project, with P1, to draft the documents that became the group's work product. Her roles as meeting facilitator, recorder, and author of the work products were unchallenged and universally acknowledged, influencing the shared perception of how the work was performed.

\subsubsection{Meeting Time Exhibited Good Interaction}

The group developed a moderately strong understanding that the meeting time was marked by good interaction in terms of sharing ideas, listening to each other and respecting differences of opinion, (Table 4-2, Component 2.2). This component of the team interaction mental model emerged at the second interview as moderately strongly shared and sustained that degree of sharedness through the third interview, illustrating a neutral transition.

The group's communication rules, communication roles, and the functions of their communications are all tied to the development of this shared understanding. The group's adherence to Rule 4.1 When: Members follow common turn-taking practices contributes to their perception that they shared ideas and listened to each other. Their respect for Rule 2.1 What: Members were expected to communicate respectfully supports a shared sense of listening and respect. Their Rule 2.2 What: A member was free to speak his mind relates to their sense that a variety of ideas were shared. 
Many of the group task roles identified also contribute to the development of this model. Most of the task roles observed (Initiator-contributor, Information Giver/Seeker, Opinion Giver/Seeker, Orienter, Elaborator, and Evaluator-critic) create interactions characterized by sharing, listening, and respecting differences. These roles were observed in nearly all of the group's interaction events and were enacted by multiple group members. Enacting and interacting in these functional roles seems to influence the group's shared sense of the nature of their interaction.

The profile of the group's communication functions also supports the group's shared thinking about the nature of the interaction. The high proportion of expressions of agreement (17.5\%) contrasted with the extremely low proportion of expressions of tension $(.3 \%)$ and antagonism (.1\%) reflects a group communication characterized by politeness, respect, and openness to ideas. Further, the contrast between task-related messages (74\%) and socioemotional messages (26\%) demonstrates the group's strong emphasis on task communication. Considering the nature of the group's task, this communication includes sharing ideas about problem and solution.

\subsubsection{P4 was the Leader with High Concern for the Task}

The group developed a moderately strong shared sense that $\mathrm{P} 4$ was the leader of the group, and that her leadership was characterized by a high concern for the task, (Table 4-2, Component 5.3). This component of the team interaction model was reported initially at the second interview and continued at the third interview at the same strength, illustrating a neutral transition. 
Four of the five communication variables explain the development of this component of the task model. Perhaps most obviously, the P4's communication roles influenced the formation of this mental model. The facilitation roles she performed such as being the scribe, the one who scheduled meetings, the one who prepared drafts of their work products, and the one who facilitated each meeting, and the Orienter role from the Benne and Sheats (1948) typology together characterize her as a leader. Two communication rules also reflect her leadership, specifically Rule 1.1 Who: Leader starts the meeting and Rule 1.3 Who: Leader was permitted to re-focus the conversation. The fact that $\mathrm{P} 4$ took more speaking turns than anyone else in the group (approximately a third each meeting), combines with the other evidence of her leadership to add to the shared sense about her as the leader. P4's leadership reflected a high concern for the task. The communication themes that emerged from the meetings show a high concern for the task in the group's interaction. The dominant discussion themes across the whole project were all facets of understanding the problem and identifying a solution. Finally, the distribution of communication messages by function corroborates the group's high focus on the task (74\%) as contrasted with messages emphasizing socioemotional communication (26\%).

\subsubsection{Differential Influence of Communication Variables}

Although this chapter focuses primarily on reporting how the group's communication influenced their shared mental models, one situation arose within a meeting that showed how group communication variables have a differing impact on a group's shared thinking. In this example, a group member attempted to use communication to convince 
the group to share his perception and was ultimately unsuccessful in influencing the emergence of shared thinking.

In the second meeting, the group spent significant amount of time discussing the meaning of accountability, the degree to which it was a problem in the library system, and possible steps they could take to design a solution to the problem. Early in the meeting, P2 introduced the idea of creating a number of specific examples pulled from real life situations faced by members of the library system that would demonstrate employees exercising high levels of accountability. The group discussed the idea briefly and two members seemed to think it was a good idea worth pursuing. P4, however showed less enthusiasm for the idea and questioned its effectiveness. At various points throughout the meeting, P2 reiterated his idea, explaining why he felt it was a good solution. But in each instance, P4 either ignored the idea, disagreed with it, or changed the topic of conversation. Ultimately, the idea of creating examples of accountability was not pursued further by the group, and even more interestingly to this research, the idea never emerged in the group's shared mental models. Although the idea was discussed by the group, (theme number 10, in Table 5-1) it did not become part of the group's shared thinking about the task. In this example, it seems that P4's influence through her role of facilitator ultimately had a stronger impact on the group's shared thinking than the collective discussion of a particular theme.

In nearly all cases, communication had a positive effect on developing shared mental models. It influenced their creation, helped the group to develop them more fully, or simply sustained them in that the strength of sharedness did not change from one 
interview to another. In only a few cases did the group's mental models show a decrease in the degree of shared thinking, and in no cases was the weakening effect thought to have been influenced by the communication variables studied but, rather, from other sources.

\subsection{Other Influences on the Shared Mental Models}

The previous examples illustrate the influence of communication variables on the development of the group's mental models. But other influences, classified generally as external influences, were also observed in a small number of cases. In these examples, the origin of the content of the group's shared mental models was traced to influences beyond the group's communication. Several of the external influences observed in this study were:

- feedback from the Executive Committee (mandate to do more work, request to describe what a solution will look like in the system);

- knowledge about the library system (new libraries openings; moving to new libraries); and

- group members' perceptions of the individual effort of other group members.

The following examples illustrate the influence of external factors on the group's shared thinking.

\subsubsection{Difficulty Moving to New Libraries}

The group had a strongly shared sense at the second interview that one of the biggest difficulties they were facing was that four of the seven group members were moving to new library buildings, and that two of those four people were the branch managers 
supervising the enormous building/moving projects (Table 4-1, Component 5.3). The degree to which they shared this perception of difficulty weakened from the second interview to moderately strongly shared at the third interview.

The work of planning new facilities and coordinating the library moves consumed a tremendous amount of time for all the parties involved, particularly the two branch managers who were in charge of their respective new libraries. The amount of work and the disruption of their normal routines were perceived to be problematic for the group in that they prohibited those affected members from fully participating in the Accountability Group's work.

The source for this shared mental model appears to come from generally known facts about the overall environment in which the group was operating. Group members only articulated a few passing comments about the impact of those moves on their workflow, so it cannot be suggested that it was a strong theme of their conversation. But everyone in the group was aware of the projects - they had been planned for more than a year - and each group member, even those not directly impacted by the moves, was clearly sensitive to the burden such a workload was placing on their group's efforts. The fact that the degree of strength of that model weakened over time is most likely due to the passing of time's lessening the impact of the moves. At the second interview, one new library had been open for four months, and the other for only two months, so the experiences of moving and opening new facilities were still fresh in everyone's mind. By the third interview, the libraries had been up and running for eight and six months respectively, 
and many of the major problems had been resolved, likely lessening the group's sensitivity to those difficulties.

\subsection{Discussion}

\subsubsection{Communication Themes Related to the Task Shared Mental Model}

Communication themes strongly influenced the development of the group's mental models about their task. Indeed in this particular group, in many cases a direct line could be drawn between conversation topics in the group's interaction and the group's subsequent mental model of the task. This finding is naturally intuitive and is supported by this empirical research. The content of most of the models in the task domain can be traced back to conversational topics and the subsequent interpretations and meanings on those topics that the group developed collectively.

The group, however, also discussed many topics over the course of the project that did not emerge as aspects of their shared mental models. Either the themes were dropped completely from each participant's individual schema, or only a few participants expressed them so that they were not considered moderately or strongly shared. Several factors may explain why these topics were not incorporated into the models: timing, commitment to the group, and insufficient anchoring.

Regarding timing, the group spaced their work over a full year, following a pattern identified by Gersick and Davis-Sacks (1990, p. 147) in other task forces of "'punctuated equilibrium' - alternating between relatively long periods of inertia and dramatic bursts of change." The distances between group events and between group events and interviews (the method employed to capture the models) may have made it difficult for 
the ideas generated within the Accountability Group's interaction to stay in the forefront of each member's thinking. Indeed, in both the interviews and in the meetings, participants made passing comments revealing they had forgotten parts of their work, such as decisions they had reached or stages of progress, suggesting that they may have forgotten ideas that at one time or another were part of their mental models about the task or team interaction.

Commitment to the group may have also influenced the loss of topics or concepts in the model. Participation in the Accountability Group came in addition to the full responsibilities of each person's job. No individual member was excused from other duties to participate in the task force. Thus, each member had to make time in his or her schedules and workload to participate. The heavy workloads the members faced may have impeded their ability to retain and integrate all the ideas that emerged in the group's interaction into their own thinking and to be able to articulate in the interview sessions later on.

The gap between the communication themes and the mental models may also be the result of insufficient anchoring around a central understanding of the problem or the solution. The researcher observed that, in the group's discussions, group members appeared to have reached shared thinking on several ideas and themes, but the absence of those themes from the expressed mental models suggests that individual participants did not fully integrate those ideas back in their own thinking, and thus the ideas were not automatically recalled in the interviews. Although some similarity in group members' thinking about the themes emerged during meeting, if those ideas were not anchored in 
each member's individual cognitive schema about the group's task, the participants would not have easily recalled them during interviews.

\subsubsection{Communication Roles, Rules, and Functions Related to the Team Interaction Shared Mental Model}

Communication roles, rules, and functions were most visible in the development of the team interaction mental models. Both communication roles and rules reflect the behaviors group members enact when communicating and interacting. Communication function describes the purpose of message, which is often a manifestation of a role being enacted (i.e., someone playing the role of the Opinion Giver expresses herself with communication messages that Give Opinions). These three variables pair closely with the elements of a team interaction model, which is a representation of knowledge about expected behaviors among the group in terms of roles, relationships, interactions, communication patterns, or performance of tasks.

Just as it is intuitive that what members discuss as a group is later reflected in their verbalizations of their collective thinking, it is also logical that how group members behave together helps to inform and build shared understanding about expected behaviors. In the Accountability Group, this connection was also visible in the data. In fact, an even greater degree of consistency was apparent between their expressed mental models about their behaviors (team interaction) and their observed behaviors (communication roles and communication rules) than was evident with communication themes and the task mental model. For example, the group was highly consistent in its strongly shared thinking about the identification of the leader, her performance in that 
role, and the observed examples of leadership. Another example is the group's strongly shared belief that group members did not experience conflict or disagreement and maintained highly professional and civil discourse in their communication rules and the functions of communications.

The group displayed inconsistency, however, between some segments of their shared team interaction model at interview 1 and subsequent behaviors. For example, the group began the project with a moderately strongly shared sense that all members should participate equitably in the group work, yet, at the second and third interviews a shared belief emerged that not everyone was contributing equally. This discrepancy suggests that the group's initial mental model about member participation was based on an ideal model of group member participation, but group members reinterpreted expectations over the course of the project, based on ongoing collective behavior, to produce a realistic and accurate, but differing, view of participation.

What begins to emerge from this study is that, although the data to a large extent support an intuitive belief about how these communication variables in particular influence the development of shared mental models, they do not provide a complete explanation of the process. These results take a small step toward clarifying and explicating in more detail the aspects of group communication that influence a group's shared cognition. Although by no means comprehensive, the empirical findings from this one case study begin to describe the influential nature of communication on shared cognition. 


\section{Chapter 7: Conclusion}

This final chapter has several purposes. The first section briefly summarizes propositions on the relationship between small group communication and shared mental models identified in this study. The second focuses on theory and measurement associated with the shared mental model concept. The third section addresses the use of the case study approach. The fourth section discusses implications for practice. Finally, the fifth section presents some ideas for future research.

\subsection{The Influence of Communication on Shared Mental Models}

Researchers in small group communication and social cognition share a belief that group members reach shared understandings through their communication. Yet, no theory has developed that explains the nature, process, or content of the interaction that influences social cognition. This study followed an inductive method in observing a bona fide group complete a problem solving task to discover the patterns that existed in their communication that may have influenced their development of shared mental models about the task and about team interaction. From the patterns that emerged, some tentative propositions can be made about the relationship between aspects of small group communication and shared cognition.

1. The content themes in small group discussion influence a group's shared mental model about their task.

2. The functional roles enacted by group members influence a group's shared mental models of their task and of team interaction. 
3. The communication rules developed and adhered to by a group influence a group's shared mental model of team interaction.

4. The function of the messages exchanged in group communication influence a group's shared mental model of team interaction.

These propositions suggest an initial theoretical stance that at least two broadly defined aspects of group communication differentially impact shared mental model development. One aspect is the semantic aspect of communication - the meaning of the communication, the words expressed — captured in this study as the communication themes discussed by group members. This aspect of communication appears to relate predominantly to the group's mental model about their task. The meaning in the group's communication enabled them to surface, identify, and construct a shared understanding of the problem they faced, the work required to solve it, and whether the group successfully completed the work.

The other aspect of communication is the functional side of communication - the instrumentality or purpose of the communication. This side is captured in this study through the roles, rules, and functions of the communication. These functional variables influenced more strongly the group's shared mental model about their team interaction, a model that captures knowledge about the behavioral interactions among group members. In this case, what people do, how they act, and what roles they assume, provide the information that group members come to share as their understandings about team interaction. 
These are clearly tentative propositions and require further testing and exploration in other groups. For example, although the observations from the Accountability Group did not reflect this, it would of course, be possible for a group to discuss explicitly through communication themes aspects of their team interaction mental model, in addition to, or instead of using behavioral cues to inform that model. There is room for much more theoretical development in this area.

\subsection{Shared Mental Models Construct}

\subsubsection{Theory}

While the primary thrust of this study explores the relationship between group communication and shared mental models, in capturing and analyzing the group's shared mental models on task and team interaction, several questions about the shared mental model construct emerged.

1. Do some shared mental models or portions of models (expressed perhaps as elements or components of the models) have a more significant impact on the group's positive performance than others?

Within the Accountability Group, there were sub-concepts in the task and team interaction domains on which everyone or nearly everyone agreed, and portions of the models in which there was not much similarity in thinking. Is there a hierarchy across mental models (task, team interaction, equipment, team members) or within models (i.e., within a task model, understanding of the problem, understanding of task sequence, or understanding of success) such that some portions are more closely tied to the group's performance than others? Should it be suggested to work groups that they focus more on 
achieving a shared understanding in one area over another? These questions suggest the possibility that not all shared mental models have equal impact on a group's performance, a concept that makes intuitive sense and should be explored further.

2. How does the degree of specificity of a shared mental model impact group performance?

Although the methods employed in this study were not intended to capture this, the researcher observed that the Accountability Group's shared thinking about what tasks they performed tended to be rather vague and not very specific. To what extent does a group benefit from a more detailed mental model? Is this dimension of shared mental models most affected by the nature of the group's work? For example, a group performing a task with many intricate sub-tasks and work dependencies would exhibit higher performance with a more specific shared mental model of the task, but a group whose work is more conceptual or theoretical could still perform at a high degree with a more general or abstract model.

3. What is the impact when a group in fact shares an understanding for a domain or subdomain but then does not enact that understanding when it would be possible or appropriate to do so?

This phenomenon was observed in the Accountability Group. At the first interview the group voiced moderately strongly shared thinking related to group norms (most members were aware that the organization had written rules to be used in meetings and that the work should be divided evenly). However, they did not hold themselves to the meeting facilitation norms nor to the division of work norms. This gap between a 
verbalized model and practice suggests that there can be an inconsistency between a group knowing or holding a shared belief, and actually enacting that belief. This suggested finding is related somewhat to the notion of accuracy of shared mental models which has received some empirical work in the literature (Edwards, et al., 2006; Ford \& Sterman, 1998; Lim \& Klein, 2006; Rentsch \& Hall, 1994) but differs in the sense that accuracy refers to the difference or similarity between a group's model and a "known "true state of the world"” (Edwards, et al., 2006, p. 281). In this case, the difference is between the group's model in the shared cognitive space and the behaviors enacted that may or may not reflect congruence with the cognitive model. To the extent that the group's performance is positively impacted by a congruence between the cognitive model and the enacted behavior, this finding suggests that for the group not only is it important to surface and discuss the ideas in a model domain so that they become shared, but it also is important to overcome any obstacles so that the espoused model can be executed. The mental model is still a reflection of shared cognition, but it should lead to the desired behavior.

\subsubsection{Measurement}

This study makes a methodological contribution to the empirical research on shared mental models by using qualitative techniques to elicit and represent the group's shared mental models. The majority of research that has measured a group's shared mental models has used similarity ratings and Likert-scale questionnaires to elicit the models and then quantitative techniques to calculate similarity among the constructs across participants. In contrast, the methods employed in this research enabled the participants 
to supply their own ideas and terms to describe their understandings of the two domains. The overlap among their responses was determined through content analysis arriving at a degree of sharedness among the ideas expressed to produce the representations of the models. The limits to these methods are discussed in chapter three.

One implication that emerged from this method of measuring shared mental models is that, for the Accountability Group, some distinction seemed to appear between the content of mental models created through real time group discussion and the content of the mental models that were reported at the interview points throughout the life of the project. The methodology in this study was established to capture and measure mental models only through individual interviews. However, the researcher observed the creation of mental models during the meetings that were not reflected in the subsequent interviews. It was expected at the outset of the study that responses group members provided in the interviews would fully reflect the shared understandings that developed in the meetings. In analyzing the data, however, a number of ideas that appeared to the researcher to be emerging mental models in the meetings were not reported in the interview sessions. The most likely reason for these omissions is the length of time that elapsed between events. Group members simply did not retain all the ideas that appeared (through researcher observations) to be shared understandings in the meetings. This discovery suggests that another dimension of shared mental models relates to the strength of the model in terms of retention or true integration into the cognitive schema of individual members. If these emerging shared mental models are not retained over time, are they in fact useful as mental models, in terms of their ability to aid in decision- 
making, sense-making, problem solving, or facilitating information sharing? What must occur in a group's interaction for an idea or concept to be fully integrated into a shared cognitive schema?

As this relates to research and methods, this discovery suggests that future researchers consider using methods that capture not only the similarity of individual cognitive schemas across points in time to measure the degree of sharedness of the ideas in the developing shared mental models, but also the emergent mental models as they are created through interaction. In this way, the researcher would be able to compare the emergent reality-based mental models against the voiced models to identify the aspects of the schemas that are retained from the point of creation to further in the life of the group. It could be that forgetting is a necessary part of group cognition, that not all ideas, even though shared, are necessary for groups to perform their work. On the other hand, the differences in retention or integration between the models that emerge and the models that are reported may be a factor that directly affects the group's performance.

\subsection{Case Study Approach}

In a sense, the case study is a grouping mechanism, where the phenomena of interest exist within the boundary of the case. As such, the emphasis of the case study is on the many components and details of the case, not on the method of inquiry (Arneson \& Query, 2001). The complexity inherent in the case study approach requires multiple data collection methods and multiple analyses. This multiplicity is both a strength and weakness of the case study. In examining the topical concern and foreshadowed problems within a case, a researcher is challenged by the vast amount of data from different 
sources, with different foci, contributing to differing aspects of the case. The researcher works to make sense of the data, to arrive at appropriate interpretations through careful analysis, and to communicate those interpretations in clearly developed assertions about the case. The variety and quantity of the data require extensive sorting, coding, describing, categorizing, and comparing in the analysis stages of the research, but these processes are essential to developing an understanding the foreshadowed problem(s) of the topical area. These data also contribute a tremendous richness to the interpretations about the case not always available through other research approaches.

Using the case study approach for this research enables the examination of an important theoretical topical concern (development of shared mental models) in a real world setting. The case study approach also facilitates the analysis of the foreshadowed problem (the Accountability Group's communication processes) from a variety of lenses (communication themes, functions, roles, channels, rules) within a natural context. Finally, using case study in this research enables new comments to be made about the relationship between small group communication and shared cognition in this group. This relationship has not been studied previously, and the case study findings suggest the need for continued exploration of this relationship in other groups

Any case study, however, is limited by the generalizability of the findings. Although the interpretations and comments made about the case are generated directly from the case data, their transferability to other groups is not assured because they are so closely linked to the context and boundary of the case. Case studies are powerful in communicating the depth and richness of an event or phenomena, but they lack the 
extendibility of findings offered by research methods utilizing variables with strong construct reliability, standardized instruments with proven validity, and large sample sizes. Only through repeated, similar case studies with targeted modifications to variables can some evidence of generalizable findings be obtained

\subsection{Implications for Practice}

As mentioned, a number of studies have tested the relationship between shared mental models and group performance and found correlations between higher degrees of shared thinking and positive group performance (Lim \& Klein, 2006; Marks, Zaccaro, \& Mathieu, 2000; Mathieu, et al., 2000; Mitchell, 1986.) The strong relationship between shared mental models and group or team performance sets the stage for implications of the research for practice reported here. The findings from this study suggest that aspects of a group's communication can influence shared thinking. Thus, groups can employ several tactics through their communication to build shared mental models to improve performance.

The Accountability Group faced an ambiguous, complex problem. They struggled many times in their face-to-face communication to reconcile the various ideas and viewpoints presented by the members and turn them into a coherent work plan. From their struggle to unify their thinking comes the first idea for practice.

Develop the practice of intentionally eliciting the content of each member's mental models about the task throughout the life of the project.

A first step in laying the groundwork to build shared cognition is surfacing the schemas of the individuals in the group. Each group member brings his own notion about 
the work, and these individual schemas may differ tremendously across the group. One practical solution is to write a set of questions or thought prompts designed to elicit the schemas of the individual members and periodically through the group experience take the time to answer those questions. Suggested questions include:

- The decision we need to make is... / The problem we are solving is...

- It is important to include in our thinking and planning.

- $\quad$ Our goal for this project is

- To achieve that goal, we need to do these tasks:

- We will be done with our project when

- An acceptable level of success means accomplishing

- $\quad$ Our group will work best if we

- We need someone to carry out these responsibilities

Group members' responses to these types of prompts will provoke topics and themes for discussion. Employing well-known group discussion tactics such as brainstorming, nominative group technique, reflective thinking, and dialectical inquiry (Pavitt, 1998) will further enhance the discussion generated by these prompts.

The Accountability Group was tasked with resolving a perceived problem of accountability across the library system. However, when each participant was initially asked what problem he was solving, there was a unanimous sense of uncertainty about the problem. Neither could any participant offer any specificity at the beginning of the task force's activities about the tasks they needed to undertake. This situation leads to the second implication from which practitioners may benefit. 
Determine which mental models or which portions of mental models are most critical for success and be sure they are fully developed.

For a complex, novel problem-solving task such as the one the Accountability Group faced, defining the scope of the problem is critical to the group's success. Groups should identify early the mission-critical points of the task and target interaction to clarify those points first. Depending on the nature of the task, project management techniques such as mapping out a critical path or identifying task interdependencies may be useful in identifying which aspects of the group's shared mental models should assume priority.

In this case study, the Executive Committee of the library system ultimately evaluated the Accountability Group's work. As it turned out, the feedback received from that committee had a powerful effect on directing the focus of the group. As influential as any aspect of communication within the group, the information provided by the Executive Committee caused changes in the group's thinking over time, leading to this third idea for practice.

Incorporate the relevant external influences on the group's shared mental models.

Most groups operate within a larger environment. They are often interconnected to other groups or senior administrators within the organization. They are subject to external conditions regarding time, resources, and the changing scope of the task, among many other constraints. As shown in the research here, the external influences on the Accountability Group impacted the group's shared thinking. This finding suggests that groups would be wise to identify the relevant external forces and conditions as early as possible in the life of the group to incorporate that information into the group's own 
developing thinking. Techniques associated with environmental scanning for strategic planning or scenario planning may be effective for this purpose. Preparing a STEEP (social, technological, economic, environmental, and political) analysis that identifies forces in those five areas that may impact the task is a systematic way to identify and then to incorporate external influences into the group's shared thinking (Giesecke, 1998).

Also, groups would be wise to seek input early on in their work from the appropriate administrator or managing group to identify specific constraints on the project. Using a charge to establish the group's scope of work is one way to seek feedback from influential others. However, as shown in this case, the Accountability Group's charge, even though it was approved, was insufficient to elicit all the necessary feedback the group needed to incorporate into their thinking. Just as groups may benefit from the open-ended questions described earlier to clarify the group's own thinking, structured dialogue between the members of the taskforce and the administrator or authority group can raise important issues from outside the group that impact the group's thinking and subsequent work. If the Accountability Group had sought clarification from the Executive Committee about the group's task early, group members may have been able to establish clearer parameters and work more efficiently on the task.

The members of the Accountability Group were all familiar with working on task forces as an organizational unit to accomplish work for the organization. They expressed a shared sense that their experience in the Accountability Group was similar to other groups of which they had been members. And yet, even with past experience, the group 
faced challenges in maximizing effective communication that could be solved with training, which leads to the final implication of this study for the practice.

Small groups should be trained in effective communication practices, as often as needed.

Most members of the Accountability Group expressed an awareness of some group communication meeting norms established in their organization (see Appendix I: Library System Meeting Norms). However, groups should be equipped with more than just a list of norms. Groups need knowledge and training on how to communicate and interact effectively, and would benefit from continued training in these areas. In too many cases, small groups are thrust together within organizations and rushed to perform their task without being given appropriate guidance on the practices and norms that will increase the likelihood of higher group performance and satisfaction. Another problem is that groups form and re-form with shifts in membership. Training a group once, at the beginning of its time together, is insufficient. Instead, organizations should create regular, ongoing training for their groups and teams that include strategies and tactics to:

- encourage positive, open discussion such as brainstorming, nominal group technique, or devil's advocacy;

- facilitate group processes such as preparing agendas, managing meeting time effectively, and collecting outcomes of group discussion and work;

- manage conflict, such as distinguishing between cognitive and affective conflict and then encouraging appropriate speech and language patterns such that the cognitive conflict be productive rather than degenerate to affective conflict; and 
- build listening and thinking skills, such as requiring a minimum period of silence to elapse between conversational turns, or encourage speakers to rephrase the words of others before challenging their positions.

Communication skills, like most other skills sets, do not usually exist fully developed. Such skills often must be introduced through training and then practiced over time. The findings from this study that show a connection between communication and shared mental model development provide yet another argument for the need for groups to be adequately trained in effective communication skills to enhance group performance and improve the experience for each member.

\subsection{Future Research}

This study presents an exploratory look at the nature of small group communication and its impact on shared cognition. Much more work is needed to shed light on an area of inquiry that lies between two established disciplines.

As a single case study this research offers only one small piece of a large, complex puzzle. Future research could apply similar methods used in this case to other groups to add to the propositions outlined here and create more generalizable findings. Other groups could be selected based on a number of factors. First the setting in which the group is situated could be changed. This alteration would amplify the findings to the extent that communication patterns differ across professions or industries. The nature of the work being performed could also be changed. The task performed by the Accountability Group was highly unstructured and unbounded. The findings might vary considerably for a group task requiring greater precision, task interdependency, and a 
stricter performance timeline. The communication channels employed by the group were not found to be an influential factor in this study; however, only two channels were used, and one was clearly dominant. Much research focused on the communication of virtual groups and teams. The research could be mined for findings that might fill in gaps in theory being developed in this line of research as well as employing the methods of this study to virtual groups and groups who use a wide variety of channels to facilitate communication.

Another avenue of research that would contribute to knowledge building in this area would be to study other aspects of small group communication and group interaction that might prove to be influential on shared cognition. For example, an individual's commitment to the group or general group cohesion might have some impact on an individual's desire to interact with the group, thus influencing a mental model on team interaction. Similarly, an individual's commitment to the task or task acceptance might yield interesting results in how that individual factor contributes to the group's interaction and subsequent shared understandings.

A third direction for future research on this question could employ alternative methods to the same question. Instead of a single, qualitative case study, a future study could derive quantitative measures for several communication variables and for mental model similarity and test for possible correlations. This approach has the advantage of capturing a much larger sample size for increased generalizability. 


\section{Appendix A: Solicitation Letter}

July 13,2006

Dear:

I am contacting you to ask for your help. For her dissertation research, my doctoral student, Miriam Matteson, is planning to do a naturalistic study of communication among group members working on a task with the objective of determining how shared mental models develop among team or group members as they accomplish the task. Previous research has indicated that groups who develop shared mental models are usually more effective in their task performance. Her research should identify communication patterns that help or hinder the development of shared mental models and provide guidelines to administrators and group leaders for establishing and using communication as a tool for bringing about more effective resolution of tasks undertaken collaboratively.

We are looking for an organization and group that would be willing to be participants in her study and hope that you will consider letting us study a group within your organization after you have learned more about the project. Briefly, the desired characteristics of the group and task are as follows:

- The group should be small (3 to 10 members).

- They should be working on a task of reasonable complexity.

- The task should not be a routine task so that members have already devised ways of interacting and doing the task.

- Task should be in a library or archives setting.

- Accomplishing the task should be likely to take several group meetings and interim communications.

- The group should be starting on the task from August 1 through early fall, and preferably completing it by December 30, 2006. Note: Tasks that are likely to take longer are still a possibility, but Miriam may study only the early stages.

- The task should have an end-state, with perhaps a deliverable, e.g., a report or service.

The attached Research Project Summary provides more detail, including information about anonymity of individual and institution and privacy concerns. What Miriam needs to do with the group for research purposes is indicated in the data collection section. For the most part, her data-gathering would be relatively unobtrusive. She needs to attend and audio record the group's meetings and receive any messages exchanged among the group members about the task, including formal documents, such as minutes and agendas. For the latter, she could just be added to any group e-mail exchange. In addition, and this is where her data-gathering becomes obvious, (a) she needs to interview each group member three times over the course of the project (about an hour each time) for the purpose of identifying his or her mental models of the task 
(and changes over time) and (b) she needs to have the group members report briefly any task-related communications that occur outside the meetings, e.g., on an elevator. For the latter she will ask them to fill out an e-mail template providing some brief information.

Nothing is really known about how groups develop shared mental models so her research will be a significant contribution in opening that black box and will help in establishing some management guidelines for groups. Her research is particularly important in archives and libraries since we have so little empirical research about management in these types of organizations and we are increasingly relying on groups to undertake major projects.

I hope that you can help us to identify a group and task that we can study. If you think you have one, please contact me or Miriam, and we can discuss the possibility and answer any questions you may have. My phone (301-405-2047) and our e-mail addresses (whitemd@umd.edu and matteson@umd.edu) are noted. In addition to Miriam's summary, I am including a draft of the U. of Maryland's IRB form, which we would like each group member to sign; it clearly spells out that participation is voluntary and describes the individual's rights and our expectations of him or her. This kind of research is always difficult because it must be planned in advance of identifying an institution and group. Her research has been approved by her dissertation committee; identifying and obtaining the participation of an appropriate group and task is an important next step. Thank you in advance. I am sending this information to you both electronically and via regular mail since I am not sure which format is most useful for you.

For your information, Miriam is a mature doctoral student at CLIS whose major teaching and research interests are management and organizational communication; she has experience in academic libraries.

Sincerely,

Marilyn Domas White Associate Professor

Enclosures 


\title{
Appendix B: Institutional Review Board Approval and Extensions
}

\author{
。 \\ G. UNIVERSITY OF \\ INSTITUTIONAL REVIEW BOARD \\ MEMORANDUM \\ Application Approval Notification \\ To: \\ From: \\ Re: \\ Approval Date: \\ Expiration Date: \\ Type of Application: \\ Type of Research: \\ Type of Review \\ For Application: \\ Marilyn D. White \\ Miriam L. Matteson \\ College of Information Studies \\ Roslyn Edson, M.S., CIP Da \\ IRB Manager \\ University of Maryland, College Park \\ IRB Application Number: 06-0413 \\ Project Title: "The Impact of Group Interaction on Shared \\ Cognition: An Analysis of Small Group Communication" \\ September 1, 2006 \\ September 1, 2007 \\ New Project \\ Nonexempt \\ (Plcase note: This research does not qualify for exempt review because \\ the interview responses are person-identifiable until the identifiers are \\ destroyed and the disclosure of some of the responses outside the \\ research could be damaging to a subject's reputation and/ar \\ enployability. For example, team members may disclose negative \\ information about their co-worker or supervisor's involvement in a group \\ project. The confidentiality procedures reduce the risks to subjects but do \\ not affect the nonexempt status of the research.) \\ Expedited
}

The University of Maryland, College Park Institutional Review Board (IRB) approved your IRB application. The research was approved in accordance with 45 CFR 46, the Federal Policy for the Protection of Human Subjects, and the University's IRB policies and procedures. Please reference the above-cited IRB application number in any future communications with our office regarding this research.

Recruitment/Consent: For research requiring written informed consent, the IRB-approved and stamped informed consent document is enclosed. The IRB approval expiration date has been stamped on the informed consent document. Please keep copies of the consent forms used for this research for three years after the completion of the research.

Continuing Review: If you intend to continue to collect data from human subjects or to analyze private, identifiable data collected from human subjects, after the expiration date for this approval (indicated above), you must submit a renewal application to the IRB Office at least 30 days before 
Modifications: Any changes to the approved protocol must be approved by the IRB before the change is implemented, except when a change is necessary to eliminate apparent immediate hazards to the subjects. If you would like to modify the approved protocol, please submit an addendum request to the IRB Office. The instructions for submitting a request are posted on the IRB web site at: htto:/wurw, umresearchumdiodu/RB/iro Addendum\%20Protocol,htm.

Unanticipated Problems Involving Risks: You must promptly report any unanticipated problems involving risks to subjects or others to the IRB Manager at 301-405-0678 or rediangumresearch.umd,edu.

Student Researchers: Unless otherwise requested, this IRB approval document was sent to the Principal Investigator (PD). The PI should pass on the approval document or a copy to the student researchers. This IRB approval document may be a requirement for student researchers applying for graduation. The IRB may not be able to provide copies of the approval documents if several years have passed since the date of the original approval.

Additional Information: Please contact the IRB Office at 301-405-4212 if you bave any IRBrelated questions or concerns. 


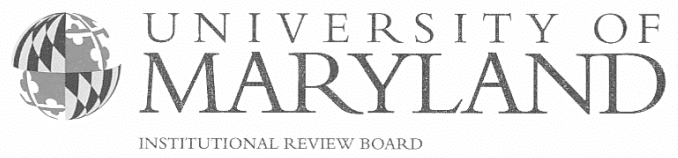

2100 Blair Lee Building

College Park, Maryland 20742-5121

301.405 4212 TEL 301.314 .1475 FAX

irb@deans.umd.edu

www.umresearch.umd.edu/IRB

July 24, 2007

\section{MEMORANDUM}

Renewal Application Approval Notification

To:

Dr. Marilyn D. White

Miriam L. Matteson

College of Information Studies

From:

Roslyn Edson, M.S., CIP, pa

IRB Manager

University of Maryland, College Park

Re:

IRB Application Number: 06-0413

Project Title: "The Impact of Group Interaction on Shared Cognition: An Analysis of Small Group Communication"

Approval Date:

July 20, 2007

Expiration Date:

July 20, 2008

Type of Application:

Renewal

Type of Research:

Non-exempt

Type of Review

For Application:

Expedited

The University of Maryland, College Park Institutional Review Board (IRB) approved your IRB application. The research was approved in accordance with 45 CFR 46, the Federal Policy for the Protection of Human Subjects, and the University's IRB policies and procedures. Please reference the above-cited IRB application number in any future communications with our office regarding this research.

Recruitment/Consent: For research requiring written informed consent, the IRB-approved and stamped informed consent document is enclosed. The IRB approval expiration date has been stamped on the informed consent document. Please keep copies of the consent forms used for this research for three years after the completion of the research.

Continuing Review: If you want to continue to collect data from human subjects or to analyze private, identifiable data collected from human subjects after the approval expiration date indicated above, you must submit a renewal application to the IRB Office at least 30 days before the approval expiration date.

Modifications: Any changes to the approved protocol must be approved by the IRB before the change is implemented, except when a change is necessary to eliminate apparent immediate hazards to the subjects. If you would like to modify the approved protocol, please submit an addendum request to the IRB Office. The instructions for submitting an addendum request are posted on the IRB website at: http:/Wwww tumresearchumd edu/liR/irb Adidendum\%20Protocollhtm.

(Continued) 
Unanticipated Problems Involving Risks: You must promptly report any unanticipated problems involving risks to subjects or others to the IRB Manager at 301-405-0678 or redson@umresearch.umd.edu.

Student Researchers: Unless otherwise requested, this IRB approval document was sent to the Principal Investigator (PI). The PI should pass on the approval document or a copy to the student researchers. This IRB approval document may be a requirement for student researchers applying for graduation. The IRB may not be able to provide copies of the approval documents if several years have passed since the date of the original approval.

Additional Information: Please contact the IRB Office at 301-405-4212 if you have any IRB-related questions or concerns. 
2100 Lee Building

College Park, Maryland 20742-5121 301.405.4212 TEL 301.314.1475 FAX

irb@deans.umd.edu

www. umresearch.umd.edu/IRB

\section{MEMORANDUM}

Application Approval Notification

\begin{tabular}{|c|c|}
\hline To: & $\begin{array}{l}\text { Dr. Marilyn D. White } \\
\text { Miriam L. Matteson } \\
\text { College of Information Studies }\end{array}$ \\
\hline From: & $\begin{array}{l}\text { Roslyn Edson, M.S., CIP } / 3 \text { for } / \\
\text { IRB Manager } \\
\text { University of Maryland, College Park }\end{array}$ \\
\hline Re: & $\begin{array}{l}\text { IRB Application Number: \# 06-0413 } \\
\text { Project Title: "The Impact of Group Interaction on Shared Cognition: } \\
\text { An Analysis of Small Group Communication" }\end{array}$ \\
\hline Approval Date: & July 10, 2008 \\
\hline Expiration Date: & July 20, 2009 \\
\hline Type of Application: & Renewal \\
\hline Type of Research: & Non-Exempt \\
\hline $\begin{array}{l}\text { Type of Review } \\
\text { For Application: }\end{array}$ & Expedited \\
\hline
\end{tabular}

The University of Maryland, College Park Institutional Review Board (IRB) approved your IRB application. The research was approved in accordance with 45 CFR 46, the Federal Policy for the Protection of Human Subjects, and the University's IRB policies and procedures. The IRB approves waiver of signed informed consent as per criteria in 45 CFR 46.116(d). Please reference the above-cited IRB application number in any future communications with our office regarding this research.

Recruitment/Consent: For research requiring written informed consent, the IRB-approved and stamped informed consent document is enclosed. The IRB approval expiration date has been stamped on the informed consent document. Please keep copies of the consent forms used for this research for three years after the completion of the research.

Continuing Review: If you intend to continue to collect data from human subjects or to analyze private, identifiable data collected from human subjects, after the expiration date for this approval (indicated above), you must submit a renewal application to the IRB Office at least 30 days before the approval expiration date.

Modifications: Any changes to the approved protocol must be approved by the IRB before the change is implemented, except when a change is necessary to eliminate apparent immediate hazards to the subjects. If you would like to modify the approved protocol, please submit an addendum request to the IRB Office. The instructions for submitting a request are posted on the IRB web site at: http://www.umresearch.umd.edu/IRB/irb_Addendum\%20Protocol.htm. 
Unanticipated Problems Involving Risks: You must promptly report any unanticipated problems involving risks to subjects or others to the IRB Manager at 301-405-0678 or

redson@umresearch.umd.edu.

Student Researchers: Unless otherwise requested, this IRB approval document was sent to the Principal Investigator (PI). The PI should pass on the approval document or a copy to the student researchers. This IRB approval document may be a requirement for student researchers applying for graduation. The IRB may not be able to provide copies of the approval documents if several years have passed since the date of the original approval.

Additional Information: Please contact the IRB Office at 301-405-4212 if you have any IRB-related questions or concerns. 


\section{Appendix C: Interview Protocol for Accountability Group}

\section{Introductory Questions}

- How did you come to be a member of this group?

- For appointees: Why do you think you were appointed to this group?

- For volunteers: Why did you volunteer for this group?

- Would you describe the problem that your group is working on?

\section{Task Questions}

- Does this problem suggest some particular task(s) the group should perform?

- What do you think the objectives/aims/goals of the group should be? Where should your effort be directed?

- How would you go about meeting these objectives?

- How will you recognize success in that meeting these objectives?

- Do you foresee any difficulties in meeting these objectives?

- What is likely to be easy about meeting these objectives?

- Is there a sequence you think the group should follow to meet these objective?

\section{Team Interaction Questions}

- How familiar you are with each member of the group? (very, somewhat, not very, not at all)

- For those with whom you are somewhat or very familiar, how did you become familiar with them?

- How should the work be divided? 
- What should meeting time be used for? How should meetings be structured? Who should meet, when?

- How should decisions be made?

- What should be done if there is disagreement?

- How should the group be organized?

- What rules of operation [expectations] about the group do you think need to be established? How?

- Knowing what you know about the people in this group, how well do you think this particular group is going to function? Why?

Responding with Yes, No, Somewhat, or Don't know, do you think that

- Team members will work well together.

- Team members will trust each other.

- Team members will communicate openly with each other.

- Team members will back each other up in carrying out team tasks.

- Team members are similar to each other in terms of personality/ temperament.

- Team members are similar to each other in terms of abilities

- Team members are aware of other team members' abilities.

- Team members will treat each other as friends.

- The team will be effective. 


\section{Appendix D: Data Analysis Matrix}

\begin{tabular}{|c|c|c|c|}
\hline Research questions & Data collected & Coding for data & Purpose of the analysis \\
\hline $\begin{array}{l}\text { What themes emerge } \\
\text { from the group } \\
\text { interaction? }\end{array}$ & $\begin{array}{l}\text { Group communications } \\
\text { data, including transcripts } \\
\text { from group meetings; e- } \\
\text { mail messages; field } \\
\text { notes; other documents }\end{array}$ & $\begin{array}{l}\text { Content analysis, using } \\
\text { constant comparison } \\
\text { approach to identify } \\
\text { topics discussed by two } \\
\text { or more members of the } \\
\text { group for a sustained } \\
\text { period of time. }\end{array}$ & $\begin{array}{l}\text { To identify the content of } \\
\text { the group interaction and } \\
\text { then to track whether it } \\
\text { appears in shared mental } \\
\text { models. }\end{array}$ \\
\hline $\begin{array}{l}\text { Are some functions of } \\
\text { communication messages } \\
\text { more influential than } \\
\text { others in developing } \\
\text { shared mental models? } \\
\text { Do the different } \\
\text { functions of } \\
\text { communication serve } \\
\text { different purposes in } \\
\text { developing the shared } \\
\text { models? }\end{array}$ & $\begin{array}{l}\text { Group communications } \\
\text { data, including transcripts } \\
\text { from group meetings; e- } \\
\text { mail messages; field } \\
\text { notes; other documents }\end{array}$ & $\begin{array}{l}\text { Use Bales' Interaction } \\
\text { Process Analysis (IPA) } \\
\text { codes. }\end{array}$ & $\begin{array}{l}\text { To create a profile of the } \\
\text { group's communication } \\
\text { messages across the } \\
\text { categories, and by } \\
\text { specific focus (task or } \\
\text { socioemotional), and then } \\
\text { to consider whether their } \\
\text { communication functions } \\
\text { impact the development } \\
\text { of mental models. }\end{array}$ \\
\hline $\begin{array}{l}\text { Are some group } \\
\text { communication roles } \\
\text { more influential in } \\
\text { developing shared mental } \\
\text { models? } \\
\text { Do the different roles } \\
\text { serve different purposes } \\
\text { in developing the shared } \\
\text { models? }\end{array}$ & $\begin{array}{l}\text { Group communications } \\
\text { data, including transcripts } \\
\text { from group meetings; e- } \\
\text { mail messages; field } \\
\text { notes; other documents }\end{array}$ & $\begin{array}{l}\text { Examine group } \\
\text { communication, } \\
\text { segmented to the unit of } \\
\text { an agenda item, and } \\
\text { assign a role(s) using the } \\
\text { Benne and Sheats (1948) } \\
\text { typology of functional } \\
\text { group roles, to the } \\
\text { dominant behaviors in } \\
\text { each segment. }\end{array}$ & $\begin{array}{l}\text { To identify what roles are } \\
\text { enacted by group } \\
\text { members and then to } \\
\text { examine which roles are } \\
\text { influential on the } \\
\text { development of mental } \\
\text { models. }\end{array}$ \\
\hline $\begin{array}{l}\text { What channels of } \\
\text { communication are used? } \\
\text { For what purposes? }\end{array}$ & $\begin{array}{l}\text { Group communications } \\
\text { data, including transcripts } \\
\text { from group meetings; e- } \\
\text { mail messages; field } \\
\text { notes; other documents }\end{array}$ & $\begin{array}{l}\text { Code communication by } \\
\text { channel of } \\
\text { communication. }\end{array}$ & $\begin{array}{l}\text { To examine how the } \\
\text { group used different } \\
\text { channels of } \\
\text { communication and to } \\
\text { examine if the choice of } \\
\text { communication channel } \\
\text { interacts with any of the } \\
\text { other communication } \\
\text { variables }\end{array}$ \\
\hline
\end{tabular}




\begin{tabular}{llll}
\hline $\begin{array}{l}\text { What group } \\
\text { communication rules } \\
\text { emerge? }\end{array}$ & $\begin{array}{l}\text { Group communications } \\
\text { data, including transcripts } \\
\text { from group meetings; e- } \\
\text { mail messages; field } \\
\text { notes; other documents }\end{array}$ & $\begin{array}{l}\text { Apply Shimanoff's } \\
(1988) \text { schema to record } \\
\text { reoccurring behaviors } \\
\text { and identify rules }\end{array}$ & $\begin{array}{l}\text { To show the recurring } \\
\text { patterns that reveal } \\
\text { normative } \\
\text { communication } \\
\text { behaviors, and then to } \\
\text { What sanctions are }\end{array}$ \\
$\begin{array}{l}\text { employed if rules are } \\
\text { violated? }\end{array}$ & & $\begin{array}{l}\text { assess whether some } \\
\text { rules influence mental } \\
\text { models. }\end{array}$
\end{tabular}

What does the team
develop shared models
about?

For a particular model, what components of the model do they identify at different stages of task performance?

How is the content and structure "shared"?

\section{Interviews with participants at different times during the project}

Content analysis applied

interview responses

Identify the degree of sharedness among group members by comparing responses to specific questions, and also collapsing questions into sub-domains/domains and comparing similarity at that level. Repeated for all three interview times.

Compare the group's shared mental models across the three data points.

\section{How does group} communication contribute to the development of shared mental model(s)?

\section{Interaction data and interview data}

$\begin{array}{ll}\begin{array}{l}\text { 1) Examine the group's } \\ \text { mental models at times } 2 \\ \text { and } 3 \text { to identify changes } \\ \text { in the model from the } \\ \text { previous times. }\end{array} & \begin{array}{l}\text { To integrate the } \\ \text { mental model } \\ \text { representations to } \\ \text { understand how } \\ \text { communication } \\ \text { contributes to mental } \\ \text { model development }\end{array} \\ \begin{array}{l}\text { 2) Analyze the } \\ \text { interaction data to }\end{array} \\ \begin{array}{l}\text { identify how the five } \\ \text { communication processes } \\ \text { may have contributed to } \\ \text { the change in the mental } \\ \text { model. }\end{array}\end{array}$

To describe the shared mental models (task and team) that develop among the group and trace changes in each model over time. This analysis also provides data for interpretations about how the models are influenced by the communication events. 


\section{Appendix E: Benne \& Sheats (1948) Functional Role Definitions}

\begin{tabular}{|c|c|}
\hline \multicolumn{2}{|r|}{ Task roles } \\
\hline Initiator-contributor & $\begin{array}{l}\text { Suggests or proposes to the group new ideas or a changed way of regarding } \\
\text { the group problem or goal. }\end{array}$ \\
\hline Information seeker & $\begin{array}{l}\text { Asks for clarification of suggestions made in terms of their factual adequacy, } \\
\text { for authoritative information and facts pertinent to the problem being } \\
\text { discussed. }\end{array}$ \\
\hline Opinion seeker & $\begin{array}{l}\text { Asks not primarily for the facts of the case but for a clarification of the values } \\
\text { pertinent to what the group is undertaking or of values involved in a } \\
\text { suggestion made or in alternative suggestions. }\end{array}$ \\
\hline Information giver & $\begin{array}{l}\text { Offers facts or generalizations which are "authoritative" or relates his own } \\
\text { experience pertinently to the group problem. }\end{array}$ \\
\hline Opinion giver & $\begin{array}{l}\text { States his belief or opinion pertinently to a suggestion made or to alternative } \\
\text { suggestions. }\end{array}$ \\
\hline Elaborator & $\begin{array}{l}\text { Spells out suggestions in terms of examples or developed meanings, offers a } \\
\text { rationale for suggestions previously made and tries to deduce how an idea or } \\
\text { suggestion would work out if adopted by the group. }\end{array}$ \\
\hline Coordinator & $\begin{array}{l}\text { Shows or clarifies the relationships among various ideas and suggestions, } \\
\text { tries to pull ideas and suggestions together or tries to coordinate the activities } \\
\text { of various members or sub-groups. }\end{array}$ \\
\hline Orienter & $\begin{array}{l}\text { Defines the position of the group with respect to its goals by summarizing } \\
\text { what has occurred, points to departures from agreed upon directions or goals, } \\
\text { or raises questions about the direction which the group discussion is taking. }\end{array}$ \\
\hline Evaluator-critic & $\begin{array}{l}\text { Subjects the accomplishment of the group to some standard or set of } \\
\text { standards of group-functioning in the context of the-group task. }\end{array}$ \\
\hline Energizer & $\begin{array}{l}\text { Prods the group to action or decision, attempts to stimulate or arouse the } \\
\text { group to "greater" or "higher quality" activity. }\end{array}$ \\
\hline Procedural-technician & $\begin{array}{l}\text { Expedites group movement by doing things for the group-performing } \\
\text { routine tasks, e.g., distributing materials, or manipulating objects for the } \\
\text { recording machine, etc. }\end{array}$ \\
\hline Recorder & $\begin{array}{l}\text { Writes down suggestions, makes a record of group decisions, or writes down } \\
\text { the product of discussion }\end{array}$ \\
\hline
\end{tabular}


Encourager

Harmonizer

Compromiser

Gate keeper and expediter

Standard setter or ego ideal

Group-observer and commentator

Follower
Praises, agrees with and accepts the contribution of others.

Mediates the differences between other members, attempts to reconcile disagreements.

Operates from within a conflict in which his idea or position is involved. He may offer compromise by yielding status, admitting his error, by disciplining himself to maintain group harmony, or by "coming half-way" in moving along with the group.

Attempts to keep communication channels open by encouraging or facilitating the participation of others, or by proposing regulation of the flow of communication.

Expresses standards for the group to attempt to achieve in its functioning or applies standards in evaluating the quality of group processes.

Keeps records of various aspects of group process and feeds such data with proposed interpretations into the group's evaluation of its own procedures.

Goes along with the movement of the group, more or less passively accepting the ideas of others, serving as an audience in group discussion and decision.

\section{Individual roles}

\section{Aggressor}

Blocker

Recognition-seeker

Self-confessor

Playboy
Deflates the status of others, expresses disapproval of the values, acts or feelings of others, attacks the group or the problem it is working on, jokes aggressively shows envy for another's contribution by trying to take credit for it, etc.

Tends to be negativistic and stubbornly resistant, disagreeing and opposing without or beyond "reason" and attempting tor bring back an issue after the group has rejected or by-passed it.

Works in various ways to call attention to himself, whether through boasting, reporting on personal achievements, acting in unusual ways, struggling to prevent his being placed in an "inferior" position, etc.

Uses the audience opportunity which the group setting provides to express personal, non-group oriented, "feeling", "insight", "ideology", etc.

Makes a display of his" lack of involvement in the group's processes. This may take the form of cynicism, nonchalance, horseplay, and other more or less studied forms of "out of field" behavior. 
Dominator

Help-seeker

Special interest pleader
Tries to assert authority or superiority in manipulating the group or certain members of the group.

Attempts to call forth "sympathy" response from other group members or from the whole group, whether through expressions of insecurity, personal confusion or depreciation of himself beyond "reason."

Speaks for the "small business man", the "grass roots" community, the "housewife", "labor", etc., usually cloaking his own prejudices or biases in the stereotype which best fits his individual need. 


\section{Appendix F: Meeting Details}

\begin{tabular}{lllll}
\hline Meeting & Date & Place & Length & Attendees \\
\hline Meeting 1 & October $3^{\text {rd }}, 2006$ & Library Branch OR & 2 hours & All participants \\
Meeting 2 & January $23^{\text {rd }}, 2007$ & Library Branch NR & 2 hours & P2, P3, P4, and P6 \\
Meeting 3 & April $19^{\text {th }}$ 2007 & Library Branch LB & 1 hour & $\begin{array}{l}\text { P1, P2 (half), P3, P4, P5 } \\
\text { (half), P6 }\end{array}$ \\
Meeting 4 & ${\text { June } 6^{\text {th }}, 2007}$ & Library Branch NR & 2 hours & P1-P6 \\
\hline
\end{tabular}

Note. Branch names not included for confidentiality. 


\section{Appendix G: Analysis of Transitions and Variables Influencing Task Mental Model}

\begin{tabular}{|c|c|c|c|c|c|c|c|c|c|}
\hline \multirow{2}{*}{\multicolumn{4}{|c|}{ Transition }} & \multicolumn{6}{|c|}{ Influence } \\
\hline & & & & \multicolumn{5}{|c|}{ Communication variables $^{d}$} & \multirow[b]{2}{*}{ Other $^{\mathrm{e}}$} \\
\hline No. & Component $^{\mathrm{a}}$ & Status $^{\mathrm{b}}$ & Time $^{c}$ & Theme & Function & Role & Rule & Channel & \\
\hline 1 & 1.4 & $S$ & $1-2$ & X & & & & & \\
\hline 2 & 1.6 & S & $1-2$ & $\mathrm{X}$ & & & & & \\
\hline 3 & 2.2 & S & $1-2$ & $\mathrm{X}$ & & $\mathrm{X}$ & & & \\
\hline 4 & 2.3 & S & $1-2$ & $\mathrm{X}$ & & & & & \\
\hline 5 & 2.4 & S & $1-2$ & $\mathrm{X}$ & & & & & \\
\hline 6 & 3.2 & S & $1-2$ & & & $\mathrm{X}$ & $\mathrm{X}$ & & \\
\hline 7 & 4.1 & S & $1-2$ & $\mathrm{X}$ & & & & & $\mathrm{E}$ \\
\hline 8 & 1.5 & S & $2-3$ & $\mathrm{X}$ & & & & & (E) \\
\hline 9 & 2.5 & S & $2-3$ & $\mathrm{X}$ & & & & & $\mathrm{E}$ \\
\hline 10 & 3.3 & S & $2-3$ & & & $X$ & & & \\
\hline 11 & 1.6 & $\mathrm{~N}$ & $2-3$ & $\mathrm{X}$ & & & & & \\
\hline 12 & 4.2 & S & $1-2$ & & & & & & E \\
\hline 13 & 5.3 & S & $1-2$ & & & & & & $\mathrm{E}$ \\
\hline 14 & 5.1 & S & $1-2$ & & & & & & $\mathrm{U}$ \\
\hline 15 & 6.1 & S & $1-2$ & & & & & & $\mathrm{U}$ \\
\hline 16 & 6.2 & S & $1-2$ & & & & & & $\mathrm{U}$ \\
\hline 17 & 2.2 & S & $2-3$ & & & & & & $\mathrm{E}$ \\
\hline 18 & 5.3 & W & $2-3$ & & & & & & E \\
\hline 19 & 4.1 & $\mathrm{~N}$ & $2-3$ & & & & & & $\mathrm{U}$ \\
\hline 20 & 5.1 & W & $2-3$ & & & & & & $\mathrm{U}$ \\
\hline 21 & 6.1 & $\mathrm{~W}$ & $2-3$ & & & & & & $\mathrm{U}$ \\
\hline 22 & 6.2 & $\mathrm{~S}$ & $2-3$ & & & & & & $\mathrm{U}$ \\
\hline a & $\begin{array}{l}\text { Numbers are cc } \\
\mathrm{W}=\text { Weaken. }\end{array}$ & omponen & number & Table & 1, the com & ent & ; $=$ & ngthen; $\mathrm{N}$ & Neutral \\
\hline b & Numbers denot & te intervi & s, e.g. & $-2=$ betv & en first an & econd & view. & & \\
\hline c & For communica & ation vari & bles, an & $\mathrm{X}$ indicate & that it infl & aced th & nsition. & & \\
\hline d & exter & 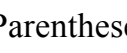 & . & 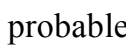 & tor. U & now & & & \\
\hline
\end{tabular}




\section{Appendix H: Analysis of Transitions and Variables Influencing Team Interaction Model}

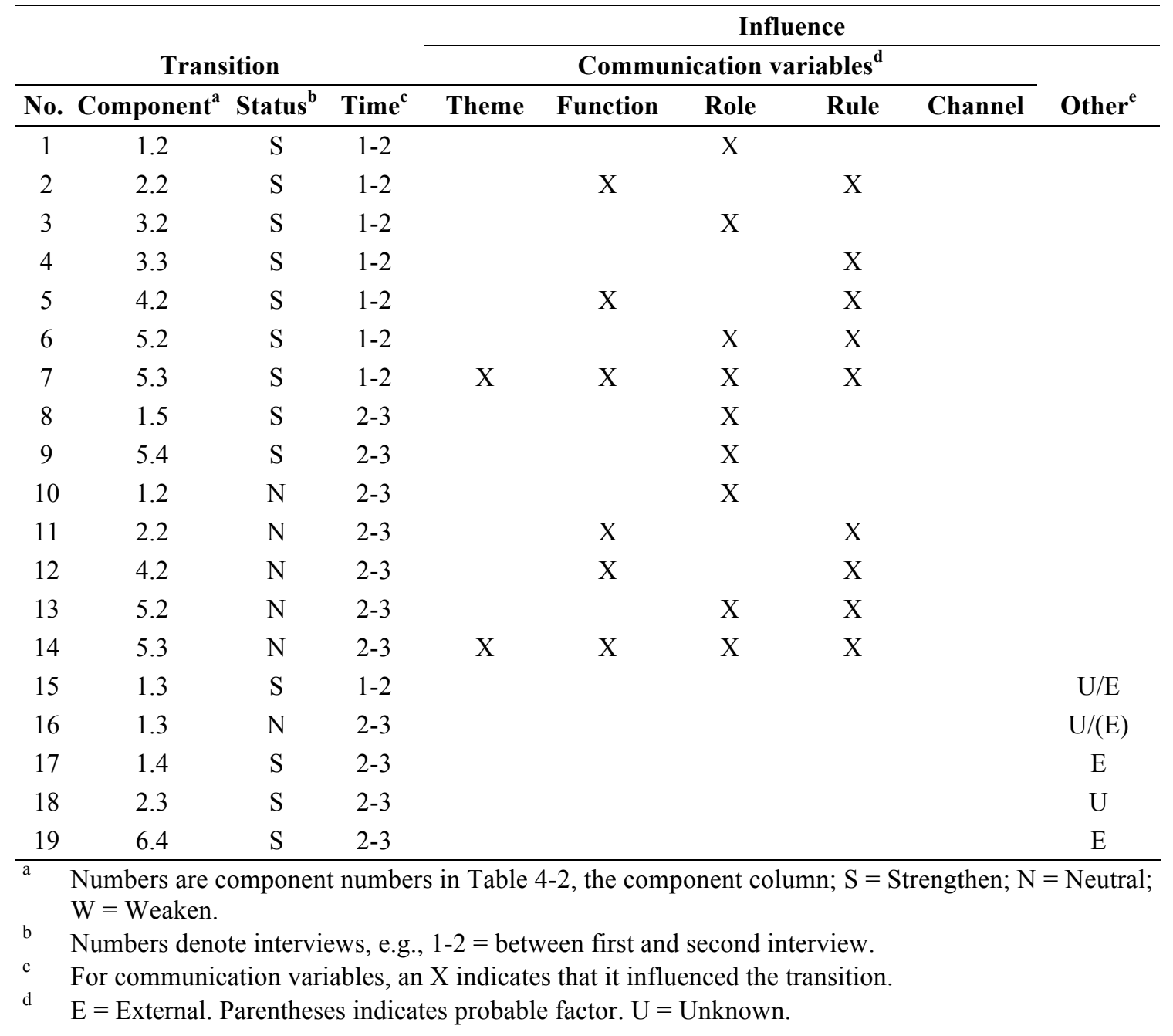




\section{Appendix I: Library System Meeting Norms}

- Start/end on time

- No sidebar meetings

- Everyone participate

- Respect each other

- Table/Parking lot for future discussions

- Listen

- Don't interrupt

- Respect confidentiality

- Challenge assumptions and risk personal discomfort to provide opportunities to learn

- Abide by group decisions and support those decisions with professional behavior

- Have an attitude of trust 


\section{Appendix J: Accountability Group Charge}

The charge of our work group is to define "accountability" and to determine if it should be incorporated as a core value in our library system's mission statement. If it is determined that the System wants to adopt Accountability as one of its guiding principles in how we provide excellence in Government, our charge would be expanded to include looking at ways in which to communicate to staff why this value is crucial to our mission and how adhering to accountability performance standards can help us achieve success. 


\section{Appendix K: Accountability Cohort Report - First Draft}

April 10, 2007

Cohort Members: [P3, P1, P4. P2, P5, P6].

Administrative Liaison, [P7].

Miriam Matteson, University of MD College of Information Studies

The charge of this cohort was to address the issue of Accountability in [the library system]. The group considered the following components:

- What is accountability?

- Is accountability a problem in [the library system]?

- What role does accountability play in making an organization successful?

- Is accountability important enough to make it a core value in how we deliver internal and external customer service?

- Can accountability be trained to?

- How do we educate staff on the importance of accountability?

- What can we put in place to hold staff accountable?

- How do we give our managers and our staff the tools they need, e.g., time and support, to help them be accountable?

The Accountability Cohort met several times in the fall of 2006. Most of our work has been conducted via e-mail. Initial sessions focused on trying to define "accountabililty" and to frame it within the context of a charge. The group struggled with the more philosophical aspects of the charge since it wasn't something that was easy to break into pieces and assign work duties to. Nevertheless, we felt that being accountable 
was crucial to the delivery of quality customer service. We discussed and tried to define each of the bulleted items:

- What is accountability: "Setting appropriate and reachable organizational goals and focusing on the work that must be done to reach those goals; communicating the goals and tasks to others; clarifying expectations and defining roles and responsibilities; establishing meaningful measurements of success; fostering effective feedback loops. Accountability requires individuals to dedicate themselves to work toward the organization's goals, taking responsibility for their behavior, their work and their outcome. It is an essential component in a successful career and a necessary element in a productive and efficient work environment." (From the Air Force outline of Accountability.)

- Is Accountability a problem in [the library system]? In June of 2006, at a Public Services Manager's meeting that focused on performance issues, accountability was identified as an area in which we needed to improve.

- What role does accountability play in making an organization successful?

Accountability and performance play a huge role in the success of any organization. In government, it's how departments deliver the best possible value for taxpayers and achieve ever higher levels of service. Robert Staub reporting on "Accountability and its role in the workplace" (see The Business Journal, January 14, 2005) stated that "Accountability is a systemic issue and must be understood in terms of a systems approach if it is to really work in any . . organization. It is a system of individuals, linked in a chain of mutuality, 
taking personal and group responsibility to achieve something meaningful - the mission of the ... organization."

- Is accountability important enough to make it a core value in how we deliver internal and external customer service? The Accountability Cohort believes that it is. In as much as it is one of [the county's] Nine Guiding Principles, it is a cornerstone in how we provide excellence in Government.

- Can Accountability be trained to? The Cohort feels that Accountability should play a part in every training that is offered in the [library system]. We may not train directly to it, but accountability is implied in all that we do.

- How do we educate staff on the importance of accountability? As mentioned above, by making accountability a part of all staff training. In addition, managers and administrators should role model the behaviors they expect in those they supervise. Talking about the importance of accountability should be a part of every staff meeting so that it becomes inculcated into the culture of the branch/unit.

- What can we put in place to hold staff accountable? Performance standards should be in all [Performance Development Plans].

- How do we give our managers and our staff the tools they need, e.g., time and support, to help them be accountable? Administrators/Managers must set realistic timetables for the accomplishment of work and provide the necessary support to make staff successful. Because accountability is systemic, we rely on each other, other units and sometimes other departments to complete our work. 
Robert Staub, quoted earlier, refers to this as the "Chain of Accountability." (Business Journal, January 14, 2005.) 


\section{Appendix L: Accountability Cohort Report - Final Draft}

July 16,2007

Cohort Members: [P3, P1, P4. P2, P5, P6].

Administrative Liaison, [P7].

Miriam Matteson, University of MD College of Information Studies

\section{Recommendations}

- All [library system] units (branches and offices) will adopt the Air Force definition for accountability:

Setting appropriate and reachable organizational goals and focusing on the work that must be done to reach those goals; communicating the goals and tasks to others; clarifying expectations and defining roles and responsibilities; establishing meaningful measurements of success; and fostering effective feedback loops. Accountability requires individuals to dedicate themselves

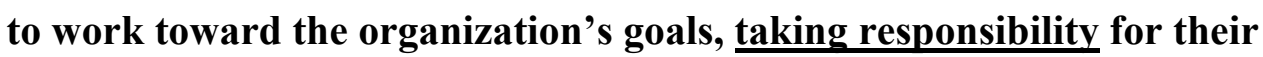
behavior, their work, and their outcome. It is an essential component in a successful career and a necessary element in a productive and efficient work environment.

- Each unit will develop a plan to demonstrate accountability in two to three work areas specific to their unit. This could be included as a separate section in the annual work plan. Possible topics could include:

- Provide courteous and prompt telephone service

- Greet all customers 
- Arrive promptly at work

- Arrive to the public services desks on time

- Respond promptly to internal customers' requests

- Provide full information in a timely manner to staff

- Get new materials to customers within 48 hours and hold materials to customers within 24 hours

- Whenever possible, respond to e-mail and voice mail within 48 hours

- Limit the use of bcc's when writing e-mail (be transparent)

- If an issue arises, let the person(s) who can do something about it know immediately

- Take ownership in the success of communication

- Take ownership in the success of the system, team, branches

- Take ownership in delivering quality customer service

- [Performance Development Plans] for ALL positions and levels will be posted on the Intranet.

- All staff will be given the time, resources and support needed in order to be successful in achieving accountability.

- Implement the 360-degree appraisal for Managers/Administrators.

- Accountability should be stressed in the NEW Customer Services Manual.

- All staff are responsible for achieving the outcomes of [the library system's] goals. 


\section{Accountability Measurements}

- At least $95 \%$ of staff will earn a "meets expectations" or above on [Performance Development Plans] and [Standards of Service].

- Comments and Suggestions Forms should be consistently forwarded to Library Administration. All managers should use these comments and suggestions, and [the library system's] responses to those comments, as an additional tool for coaching and training staff.

- Managers will use [Performance Development Plans] and [Standards of Service] with staff to ensure that they understands the importance of accountability to external and internal customer satisfaction. In addition, managers will engage in ongoing interaction with their staffs where communication is encouraged and expectations are clarified.

- All staff should read and have thorough understanding of the New Customer Services Manual. All staff will be required to sign off that they have read and understand the manual.

- Use 360 Degree appraisals for Managers and Administrators. 


\section{References}

Aldag, R. J., \& Fuller, S. R. (1993). Beyond fiasco: A reappraisal of the groupthink phenomenon and a new model of group decision processes. Psychological Bulletin, 113(3), 533-552.

Allard-Poesi, F. (1998). Representations and influence processes in groups: Towards a socio-cognitive perspective on cognition in organization. Scandinavian Journal of Management, 14(4), 395-420.

Andres, H. P. (2006). The impact of communication medium on virtual team group process. Information Resources Management Journal, 19, 1-17.

Arneson, P., \& Query, J., Jim L. (2001). The case study: Revitalizing a nonprofict health organization. In S. L. Herndon \& G. L. Kreps (Eds.), Qualitative research: Applications in organizational life (2nd ed., pp. 151-169). Cresskill, NJ: Hampton Press.

Bales, R. F. (1951). Interaction process analysis: A method for the study of small groups. Cambridge, MA: Addison-Wesley

Bales, R. F. (1953). The equilibrium problem in small groups. In T. Parsons, R. F. Bales \& E. A. Shils (Eds.), Working papers in the theory of action (pp. 111-161). Glencoe, IL: The Free Press.

Bales, R. F. (1958). Task roles and social roles in problem-solving groups. In E. E. Maccoby, T. M. Newcomb \& E. L. Hartley (Eds.), Readings in social psychology (3rd ed., pp. 437-447). New York: Holt, Rinehart and Winston.

Bales, R. F., \& Hare, A. P. (1965). Diagnostic use of the interaction profile. The Journal of Social Psychology, 67, 239-258.

Banks, A. P., \& Millward, L. J. (2007). Differentiating knowledge in teams: The effect of shared declarative and procedural knowledge on team performance. Group Dynamics: Theory, Research, and Practice, 11(2), 95-106.

Barge, J. K., \& Keyton, J. (1994). Contextualizing power and social influence in groups. In L. R. Frey (Ed.), Group communication in context: Studies in natural groups (pp. 85-105). Hillsdale, NJ: Lawrence Erlbaum.

Benbunan-Fich, R., Hiltz, S. R., \& Turoff, M. (2003). A comparative content analysis of face-to-face vs. asynchronous group decision making. Decision Support Systems, 34(4), 457-469. 
Benne, K. D., \& Sheats, P. (1948). Functional roles of group members. Journal of Social Issues, 4(2), 41-49.

Burgoon, J. K. (2003). Spatial relationships in small groups. In R. Y. Hirokawa, R. S. Cathcart, L. S. Samovar \& L. D. Henman (Eds.), Small group communication: Theory \& practice: An anthology (8th ed., pp. 85-96). Los Angeles: Roxbury.

Butler, M. S. (1995). A collaborative project on information resources in the workplace. Business Communication Quarterly, 58(3), 52-53.

Cannon, M. D., \& Edmondson, A. C. (2001). Confronting failure: antecedents and consequences of shared beliefs about failure in organizational work groups. Journal of Organizational Behavior, 22(2), 161-177.

Cannon-Bowers, J. A., \& Salas, E. (2001). Reflections on shared cognition. Journal of Organizational Behavior, 22, 195-202.

Cannon-Bowers, J. A., Salas, E., \& Converse, S. (1993). Shared mental models in expert team decision making. In J. Castellan, N. J. (Ed.), Individual and group decision making (pp. 221-246). Hillsdale, NJ: Lawrence Erlbaum.

Cannon-Bowers, J. A., Tannenbaum, S. I., Salas, E., \& Volpe, C. E. (1995). Defining competencies and establishing team training requirements. In R. A. Guzzo \& E. Salas (Eds.), Team effectiveness and decision making in organizations (pp. 333380). San Francisco: Jossey-Bass.

Carron, A. V., Brawley, L. R., Eys, M. A., Bray, S., Dorsch, K., Estabrooks, P., et al. (2003). Do individual perceptions of group cohesion reflect shared beliefs? Small Group Research, 34(4), 468-496.

Cooke, N. J., Salas, E., Kiekel, P. A., \& Bell, B. (2004). Advances in measuring team cognition. In E. Salas \& S. M. Fiore (Eds.), Team cognition: Understanding the factors that drive process and performance (pp. 83-106). Washington, DC: American Psychological Association.

Creswell, J. W. (1998). Qualitative inquiry and research design: Choosing among five traditions. Thousand Oaks, CA: Sage.

Creswell, J. W. (2003). Research design: Qualitative, quantitative, and mixed methods approaches (2nd ed.). Thousand Oaks, CA: Sage.

Dimitroff, R. D., Schmidt, L. A., \& Bond, T. D. (2005). Organizational behavior and disaster: A study of conflict at NASA. Project Management Journal, 36(1), 2838. 
Dipboye, R. L., Smith, C. L., \& Howell, W. C. (1994). Understanding industrial and organizational psychology: An integrated approach (Vol. 2). Fort Worth, TX: Harcourt Brace College Publishers.

Eby, L. T., Cader, J., \& Noble, C. L. (2003). Why do high self-monitors emerge as leaders in small groups? A comparative analysis of the behaviors of high versus low self-monitors. Journal of Applied Social Psychology, 33(7), 1457-1479.

Edwards, B. D., Day, E. A., Arthur, W., \& Bell, S. T. (2006). Relationships among team ability composition, team mental models, and team performance. Journal of Applied Psychology, 91(3), 727-736.

Eskilson, A., \& Wiley, M. G. (1976). Sex composition and leadership in small groups. Sociometry, 39, 183-194.

Ford, D. N., \& Sterman, J. D. (1998). Expert knowledge elicitation to improve formal and mental models. System Dynamics Review, 14(4), 309-340.

Frey, L. R. (1994). The naturalistic paradigm: Studying small groups in the postmodern era. Small Group Research, 25(4), 551-577.

Fussell, S. R., \& Kreuz, R. J. (1998). Social and cognitive approaches to interpersonal communication. Mahwah, NJ: Lawrence Erlbaum.

Gersick, C. J. G., \& Davis-Sacks, M. L. (1990). Summary: Task forces. In J. R. Hackman (Ed.), Groups that work (and those that don't) (pp. 146-153). San Francisco, CA: Jossey-Bass.

Giesecke, J. (1998). Scenario planning for libraries. Chicago: American Library Association.

Gilsdorf, J. W. (1998). Organizational rules on communicating: How employees re -- and are not -- learning the ropes. Journal of Business Communication, 35(2), 173-201.

Goodman, B. A., Linton, F. N., Gaimari, R. D., Hitzeman, J. M., Ross, H. J., \& Zarrella, G. (2005). Using dialogue features to predict trouble during collaborative learning. User Modeling and User-Adapted Interaction, 15(1), 85-134.

Goodwin, S. A., \& Fiske, S. T. (1994). Social cognition research and small group research, a West Side Story or ... ? Small Group Research, 25(2), 147-171.

Greenberg, J. (2002). Managing behavior in organizations (2nd ed.). Upper Saddle River, NJ: Prentice Hall.

Guba, E. G. (1981). Criteria for assessing the trustworthiness of naturalistic inquiries. Educational Communication and Technology Journal, 29(2), 75-91. 
Hackman, J. (1990). Groups that work (and those that don't): Creating conditions for effective teamwork (1st ed.). San Francisco: Jossey-Bass.

Hartley, J. (2004). Case study research. In C. Cassell \& G. Symon (Eds.), Essential guide to qualitative methods in organizational research. London: Sage.

He, J., Butler, B. S., \& King, W. R. (2007). Team cognition: Development and evolution in software project teams. Journal of Management Information Systems, 24(2), 261-292.

Herndon, S., \& Kreps, G. L. (2001). Qualitative research: Applications in organizational life (2nd ed.). Cresskill, N.J.: Hampton Press.

Higgins, E. T. (1992). Achieving 'shared reality' in the communication game: A social action that creates meaning. Journal of Language and Social Psychology, 11(3), 107-131.

Hiltz, S. R., Johnson, K., \& Turoff, M. (1986). Experiments in group decision making. Human Communication Research, 13(2), 225-252.

Hirokawa, R. Y. (1980). A comparative analysis of communication patterns within effective and ineffective decision-making groups. Communication Monographs, 47(4), 312-321.

Hirokawa, R. Y. (1994). Functional approaches to the study of group discussion: Even good notions have their problems Small Group Research, 25(4), 542-550.

Hirokawa, R. Y., Cathcart, R. S., Samovar, L. A., \& Henman, L. D. (2003). Small group communication: Theory \& practice: An anthology. Los Angeles: Roxbury.

Hogg, M. A., Fielding, K. S., Johnson, D., Masser, B., Russell, E., \& Svensson, A. (2006). Demographic category membership and leadership in small groups: A social identity analysis. Leadership Quarterly, 17(4), 335-350.

Hogg, M. A., Hains, S. C., \& Mason, I. (1998). Identification and leadership in small groups: Salience, frame of reference, and leader stereotypicality effects on leader evaluations. Journal of Personality \& Social Psychology, 75(5), 1248-1263.

Jabs, L. B. (2005). Communicative rules and organizational decision making. Journal of Business Communication, 42(3), 265-288.

Janis, I. (1972). Victims of groupthink. Boston: Houghton Mifflin.

Jonassen, D. H. (2000). Toward a design theory of problem solving. Educational Technology Research and Development 48(4), 63-85. 
Jones, P. E., \& Roelofsma, P. H. M. P. (2000). The potential for social contextual and group biases in team decision-making: biases, conditions and psychological mechanisms. Ergonomics, 43(8), 1129-1152.

Kelly, J. R. (2000). Interaction process analysis in task-performing groups. In A. P. Beck \& C. M. Lewis (Eds.), The process of group psychotherapy: Systems for analyzing change (pp. 49-65). Washington, DC: American Psychological Association.

Keyton, J. (1997). Coding communication in decision-making groups. In L. R. Frey \& J. $\mathrm{K}$. Barge (Eds.), Managing group life: Communicating in decision-making groups (pp. 236-269). Boston: Houghton Mifflin.

Keyton, J., \& Beck, S. J. (2009). The influential role of relational messages in group interaction. Group Dynamics: Theory, research, and Practice, 13(1), 14-30.

Kim, P. H. (2003). When private beliefs shape collective reality: The effects of beliefs about coworkers on group discussion and performance. Management Science, 49(6), 801-815.

Klimoski, R., \& Mohammed, S. (1994). Team mental model: Construct or metaphor? Journal of Management, 20(2), 403-437.

Kraiger, K., \& Wenzel, L. H. (1997). Conceptual development and empirical evaluation of measures of shared mental models as indicators of team effectiveness. In M. T. Brannick, E. Salas \& C. Prince (Eds.), Team performance assessment and measurement: Theory, meothds, and applications (pp. 63-84). Mahwah, NJ: Lawrence Erlbaum.

Kramer, M. W., \& Hess, J. A. (2002). Communication rules for the display of emotions in organizational settings. Management Communication Quarterly, 16(1), 66-80.

Krauss, R. M., \& Fussell, S. R. (1991). Constructing shared communicative environments. In L. B. Resnick \& J. M. Levine (Eds.), Perspectives on socially shared cognition (pp. 172-200). Washington, DC: American Psychological Association.

Langan-Fox, J., Code, S., \& Langfield-Smith, K. (2000). Team mental models: Techniques, methods, and analytic approaches. Human Factors: The Journal of the Human Factors and Ergonomics Society, 42(2), 242-271.

Langfield-Smith, K. (1992). Exploring the need for a shared cognitive map. Journal of Management Studies, 29(3), 349-368. 
Levesque, L. L., Wilson, J. M., \& Wholey, D. R. (2001). Cognitive divergence and shared mental models in software development project teams. Journal of Organizational Behavior, 22(2), 135-144.

Lim, B.-C., \& Klein, K. J. (2006). Team mental models and team performance: a field study of the effects of team mental model similarity and accuracy. Journal of Organizational Behavior, 27(4), 403-418.

Mabry, E. A. (1985). The effects of gender composition and task structure on small group interaction. Small Group Behavior, 16(1), 75-96.

Marks, M. A., Zaccaro, S. J., \& Mathieu, J. E. (2000). Performance implications of leader briefings and team-interaction training for team adaptation to novel environments. Journal of Applied Psychology, 85(6), 971-986.

Mathieu, J. E., Goodwin, G. F., Heffner, T. S., Salas, E., \& Cannon-Bowers, J. A. (2000). The influence of shared mental models on team process and performance. Journal of Applied Psychology, 85(2), 273-283.

Maxwell, J. A. (1996). Qualitative research design: An interactive approach. Thousand Oaks, CA: Sage.

Mitchell, R. (1986). Team building by disclosure of internal frames of reference. Journal of Applied Behavioral Science, 22(1), 15-28.

Mohammed, S., \& Dumville, B. C. (2001). Team mental models in a team knowledge framework: expanding theory and measurement across disciplinary boundaries. Journal of Organizational Behavior, 22(2), 89-106.

Mohammed, S., Klimoski, R., \& Rentsch, J. R. (2000). The measurement of team mental models: We have no shared schema. Organizational Research Methods, 3(2), 123-165.

Mudrack, P. E., \& Farrell, G. M. (1995). An examination of functional role behavior and its consequences for individuals in group settings. Small Group Research, 26(4), $542-571$.

Mumford, T. V., Van Iddekinge, C. H., Morgeson, F. P., \& Campion, M. A. (2008). The team role test: Development and validation of a team role knowledge situational judgment test. Journal of Applied Psychology, 93(2), 250-267.

Nye, J. L. (2002). The eye of the follower: Information processing effects on attributions regarding leaders of small groups. Small Group Research, 33(3), 337-360. 
Park, H. S. (2008). The effects of shared cognition on group satisfaction and performance: Politeness and efficiency in group interaction. Communication Research, 35(1), 88-108.

Pavitt, C. (1998). Small group communication: A theoretical approach 3rd. Retrieved March, 02, 2009, from http://www.udel.edu/communication/COMM356/pavitt/pavittbooktoc.html

Pavitt, C., Whitchurch, G. G., McClurg, H., \& Petersen, N. (1995). Melding the objective and subjective sides of leadership: Communication and social judgments in decision making groups. Communication Monographs, 62(3), 243-264.

Piliavin, J. A., \& Martin, R. R. (1978). The effects of the sex composition of groups on style and of social interaction. Sex Roles, 4, 281-296.

Poole, M. S. (1999). Group communication theory. In L. R. Frey (Ed.), The handbook of group communication theory and research (pp. 37-70). Thousand Oaks, CA: Sage.

Rahim, M. A. (2002). Toward a theory of managing organizational conflict. International Journal of Conflict Management, 13(3), 206-235.

Rentsch, J. R., \& Hall, R. J. (1994). Members of great teams think alike: A model of team effectiveness and schema similarity among team members. Advances in Interdisciplinary Studies of Work Teams, 1, 223-261.

Rentsch, J. R., Heffner, T. S., \& Duffy, L. T. (1994). What you know is what you get from experience: Team experiende related to teamwork schemas. Group \& Organization Management, 19(4), 450-474.

Rentsch, J. R., \& Klimoski, R. J. (2001). Why do "great minds"; think alike? Antecedents of team member schema agreement. Journal of Organizational Behavior, 22(2), 107-120.

Rentsch, J. R., \& Woehr, D. J. (2004). Quantifying congruence in cognition: Social relations modeling and team member schema similarity. In S. M. Fiore \& E. Salas (Eds.), Team cognition: Understanding the factors that drive process and performance. (pp. 11-31). Washington, DC: American Psychological Association.

Rouse, W. B., \& Morris, N. M. (1986). On looking into the black box: Prospects and limits in the search for mental models. Psychological Bulletin, 100(3), 349-363.

Rozell, E. J., \& Gundersen, D. E. (2003). The effects of leader impression management on group perceptions of cohesion, consensus, and communication. Small Group Research, 34(2), 197-222. 
Sacks, H., Schegloff, E. A., \& Jefferson, G. (1974). A simplest systematics for the organization of turn-taking for conversation. Language, 50(4), 696-735.

Schall, M. S. (1983). A communication-rules approach to organizational culture. Administrative Science Quarterly, 28(4), 557-581.

Scheerhorn, D., \& Geist, P. (1997). Social dynamics in groups. In L. R. Frey \& J. K. Barge (Eds.), Managing group life: Communicating in decision-making groups (pp. 81-103). Boston: Houghton Mifflin.

Schwartzman, R. (2006). Virtual group problem solving in the basic communication course: lessons for online learning. Journal of Instructional Psychology, 33(1), 314.

Shimanoff, S. B. (1980). Communication rules: Theory and research. Beverly Hills: Sage.

Shimanoff, S. B. (1988). Group interaction via communication rules. In R. S. Cathcart \& L. A. Samovar (Eds.), Small group communication: A reader (pp. 50-64). Dubuque: William C. Brown.

Shirani, A. I. (2006). Sampling and pooling of decision-relevant information: Comparing the efficiency of face-to-face and GSS supported groups. Information \& Management, 43(4), 521-529.

Smith-Jentsch, K. A., Mathieu, J. E., \& Kraiger, K. (2005). Investigating linear and interactive effects of shared mental models on safety and efficiency in a field setting. Journal of Applied Psychology, 90(3), 523-535.

Sparrowe, R. T., Soetjipto, B. W., \& Kraimer, M. L. (2006). Do leaders' influence tactics relate to members' helping behavior? It depends on the quality of the relationship. Academy of Management Journal, 49(6), 1194-1208.

Stake, R. K. (1994). Case studies. In N. K. Denzin \& Y. S. Lincoln (Eds.), Handbook of qualitative research (pp. 236-247). Thousand Oaks, CA: Sage.

Strauss, A., \& Corbin, J. (1998). Basics of qualitative research: Techniques and procedures for developing grounded theory (2nd ed.). Thousand Oaks, CA: Sage.

Strijbos, J. W., Martens, R. L., Jochems, W. M. G., \& Broers, N. J. (2004). The effect of functional roles on group efficiency. Small Group Research, 35(2), 195-229.

Timmerman, C. E., \& Scott, C. R. (2006). Virtually working: Communicative and structural predictors of media use and key outcomes in virtual work teams. Communication Monographs, 73(1), 108-136. 
Tindale, R. S., \& Kameda, T. (2000). "Social Sharedness" as a unifying theme for information processing in groups. Group Processes \& Intergroup Relations, 3(2), 123-140.

Tindall, J. H., Houtz, J. C., Hausler, R., \& Heimowitz, S. (1982). Processes of creative problem solvers in groups. Small Group Behavior, 13(1), 109-116.

Tyler, B. B., \& Gnyawali, D. R. (2009). Managerial collective cognitions: An examination of similarities and differences of cultural orientations. Journal of Management Studies, 46(1), 93-126.

US Census Bureau (2008). Household income rises, poverty rate unchanged, number of uninsured down Retrieved April 5, 2009, from http://www.census.gov/PressRelease/www/releases/archives/income_wealth/012528.html

Wallace, W. A. (1987). Capital costs versus costs-in-use: a content analysis of design team member communication patterns. Construction Management \& Economics, 5(4), S73-S92.

Walsh, J. P. (1995). Managerial and organizational cognition: Notes from a trip down memory lane. Organization Science, 6(3), 280-321.

Wheelan, S. A., \& Krasick, C. L. (1993). The emergence, transmission, and acceptance of themes in a temporary system of interacting groups. Group \& Organization Management, 18(2), 237-260.

Zigurs, L., \& Kozar, K. A. (1994). An exploratory study of roles in computer-supported groups. MIS Quarterly, 18(3), 277-297. 